UNIVERSIDADE DE SÃO PAULO

ESCOLA DE ENFERMAGEM

DÉBORA ASTOLFO DE LIMA

A SATISFAÇÃO DA CRIANÇA E DA FAMÍLIA ACERCA DO MANEJO DA DOR EM UM PRONTO-SOCORRO INFANTIL

SÃO PAULO 


\section{DÉBORA ASTOLFO DE LIMA}

\section{A SATISFAÇÃO DA CRIANÇA E DA FAMÍLIA ACERCA DO MANEJO DA DOR EM UM PRONTO-SOCORRO INFANTIL}

Versão corrigida da dissertação apresentada ao Programa de Pós-Graduação em Enfermagem (PPGE) da Escola de Enfermagem da Universidade de São Paulo para obtenção do título de Mestre em Ciências.

Área de concentração: Cuidado em Saúde

Orientadora: Prof. ${ }^{\underline{a}}$ Dra . Lisabelle Mariano Rossato

\section{VERSÃO CORRIGIDA}

A versão original encontra-se disponível na Biblioteca da Escola de Enfermagem da Universidade de São Paulo e na Biblioteca Digital de Teses e Dissertação da Universidade de São Paulo.

\section{SÃO PAULO}


AUTORIZO A REPRODUÇÃO E DIVULGAÇÃO TOTAL OU PARCIAL DESTE TRABALHO, POR QUALQUER MEIO CONVENCIONAL OU ELETRÔNICO, PARA FINS DE ESTUDO E PESQUISA, DESDE QUE CITADA A FONTE.

Assinatura:

Data:

Catalogação na Publicação (CIP)

Biblioteca "Wanda de Aguiar Horta"

Escola de Enfermagem da Universidade de São Paulo

Lima, Débora Astolfo de

A satisfação da criança e da família acerca do manejo da dor em um pronto-socorro infantil / Débora Astolfo de Lima. São Paulo, 2017.

$131 \mathrm{p}$.

Dissertação (Mestrado) - Escola de Enfermagem da Universidade de São Paulo.

Orientadora: Prof. ${ }^{a} \mathrm{Dr} .{ }^{\mathrm{a}}$ Lisabelle Mariano Rossato

Área de concentração: Cuidado em Saúde

1. Dor. 2. Satisfação do paciente. 3. Crianças. 4. Serviços médicos de emergência. 5. Enfermagem pediátrica. 6 . Garantia da Qualidade dos Cuidados de Saúde. I. Título. 


\section{FOLHA DE APROVAÇÃO}

Nome: DÉBORA ASTOLFO DE LIMA

Título: A SATISFAÇÃO DA CRIANÇA E DA FAMÍLIA ACERCA DO MANEJO DA DOR EM UM PRONTO-SOCORRO INFANTIL

Dissertação apresentada ao Programa de Pós-Graduação em Enfermagem da Escola de Enfermagem da Universidade de São Paulo para obtenção do título de Mestre em Enfermagem.

Aprovado em:

\section{Banca Examinadora}

Prof. Dr.

Instituição:

Julgamento:

Assinatura:

Prof. Dr.

Instituição:

Julgamento:

Assinatura:

Prof. Dr.

Instituição:

Julgamento:

Assinatura: 


\section{Dedicatóría}

Aos meus pais, Marli e Wílson que sempre me acompanharam e incentivaram na busca pelo conhecimento.

Aos meus irmãos Renan e Barbara pelo apoio e momentos de descontração.

A Ana Luísa pelo carinho, amor, paciência e incentivo sempre.

As minhas avós $\mathcal{A}$ lmezira e Amélia pela compreensão nos meus momentos de ausência.

E finalmente, ao meu avô Ilson (in memoriam), quem eu sempre vou amar. 


\section{Agradecímentos}

Agradeço aos meus pais $\mathcal{M}$ arli e Wílson, pelo amor e incentivo aos estudos.

À minha orientadora, Professora Doutora Lísabelle Mariano Rossato, que me recebeu de braços abertos e sorriso no rosto desde o primeiro encontro, me deixando encantada e despertando ainda mais o meu desejo de pesquisar na área da saúde da criança. Obrigada pela paciência, disposição, apoio, carinho e por compreender e me ajudar nas minhas limitações.

As críanças, que me conquistam todos os dias com seu carinho, amor e autenticidade. Muito obrigada a todas crianças que fizeram parte deste trabalho, por compartilharem comigo suas experiências.

Aos meus irmãos Renan e Barbara, que me ajudaram nos momentos de distração com suas danças, saídas, conversas e risadas.

A minha companheira Ana Luisa pelo amor, carinho, paciência e por todas as correções de trabalho.

A professora Dra. Líslaine Aparecida Fracolli e a Professora Dra. Lucíla Castanheira Nascímento pelas considerações no meu exame de qualificação.

A Danila que sempre se mostrou interessada e disposta a ajudar em todos os momentos.

A Escola de Enfermagem da Uníversidade de São Paulo pelo suporte durante esta trajetória.

Aos participantes do grupo $\mathcal{N} i p p e l$ - $\mathcal{N} u ́ c l e o$ Interdiscíplinar de Pesquísa em Perdas e Lutos pelas discussões e enriquecimento deste trabalho. 
Ao $\mathcal{H}$ Sospital São Camílo, que foi onde despertou meu interesse pelo tema do estudo e que permitiu que este trabalho fosse realizado.

À equipe de enfermagem do Pronto Socorro Infantíl, pelo força e ajuda durante a fase de seleção das crianças para a coleta de dados.

Às minhas amigas de São Carlos, que se tornaram minhas irmãs: "Tatá", OCiviía, "Josî" e "Marí". 
Lima DA. A satisfação da criança e da família acerca do manejo da dor em um pronto-socorro infantil [dissertação]. São Paulo: Escola de Enfermagem, Universidade de São Paulo; 2017.

\section{RESUMO}

Introdução: A dor da criança é uma das queixas de maior procura pelos serviços de urgência e de emergência e seu manejo tem sido um motivo de preocupação pelos profissionais de saúde. Para avaliar os cuidados prestados aos pacientes, são utilizados indicadores de qualidade, dentre eles, a satisfação. Objetivo: Compreender a satisfação da criança e de seu familiar acerca do manejo da dor no pronto-socorro infantil. Metodologia: Estudo qualitativo exploratório e descritivo. Para a discussão dos dados foi utilizado o modelo de Donabedian. Os participantes deste estudo foram constituídos por crianças entre seis e 12 anos de idade e seus familiares. As entrevistas foram gravadas e os dados analisados à luz da análise temática. Resultados: Foram entrevistados 19 crianças e 19 familiares entre outubro de 2016 a maio de 2017. Os resultados sobre a percepção da satisfação acerca do manejo da dor no pronto-socorro infantil compuseram o Tema 1: A satisfação percebida pelas crianças e familiares, composto por três subtemas: "Atendimento prioritário", "alívio rápido da dor" e "Acolhimento pela equipe" A satisfação percebida pelas crianças composto por um subtema: "Necessidades básicas atendidas". A satisfação percebida pelos familiares, composto por um subtema: "Investigação dos sintomas". E a insatisfação percebida acerca do manejo da dor no pronto-socorro infantil compuseram o Tema 2: A insatisfação percebida pelas crianças e familiares, composto por um subtema: "Demora em aliviar a dor" A insatisfação percebida pelas crianças composto por dois subtemas: "Procedimentos dolorosos" e "Ambiente desconfortável". A insatisfação percebida pelos familiares composto por um subtema: "Demora pelos resultados dos exames". Conclusão: Observou-se que a satisfação da criança e de seus familiares foi muito mais do que o alívio da dor, ou o atendimento prioritário. Englobou também o ambiente e o acolhimento pela equipe. É recomendado que o cuidado do profissional de saúde seja direcionado às singularidades das crianças e de suas famílias.

Descritores: Dor. Satisfação do Paciente. Criança. Serviços Médicos de Emergência. Enfermagem Pediátrica. Garantia da Qualidade dos Cuidados de Saúde. 

Lima DA. The satisfaction of the child and the family with pain management in the pediatric emergency department [dissertation]. São Paulo: School of Nursing, University of São Paulo; 2017.

\section{ABSTRACT}

Introduction: Child pain is one of the most pressing complaints of emergency services and its management has been a cause of concern for health professionals. To assess the care provided to patients, quality indicators are used, among them, the satisfaction. Objective: To understand the satisfaction of the child and his/her family with pain management in the emergency room. Methodology: A qualitative, exploratory and descriptive study. To discuss our data was used the Donabedian model. The study population consisted of children between six and 12 years age and their family. Interviews were recorded and data analyzed in the light of the thematic analysis. Results: We interviewed 19 children and 19 family members between october 2016 and may 2017. The results on the perception of satisfaction with pain management in the emergency room constituted theme 1: Children's and their families perceived satisfaction, composed of three sub-themes: "Priority in care", "quick pain relief" and "warm welcome at the hospital". Children's perceived satisfaction, composed of one sub-theme: "Basic needs met". Families' perceived satisfaction, composed of one sub-theme: "Investigation of symptoms". And the results on the perception of dissatisfaction with pain management in the emergency room constituted theme 2: Children's and their families perceived satisfaction, composed of one sub-theme: "Delays in relieving pain". Children's perceived dissatisfaction composed of with two sub-themes: Painful Procedures "and" Uncomfortable Environment". Families' perceived dissatisfaction composed of one sub-theme: "Delays in the results of the exams". Conclusion: We observed that the satisfaction of the child and his/her family with pain management was beyond pain relief or priority care. Also included the environment and the warm welcome given by the healthcare team. We recommend that the care provided by the health professional be directed to the singularities of each child and their family.

Key words: Pain. Patient Satisfaction. Child. Emergency Medical Services. Pediatric Nursing. Quality Assurance, Health Care. 


\section{LISTA DE ILUSTRAÇÕES}

Figura 1 - Desenho da criança 02 de como foi seu dia no Pronto-Socorro............43

Figura 2 - Desenho da criança 03 de como foi seu dia no Pronto-Socorro............43

Figura 3 - Desenho da criança 05 de como foi seu dia no Pronto-Socorro............44

Figura 4 - Desenho da criança 06 de como foi seu dia no Pronto-Socorro............44

Figura 5 - Desenho da criança 07 de como foi seu dia no Pronto-Socorro............45

Figura 6 - Desenho da criança 10 de como foi seu dia no Pronto-Socorro............45

Figura 7 - Desenho da criança 16 de como foi seu dia no Pronto-Socorro............46

Figura 8 - Desenho da criança 17 de como foi seu dia no Pronto-Socorro............46

Figura 9 - Desenho da criança 19 de como foi seu dia no Pronto-Socorro............47 


\section{LISTA DE SIGLAS}
ANA
American Nurse Association
APS American Pediatric Society (Sociedade Americana de Dor)
ASQC American Society for Quality Control (Sociedade Americana para o Controle da Qualidade)
CAC Colégio Americano de Cirurgiões
CCAH Comissão Conjunta de Acreditação Hospitalar
EEUSP Escola de Enfermagem da Universidade de São Paulo
HU-USP Hospital Universitário da Universidade de São Paulo
IASP International Association for the Study of Pain (Associação
Internacional para o Estudo da Dor)
TJC The Joint Commission
JCAH Joint Commission on Accreditation of Hospitals
JCl Joint Comission Internacional
JUSE Union of Japanese Scientists and Engineers (União Japonesa dos Cientistas Engenheiros)
PPGE Programa de Pós-Graduação em Enfermagem
PPH Programa de Padronização Hospitalar
PSA Pronto Socorro Adulto
PSI Pronto Socorro Infantil
TCLE Termo de Consentimento Livre e Esclarecido
UFSCar Universidade Federal de São Carlos
UTIP Unidade de Terapia Intensiva Pediátrica 


\section{SUMÁRIO}

1. Apresentação pessoal.......................................................................14

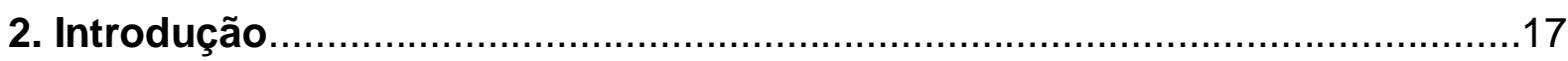

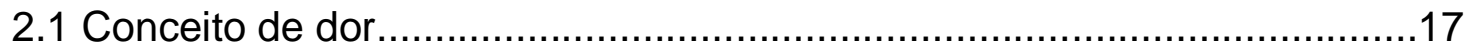

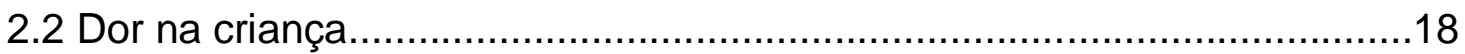

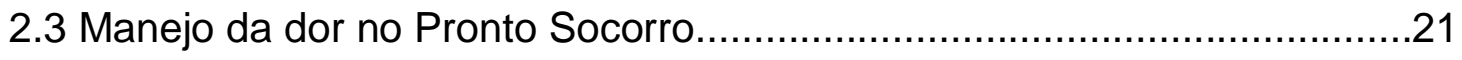

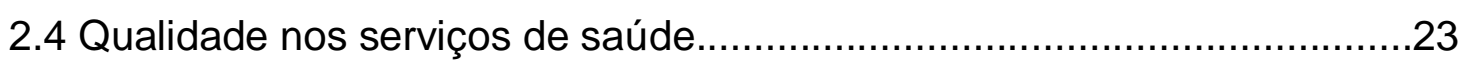

2.5 Satisfação do

paciente.

3. Objetivo

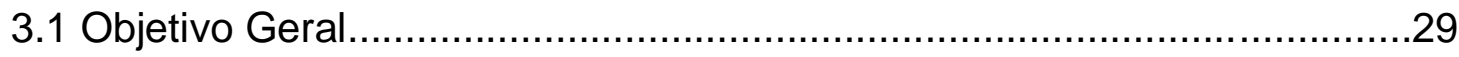

4. Metodologia

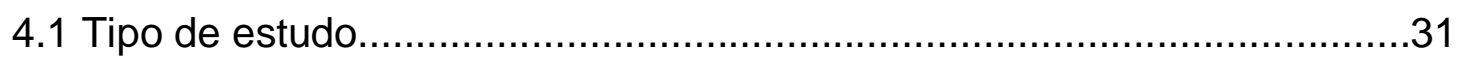

4.2 O Modelo de Donabedian como Perspectiva Teórica.................................31

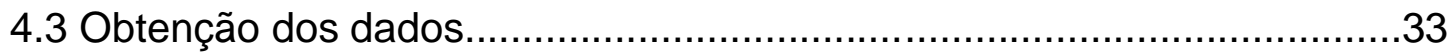

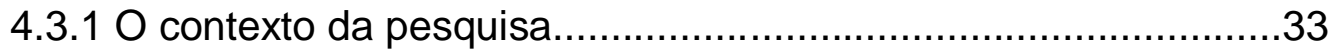

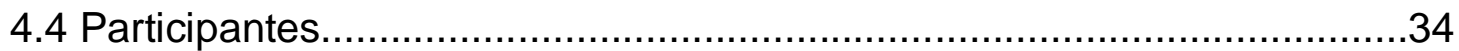

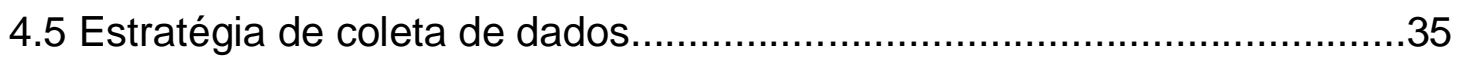

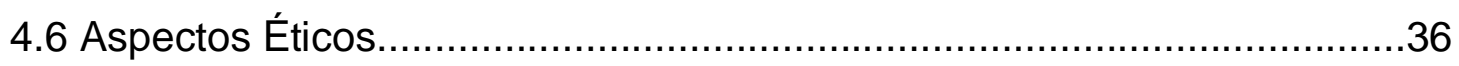

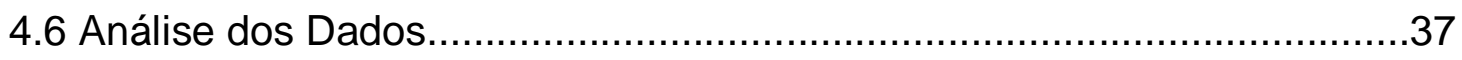

5. Resultados

5.1 Panorama do cenário de estudo e contextualização dos

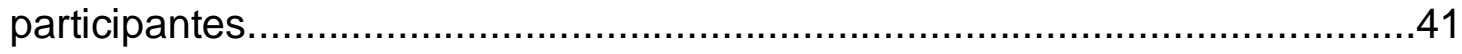

5.2 A experiência do atendimento no pronto-socorro infantil, segundo a perspectiva da criança.

5.3 Percepção da Satisfação da criança e de seus familiares acerca do manejo da dor no Pronto-Socorro Infantil. 
5.3.1 Tema 1: A satisfação percebida pelas crianças e familiares acerca do manejo

Infantil. 47

5.3.1.1

Atendimento

prioritário .48

5.3.1.2 Alívio rápido da dor. .50

5.3.1.2

Acolhimento pela

equipe. .51

5.3.1.3

Necessidades

básicas

atendidas. .52

5.3.1.5

Investigação

dos

sintomas. .53

5.3.2 Tema 2: A insatisfação percebida pelas crianças e familiares acerca do manejo da dor no Pronto Socorro Infantil. .54

5.3.2.1 Demora em aliviar a dor. .55

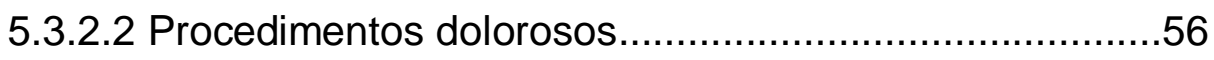

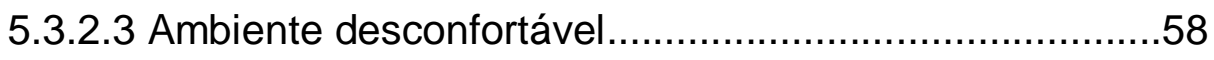

5.3.2.4 Demora pelos resultados dos exames..........................59

5. Discussão 61

Considerações Finais. .71

Referências. .74

\section{Apêndices}


APRESENTAÇÃO 


\section{APRESENTAÇÃo}

Meu interesse em trabalhar com crianças teve início no final da graduação em enfermagem em 2011 pela Universidade Federal de São Carlos (UFSCar), quando fiz estágio em pediatria. Eu fiquei encantada com as conversas que tinha com as crianças, com o vínculo que criamos em tão pouco tempo de convivência no estágio e de como era diferente de trabalhar com os pacientes adultos, isso foi o que mais me chamou a atenção. Quando terminei a faculdade, eu tinha um objetivo, trabalhar na área da pediatria, e então, resolvi aprofundar meus conhecimentos iniciando uma especialização. Fiz Pós-Graduação em Pediatria e Neonatologia em 2012 no Instituto Israelita Albert Einstein e durante o curso participei de um processo seletivo no Hospital São Camilo e fui aprovada como Enfermeira Trainee da Pediatria.

Durante o programa de 10 meses do Trainee, trabalhei na Unidade de Internação Infantil, Unidade de Terapia Intensiva Pediátrica (UTIP) e no Pronto Socorro Infantil (PSI), os ambientes eram bem diferentes e a situação dos pacientes também, mas durante esta experiência os procedimentos invasivos estavam presentes em todas as situações e eu presenciei inúmeras vezes eles sendo realizados sem a devida atenção dos profissionais, como por exemplo a punção venosa periférica, que pode ser considerado um procedimento básico e tranquilo pela equipe de enfermagem, mas ele também pode trazer sérias consequências se for realizado de forma inadequada, desconsiderando a dor e o sofrimento emocional da criança e sua família naquela situação hospitalar. Assim, surgiu meu interesse pelo tema dor, e acabei desenvolvendo meu projeto de conclusão do Trainee sobre esse assunto, o efeito do Brinquedo Terapêutico no procedimento de punção venosa.

Como conclusão do trabalho, relatei que as crianças entendiam melhor 0 procedimento e assim, ficavam menos ansiosas durante o procedimento, inclusive me falavam antecipadamente o que iria acontecer, porém, não tínhamos o material adequado no hospital e eu tive que improvisar o brinquedo. No final quando mostrei o resultado para a chefia do meu setor, não tive apoio para implementação. Fiquei intrigada em saber porque algo que era comprovado cientificamente era tão desvalorizado pela equipe.

No final do programa, fui contratada para trabalhar no Pronto Socorro Infantil, e, como enfermeira do setor, percebi que a dor, apesar do protocolo institucional, 
ainda é subjugada e subtratada pela equipe de saúde, tanto da enfermagem como da equipe médica. Os profissionais não possuem capacitação constante e podem ter dificuldade de avaliar, gerenciar e tratar a dor em pediatria.

Por isso, em 2015, procurei uma professora universitária que trabalhasse com o tema dor em pediatria e fazendo pesquisas na internet, nas escolas de enfermagem, encontrei a professora Dra. Lisabelle Mariano Rossato, marcamos um encontro na escola e conversamos sobre meu interesse em fazer mestrado no tema dor, ela conversou comigo e parecia que já nos conhecíamos, de tão simpática e empolgada que me atendeu. Ingressei no Mestrado do Programa de Pós-Graduação da Escola de Enfermagem da Universidade de São Paulo - PPGE no meio do ano de 2015. Durante o programa, fiz disciplinas que contribuíram para encaminhar meu projeto. Um de nossos objetivos era entender se o que já está sendo feito no hospital com o protocolo de dor era suficiente para a criança e para a família e o que poderia melhorar ou mudar. Então, decidimos que nosso tema seria a satisfação da criança e da família com o manejo da dor em um pronto Socorro Infantil.

Durante o mestrado participei do grupo Núcleo Interdisciplinar de Pesquisa em Perdas e Luto, onde tive a oportunidade de participar de discussões valiosas e ajuda durante o processo do trabalho dos participantes.

No hospital onde trabalho comecei a fazer parte do Grupo de Dor, onde buscamos compreender e discutir formas melhores e mais adequadas sobre 0 manejo da dor nas crianças e assim aprimorar e melhorar a segurança do paciente e sua satisfação. Em agosto de 2017 fizemos o primeiro workshop de dor no hospital para mostrar a importância e conscientizar os profissionais da saúde sobre a dor.

Todos estes processos foram importantes para a construção da minha dissertação de mestrado e me ajudaram a enxergar outros pontos de vista que foram essenciais para o resultado deste trabalho. 


\section{INTRODUÇÃO}

\subsection{CONCEITO DE DOR}

Segundo a Associação Internacional para o Estudo da Dor (IASP), a dor é definida como "uma sensação ou uma experiência emocional desagradável associada a um dano tecidual real ou potencial, ou descrita em termos de tal dano" (IASP, 2011, p.3). A dor representa uma experiência subjetiva e cada indivíduo a sente de forma única, podendo utilizar a linguagem verbal ou não verbal para expressá-la. Assim como descrito, "a inabilidade de comunicar verbalmente a dor não nega a possibilidade de o indivíduo a ter experienciado e sua necessidade de receber o tratamento adequado para o seu alívio" (IASP, 2011, p.3). A IASP propôs este conceito de dor em 1979 e tem se mantido atualizado até os dias de hoje (IASP, 2011).

A dor faz parte da história de vida de praticamente todas as pessoas; no entanto, descrever nossa própria dor é uma tarefa difícil. Ainda mais difícil e complexo é entender a dor do outro, porque a dor é uma experiência pessoal, que varia conforme as características do organismo de cada um, de sua experiência e contexto (Carvalho, 1999). Outra definição de dor proposta afirma que "a dor de uma pessoa é exatamente como essa pessoa diz que é, e existe sempre que a pessoa afirmar sua existência." (McCaffery, 1989, p.7).

Podemos classificar a dor, segundo sua duração, em três tipos: aguda, crônica ou recorrente. A dor aguda se manifesta temporariamente por um período curto, variando de minutos a semanas, relacionada com lesões por inflamação, infecção, traumatismo, ou outras causas e que, geralmente, desaparece após o diagnóstico e tratamento da causa. A dor crônica tem uma duração maior, de meses a anos e, normalmente, relaciona-se com um processo de doença, ou com uma lesão previa, como artrite, dor do paciente com câncer, dor relacionada a esforços repetitivos durante o trabalho e dor nas costas. Por outro lado, a dor recorrente, se manifesta em curtos períodos, mas com grande frequência, como a enxaqueca (McGrath, 1990).

A dor aguda está associada a lesões teciduais por traumas, infecção ou inflamação, sendo um mecanismo de defesa e alerta do corpo. Ela é repentina e, 
frequentemente, desaparece após o tratamento. Na maioria das vezes, ela causa alterações nos sinais vitais como taquicardia, taquipnéia e aumento da pressão arterial (Carvalho, 1999).

Um estudo realizado pelo presidente da Sociedade Americana de Dor em 1990 pelo Dr. Mitchell Max mostrou que a avaliação e o tratamento da dor não apresentavam melhora nos últimos 20 anos. Segundo ele, a avaliação era prejudicada porque os pacientes não a reportavam aos médicos e enfermeiros, os enfermeiros não eram capazes de ajudar com as dosagens das medicações e os médicos eram resistentes e não prescreviam opióides (Baker, 2017).

Diante deste quadro, a Sociedade Americana de Dor e a Agência Americana de Pesquisa e Qualidade em Saúde Pública, com o objetivo de tornar a dor visível, a instituíram como o quinto sinal vital (Baker, 2017). Para isso, a dor deveria ser sempre registrada, ao mesmo tempo que os outros sinais vitais como temperatura, pressão arterial, frequência respiratória e saturação. Por este motivo, a dor passou a ser chamada de o 5은 sinal vital (Sousa, 2002).

Para enfatizar a importância da dor, o instituto de acreditação hospitalar do Estados Unidos, The Joint Commission (TJC), também conhecida como Joint Commission International $(\mathrm{JCl})$, passou a avaliar a dor na acreditação hospitalar, acrescentando a dor como item obrigatório na avaliação dos sinais vitais, para que fosse verificada habitualmente (Phillips, 2000). A introdução da dor pela TJC, colaborou para o conhecimento que temos hoje sobre o direito do paciente em ter sua dor avaliada, tratada e gerenciada (Phillips, 2000).

\subsection{DOR NA CRIANÇA}

Com relação à dor da criança, estudos começaram a surgir somente na década de 80 e tiveram mais força nos anos 90, quando foi descoberto por pesquisadores que as crianças eram capazes de descrever sua própria dor, se utilizado um instrumento adequado (Tacla et al., 2008).

Historicamente, as crianças tinham sua dor subtratada. Uma das razões é que supunha-se que as crianças tinham o sistema nervoso imaturo e incompleto e que por não ter experiência de dor anterior, não eram capazes de sentir a mesma dor que os adultos (Swafford, 1968). Há três décadas, ainda se acreditava que as crianças e, principalmente os neonatos, tinham menor capacidade que os adultos 
para sentir e se lembrar da dor e, por isso, necessitavam de menos analgesia (Burrows, 1993; Wellington, 1993).

Apesar dos avanços nos estudos científicos na área de dor pediátrica, ainda hoje nos confrontamos com problemas relacionados com a avaliação e o tratamento adequado da dor, o que compromete o atendimento dado às crianças, fazendo com que elas sofram desnecessariamente as consequências devido a sua avaliação inadequada (Manocha, 2016; Thrane et al., 2016).

A forma como a criança percebe e demonstra sua dor varia de acordo com sua história, incluindo idade, nível de desenvolvimento cognitivo, temperamento, quantidade e qualidade das experiências anteriores com dor, comportamento familiar e meio cultural (Carvalho, 1999; Ferreira, 2009).

A avaliação e o tratamento da dor são essenciais para a assistência ao paciente, independentemente da sua idade. Entretanto, a avaliação e o tratamento da dor na criança tem sido um desafio para a equipe assistencial (Kanai, Fidelis, 2010).

A dor da criança não recebe a mesma atenção que a dos adultos por diversos motivos, dentre eles destaca-se a dificuldade dos profissionais em mensurar a dor infantil, seja por não perguntar se criança sente dor, ou por desconhecer que a criança menor possui maior dificuldade em comunicá-la (Rossato, 2006).

Durante a avaliação da dor, também são identificados os fatores que podem modificar a experiência da dor como fatores fisiológicos, cognitivos, afetivos, comportamentais e contextuais e suas interações. Três fatores são fundamentais para acessar a dor nas crianças: o autorrelato, seu comportamento e alteração dos sinais vitais. Este último não deve ser avaliado isoladamente, pois a criança pode apresentar os sinais alterados por estar ansiosa com a situação estressante do ambiente hospitalar (Howard et al., 2012).

O auto relato é o padrão ouro de avaliação da dor e a abordagem preferida para as crianças (Bennet et al., 2009; Howard et al., 2012). Assim, quando a criança nos conta sobre sua dor, descrevendo sua experiência com suas palavras, ela consegue explicá-la melhor (McGrath, 1990).

A avaliação da dor em crianças escolares pode parecer ser mais simples, haja vista que são capazes de comunicar sua experiência de dor. Porém sua interpretação é difícil porque quando a criança traduz sua interpretação em palavras, utilizado recursos verbais e cognitivos, ela ainda em desenvolvimento, podendo 
oferecer um relato da dor pouco fiel a sua experiência real. Além disso, deve-se levar em consideração que nem todas as crianças escolares possuem o mesmo desenvolvimento cognitivo (Manocha, 2016).

No entanto, em função da dificuldade de avaliação, devido às diferenças de entendimento das crianças, relacionadas com seu desenvolvimento cognitivo, foram desenvolvidas escalas, instrumentos criados a partir da década de 80 , com 0 objetivo de facilitar a comunicação e compreensão da dor (Finley, 2010).

Esses instrumentos podem ser unidimensionais, ou seja, levam em consideração apenas uma característica da dor, em geral a intensidade, ou, multidimensionais, considerando duas ou mais características na avaliação da dor, como sua intensidade, localização e qualidade (Pereira, 1998).

Diversos instrumentos unidimensionais são frequentemente empregados em hospitais, por serem de aplicação fácil, rápida e confiável (Gonçalves et al., 2013). Dentre eles a Escala de FACES revisada, a Escala de Faces de Wong -Baker e a Escala Visual Analógica têm sido utilizadas com sucesso em unidades de emergência infantil (Fein et al., 2012).

A escolha de um instrumento, para avaliação da dor na criança, é complexa, porque não existe uma escala validada, segura, simples e objetiva que atenda a todas as necessidades das crianças e que contemple todas as faixas etárias (Damasceno et al., 2007).

Mesmo utilizando instrumentos validados para avaliar a dor, as crianças podem negar sua dor por medo de seu tratamento, ou por acreditarem que merecem um castigo por algo de errado que tenham feito. Além disso, a criança pode negar a dor simplesmente quando perguntado por uma pessoa estranha a ela. Assim, devemos considerar também, além da dor referida pela criança, a dor relatada pelos acompanhantes (Hockenberry et al., 2014).

Para que a avaliação da dor seja eficaz e eficiente, os profissionais de saúde precisam ter interesse e se capacitarem continuamente quanto aos métodos de avaliação da dor em crianças e utilizar estes instrumentos em sua prática profissional (Gonçalves et al., 2013). Além da avaliação, é preciso registrar e reavaliar a dor em intervalos regulares, de acordo com as necessidades da criança e do ambiente. Somente assim é possível verificar se o tratamento é eficiente (Bennet et al., 2009). 
A atitude dos enfermeiros com relação à dor está relacionada com seu conhecimento, avaliação subjetiva, envolvimento emocional e percepção. Os profissionais de saúde que não receberam capacitação sobre o tema da dor são os que mais demonstram comportamentos desfavoráveis frente à criança com dor (Cordero et al., 2012).

Resultados de pesquisas mostram que o tratamento inadequado da dor pode ter efeitos prejudiciais, como longo período de internação, cicatrização mais lenta, depressão, ansiedade e custos sociais e econômicos mais altos (Byczkowski et al., 2013; Gill et al., 2013; Weingarten et al., 2014).

\subsection{MANEJO DA DOR NO PRONTO-SOCORRO}

O manejo de dor foi definido como ações realizadas entre os profissionais de saúde, familiares e a criança visando a aliviar ou a minimizar a dor na criança (Queiroz, 2007).

O manejo da dor exige do profissional de saúde a habilidade de perceber a dor no paciente, de escolher a estratégia correta para sua avaliação e, consequentemente, seu alívio. O despreparo do profissional na identificação da dor, ou a desvalorização da queixa, pode desqualificar o processo de cuidar (Araujo, 2015).

As intervenções farmacológicas e não farmacológicas constituem o manejo da dor. A farmacológica é, normalmente, prescrita pelo profissional de saúde médico, que prescreve medicações como analgésicos, anestésicos, sedativos e anticonvulsivantes, entre outras drogas utilizadas no tratamento para dor (Linhares, 2010).

Para o manejo não farmacológico da dor, deve-se avaliar o tipo de dor (aguda, recorrente e/ou crônica), seu contexto (procedimentos ou exames invasivos dolorosos, cirurgia ou quadro clínico) e sua característica (localização, intensidade, duração e qualidade afetiva) (Linhares, Doca, 2010).

Algumas estratégias para o manejo não farmacológico são utilizadas para diminuir a dor percebida pelas crianças, desviando sua atenção para algo diferente, como a leitura de um livro, desenho na televisão ou ouvir uma música. Além dessas técnicas, a aplicação de calor, frio e massagem, também podem ser utilizadas com a mesma finalidade (McCaul, 1994; Leão, 2004). 
A distração é, comumente, utilizada em ambientes como o pronto-socorro e ela é melhor aproveitada quando a estratégia é adaptada para a idade e desenvolvimento da criança (Vessey et al., 1994). Ela pode ser usada por qualquer pessoa; porém, os enfermeiros são os profissionais de saúde que estão mais próximos da criança, e os pais, são os principais usuários das distrações (Linhares, 2010). Segundo Walworth (2005), a distração pode diminuir o tempo para a realização dos procedimentos e o número de funcionários necessário.

A associação entre práticas farmacológicas e não farmacológicas é eficaz e tem como objetivo minimizar o desconforto causado pela dor, podendo melhorar a adesão das crianças ao tratamento e deixá-las mais confortáveis durante suas atividades (Silva et al., 2007).

Apesar dos avanços científicos na área de dor pediátrica, ainda existem lacunas na transferência de conhecimentos para a prática clínica, fazendo com que o manejo da dor nas crianças seja inadequado e, portanto, não colaborando para a melhoria do seu atendimento (Linhares, 2010).

O manejo da dor é importante principalmente em cenários como o prontosocorro, que pode ser vivenciado pelas crianças como estressante, pelo desconhecimento do ambiente hospitalar, pela quantidade de pessoas desconhecidas e pela separação e distanciamento dos familiares (Uspal et al., 2012). Este momento pode ser amenizado, em parte, pela presença do acompanhante, assegurado como direito pelo Estatuto da Criança e do Adolescente, que pode permanecer com a criança durante todo o atendimento (Brasil., 13 de julho de 1990).

O pronto-socorro é procurado por diferentes queixas, dentre as quais se destaca a dor (Souza et al., 2012). Um estudo realizado por Wier et al. (2013) em uma unidade de urgência e emergência nos Estados Unidos da América, apontou que a dor é uma das cinco razões de maior procura pelo pronto-socorro. Da mesma forma, no Brasil, estudos mostram que a dor é uma das principais queixas de pacientes pediátricos para procurar um pronto-socorro infantil (Costa, 2015; Vale et al., 2015).

Apesar da grande procura pelo serviço, sabemos que as crianças tendem a receber menos analgesia nos setores de emergência pediátrica, comparada aos adultos com o mesmo escore de dor (Jadav et al., 2009). O Committee on Advancing Pain Research, Care, and Education (2011) afirma que a dor e sua 
gestão em crianças são um desafio e que protocolos adequados para seu manejo estão, às vezes ausentes até mesmo em departamentos de emergência pediátrica.

\subsection{QUALIDADE NOS SERVIÇOS DE SAÚDE}

Desde o início, o ser humano buscava a qualidade em seu trabalho e produtos. Como exemplo disso, temos a construção das pirâmides no Egito e a arquitetura e artes de povos antigos. Porém, com o rápido avanço industrial, as características dos produtos mudaram, pois houve a necessidade de aumentar a produção e, com isso, a quantidade passou a ser mais importante do que a qualidade. Assim, os produtos não tinham a mesma excelência que antes e, além disso, também foi necessário aumentar o número de trabalhadores e qualificá-los. (Rodrigues, 2011).

Durante a década de 50 , devido à piora da qualidade dos produtos, foi criada a Sociedade Americana para o Controle de Qualidade (ASQC) e, no mesmo ano, a União Japonesa dos Cientistas Engenheiros (JUSE). Em decorrência da preocupação com a gestão da qualidade, ambas instituições acreditavam que a qualidade poderia ser um fator de transformação no relacionamento da empresa com o público-alvo, adicionando valor ao seus serviços (Rodrigues, 2011).

A qualidade vai além do produto uma vez que ela leva em consideração o sistema: a valorização e a satisfação dos clientes, o aumento e competitividade no mercado e menor custo operacional. Um serviço tem qualidade se vai ao encontro, ou se supera as expectativas do consumidor (Rodrigues, 2011)

A Organização Mundial de Saúde (OMS) definiu qualidade como um conjunto de elementos que inclui um alto grau de excelência profissional, utilização dos recursos com eficiência, risco mínimo para o cliente e alto grau de satisfação por parte dos clientes, levando em consideração os valores sociais existentes (Organização Mundial da Saúde, 1981).

O interesse pela qualidade nos serviços de saúde teve início no ensino e prática médica, em 1910, quando foi publicado o estudo Medical Education in the United States and Canada, conhecido como o Relatório Flexner, sobre a reforma do modelo de educação médica nos Estados Unidos. Após o relatório, muitas escolas de medicina foram fechadas por falta de condições sob o ponto de vista da estrutura, dos equipamentos e do ensino. Regras foram criadas descrevendo as condições 
mínimas para o funcionamento de escolas e hospitais de ensino, além da qualificação dos trabalhadores (Filho, 2010).

$\mathrm{Na}$ mesma época, Codman, um médico cirurgião norte-americano, publicou trabalhos sobre a necessidade e importância de garantir a qualidade dos resultados das intervenções e procedimentos médicos, desenvolvendo um sistema de padronização hospitalar (Feldman, 2004).

A partir de 1913, teve início a avaliação da qualidade na saúde com a formação do Colégio Americano de Cirurgiões (CAC) que instituiu o Programa de Padronização Hospitalar (PPH) e definiu padrões para garantir a qualidade da assistência aos clientes, continuando até a década de 1950 (Feldman, 2004).

A partir de então, o Colégio Americano de Clínica Médica, a Associação Americana de Hospitais, a Associação Médica Americana e a Associação Médica do Canadá se juntaram ao Colégio de Cirurgiões para fundar a Comissão Conjunta de Acreditação dos Hospitais (CCAH), uma organização independente, sem fins de lucro, cuja finalidade principal era oferecer uma acreditação voluntária, ou seja, uma avaliação do serviço (Novaes, 2015).

Em 1951, foi criado o programa de Acreditação Joint Commission on Accreditation of Hospitals (JCAH), uma empresa privada, que tinha como objetivo monitorar a qualidade dos serviços de saúde (Novaes, Paganini, 1994). Em 1987, com a incorporação de outras organizações de saúde, mudou seu nome para The Joint Commission on Accreditation of Healthcare Organizations - JCAHO e, desde então, é reconhecida como The Joint Commission (Novaes, 2007).

A acreditação é um modelo de avaliação e certificação externa de qualidade do serviço de saúde, a partir de critérios predefinidos por especialistas na área da saúde. Tem como objetivo a melhoria contínua e é pautada por três princípios: os hospitais se inscrevem voluntariamente, é periódica e é reservada, ou seja, as informações não são divulgadas e o certificado tem duração de dois a três anos (Brasil, 2002).

Na América Latina e no Brasil, a Organização Mundial da Saúde (OMS), em 1989, iniciou o trabalho na área hospitalar abordando o tema: Qualidade da Assistência. Reuniram-se 30 países que concluíram que a acreditação seria o elemento estratégico para desencadear as iniciativas de qualidade nos serviços de saúde (Feldman, 2004). 
Avedis Donabedian, médico pediatra armênio, foi o primeiro autor que se dedicou a estudar a qualidade nos serviços de saúde, a partir dos conceitos de estrutura, processo e resultado, uma tríade, correspondente à Teoria Geral de Sistemas (Donabedian, 1980). Segundo ele, estrutura corresponde às características do local onde o cuidado é prestado. Uma estrutura mais adequada aumenta a probabilidade de a assistência prestada ser de melhor qualidade (Donabedian, 1980). Processo compreende as atividades desenvolvidas entre os profissionais de saúde e os pacientes e o resultado é a consequência da assistência realizada, refletindo as mudanças observadas no estado de saúde do paciente, inclusive seu grau de satisfação (Donabedian, 1980).

Em 1990, Donabedian ampliou os princípios descrevendo o que ele chamou de "Os Sete Pilares da Qualidade": eficácia, efetividade, eficiência, otimização, aceitabilidade, legitimidade e igualdade. A eficácia é a capacidade de melhoria na saúde e no bem-estar, ou seja, o melhor que se pode fazer levando em consideração o estado de saúde do paciente; a efetividade é o grau atingível na busca da melhoria das condições da prática cotidiana; a eficiência é a capacidade de se obter o melhor resultado com o menor custo; a otimização representa o balanço entre o custo e o benefício; a aceitabilidade significa a adaptação do cuidado aos desejos, expectativas e valores do paciente e de seus familiares; a legitimidade é a aceitação do cuidado pela comunidade e a equidade é a igualdade na distribuição dos cuidados (Donabedian, 1990).

Para que haja uma melhoria na qualidade do cuidado ao paciente, deve haver integração entre as áreas hospitalares tais como assistencial, administrativa, ética, educação e pesquisa, buscando superar suas expectativas (Feldman, 2004).

Outro item importante na qualidade, são os indicadores de qualidade que avaliam e permitem o monitoramento e identificação de oportunidade de melhoria de serviços e de mudanças positivas com relação ao alcance da qualidade a um custo razoável (D'innocenzo et al., 2006).

Gestores, pesquisadores e profissionais de saúde utilizam indicadores de qualidade para avaliar e melhorar a qualidade dos cuidados prestados aos pacientes (Schuster, 2015). A satisfação pode, por si só, ser um bom indicador de qualidade do atendimento (Thomas, 1996).

\subsection{SATISFAÇÃO DO PACIENTE}


A satisfação pode ser definida como uma função das percepções do cliente e de suas expectativas, pois o cliente satisfeito é aquele que percebe que o atendimento de suas necessidades pela instituição é, pelo menos, igual àquele que se esperava. Para isso, necessita-se conhecer as expectativas do cliente e, em seguida, quais as suas percepções com relação ao cumprimento dessas expectativas (Deming, 1990; Alves, 2003).

A satisfação do paciente foi definida como a relação entre as expectativas pessoais e a percepção do cuidado efetivamente recebido (Risser, 1975). A American Nurse Association (ANA) define a satisfação do paciente como a medida da opinião do paciente, ou do familiar, sobre o atendimento recebido pela equipe de enfermagem (ANA, 1999). Com Donabedian, a satisfação do paciente foi inserida na avaliação da qualidade em saúde, como um indicador de resultado da qualidade da assistência prestada (Donabedian, 1984).

Os níveis de satisfação, bem como as expectativas, variam de um paciente para outro. Considerando-se que cada indivíduo percebe o mundo de uma forma singular, fica evidente a importância de se conhecer as necessidades dos pacientes para que se possa proporcionar serviços que gerem elevados níveis de satisfação (Freitas, 2013).

Os índices de satisfação estão relacionados com os aspectos psicossociais do cuidado, tais como comunicação, preferências pessoais e aspectos culturais, podendo não refletir os reais acontecimentos, mas sim as expectativas e percepções dos pacientes (Afilalo, 1996).

O departamento de emergência é um cenário importante para se avaliar a satisfação do paciente. Ele fornece a primeira e única experiência do serviço hospitalar para muitas pessoas e, sendo assim, tem sido considerado como um fator determinante da reputação de um hospital (Stuart et al., 2003).

A superlotação do pronto-socorro foi negativamente associada à satisfação do atendimento (Pines et al., 2008), uma que vez que pode causar atraso ou interrupção do atendimento, desafiando a capacidade dos profissionais de saúde para prestar atendimento respeitoso e sensível (O'malley et al., 2008). Além disso, as interações com os profissionais de saúde são muitas vezes curtas e intensas, deixando pouco espaço para o cuidado emocional, psicológico e social (Baren, 2001; O'malley et al., 2008). 
A satisfação dos pais com a qualidade dos cuidados recebidos no hospital tem sido associada à melhor adesão aos tratamentos e resultados positivos (Kelly, 2000). Fornecer esses cuidados é um desafio, pois além da superlotação, a ansiedade dos pais, frente à necessidade de uma visita de emergência, o medo dos efeitos prejudiciais das medicações, os atrasos e a limitação de profissionais de saúde, também constituem uma preocupação (Downey, 2010; Lowe et al., 2012).

Os estudos publicados que abordam a satisfação com 0 atendimento de emergência pediátrica mostram que a classificação de risco, o tempo de espera mais curto (Waseem et al., 2003; Locke et al., 2011; Alston et al., 2015), a comunicação efetiva entre pacientes/acompanhantes e profissionais de saúde, o trabalho em equipe entre médicos e enfermeiros, a informação adequada sobre possíveis atrasos, (Kelly, 2000; Margaret et al., 2002; Waseem et al., 2003; Pagnamenta, Benger, 2008; Locke et al., 2011) e o maior tempo despendido pelo profissional para o cuidado (Alston et al., 2015) estão associados ao aumento da satisfação dos pais.

Além do alivio da dor (Margaret et al., 2002; Pagnamenta, 2008; Gill, et al., 2013), os pais buscam cuidados como a distração da criança diante de procedimentos dolorosos e o questionamento da dor para a criança, garantindo que ela seja abordada adequadamente, bem como a preocupação pela descoberta da causa da dor (Byczkowski et al., 2013).

Ouvir os pontos de vista dos pais é uma das formas mais eficazes de melhorar a qualidade do serviço de saúde segundo o Department of Health (2004). Ademais, a compreensão da satisfação das crianças também é necessária para otimizar a prestação de cuidados no departamento de urgência e de emergência (Stewart et al., 2000; Pines et al., 2008; Robinson et al., 2008; Weingarten et al., 2014).

A avaliação e o manejo da dor são duas das diversas variáveis relacionadas com a satisfação das crianças e das famílias que precisam ser mais exploradas. Um estudo de Weingarten et al. (2014) propôs que estudos qualitativos também fossem realizados com o objetivo de aumentar a compreensão sobre a satisfação das crianças com o manejo da dor no pronto-socorro.

Sabe-se que, quando a população em questão é a infantil, tudo parece ser mais complicado. O primeiro passo para melhorar o tratamento da dor desses pacientes é avaliar com precisão e de forma sistemática o cuidado real a ser 
fornecido. Isto requer a identificação de lacunas na avaliação e tratamento da dor, proporcionando melhores resultados, a partir da análise de medidas relevantes de desempenho baseadas em evidências.

Seria conveniente assumir que o alívio da dor e a satisfação da criança e da família estão estreitamente correlacionados. Em outras palavras, para assumir-se que a dor é bem controlada, tanto os pacientes quanto seus familiares terão de estar satisfeitos.

Diante do exposto, este trabalho busca conhecer, sob o ponto de vista da criança e de sua família, a satisfação com o manejo da dor no pronto-socorro infantil, com o objetivo de melhorar a qualidade dos serviços de saúde.

Assim, temos como pergunta de pesquisa "Qual a satisfação da criança e de sua família com o manejo da dor em um pronto-socorro infantil?" 


\section{OBJETIVO}

Compreender a satisfação da criança e de seu familiar acerca do manejo da dor em um pronto-socorro infantil no município de São Paulo. 
METODOLOGIA 


\section{METODOLOGIA}

\subsection{TIPO DE ESTUDO}

Trata-se de um estudo com abordagem qualitativa, exploratório e descritivo (Hungler et al., 2004; Creswell, 2007), envolvendo entrevista semiestruturada (Rubin H, Rubin I, 1995; Sandelowski, Barroso, 2003a; 2003b; Sandelowski, Leeman, 2012) e análise temática dos dados (Braun e Clarke, 2006). Esta abordagem permite retratar a experiência única da criança e de seu familiar, de acordo com seu ponto de vista, sobre a situação vivenciada e de suas necessidades.

A pesquisa qualitativa tem por objetivo a compreensão de um fenômeno, sob a ótica dos sujeitos, em seu próprio contexto. Para tal, o pesquisador coleta os relatos detalhados dos participantes do estudo (Creswell, 2007).

As abordagens qualitativas têm oferecido oportunidades para que os profissionais de saúde compreendam os significados, crenças e valores dos seres humanos. De fato, os profissionais de saúde necessitam de métodos que os auxiliem a penetrar na complexidade do ser humano (Pope, Mays, 2005). Nesse contexto, a pesquisa qualitativa possibilita a realização de investigações relacionadas com a prática profissional da enfermagem que, particularmente, interpreta o homem, como um organismo atuante que não permanece estático, uma vez que suas ideias e ações estão em constante modificação, de acordo com suas experiências individuais e coletivas e suas interações sociais (Minayo, 2003). Ademais, a pesquisa qualitativa permite ao pesquisador escutar o que os participantes pensam, sentem e compreendem sobre sua experiência. Este tipo de abordagem requer que o pesquisador ouça intensamente 0 participante e, para entender o significado do que está sendo dito, ele deve estar atento a cada palavra, a cada gesto durante a entrevista (Rubin H, Rubin I, 1995).

\subsection{O MODELO DE DONABEDIAN COMO PERSPECTIVA TEÓRICA}

Partindo-se do pressuposto de que a satisfação da criança e de seus familiares, acerca do manejo da dor, é muito mais que o seu alívio e não apenas um indicador isolado de qualidade, adotou-se aqui o modelo de Donabedian, ou Tríade Donabediana, como referencial teórico para a discussão dos dados.

O modelo de Donabedian, ou Tríade Donabediana, é definido como um modelo conceitual que fornece um desenho para avaliar a qualidade dos cuidados 
de saúde. De acordo com o modelo, as informações sobre a qualidade dos cuidados podem ser extraídas a partir de três categorias: estrutura, processo e resultados. Estrutura delineia o contexto no qual os cuidados são prestados, incluindo os edifícios do hospital, pessoal, financiamento e equipamento. Estrutura corresponde às características dos recursos, tanto físicos quanto humanos, ou seja: a estrutura física, equipamentos e insumos, quantidade e qualificação dos profissionais e recursos financeiros disponíveis para a manutenção da infraestrutura e da tecnologia para a viabilização dos serviços.

Processo significa as transações entre pacientes e fornecedores em todo o fornecimento de cuidados de saúde. É a soma de todas as ações que compõem saúde. Estes geralmente incluem diagnóstico, tratamento, cuidados preventivos e educação do paciente, mas pode ser expandido para incluir as ações tomadas pelos pacientes, ou seus familiares (Araújo, 2014).

Por fim, os Resultados referem-se aos efeitos dos cuidados de saúde no estado de saúde dos pacientes e populações (Donabedian, 1984). Contém todos os efeitos dos cuidados de saúde sobre os pacientes ou populações, incluindo alterações do estado de saúde, comportamento, ou conhecimento, bem como a satisfação do paciente e saúde relacionados com a qualidade de vida. Os resultados são, muitas vezes, vistos como os mais importantes indicadores de qualidade, porque a melhoria do estado de saúde do paciente é o principal objetivo dos cuidados de saúde (Araújo, 2014).

Além de analisar a qualidade dentro de uma unidade de cuidados de saúde, o modelo de Donabedian é aplicável à estrutura e ao processo para o tratamento de certas doenças e condições, com o objetivo de melhorar a qualidade da gestão de doenças crônicas (Araújo, 2014).

Indicadores de qualidade são ferramentas básicas para o gerenciamento do sistema organizacional e podem ser definidos como uma unidade de análise, quantitativa ou qualitativa, que monitora e avalia a qualidade das ações planejadas e executadas relativas à assistência e as atividades de um serviço (Pereira, Sousa, 1998; Novaes, 2015). Os indicadores são analisados sob a ótica de sete atributos de cuidados de saúde. Donabedian (1990) estabeleceu estes sete pilares como forma de ampliar o conceito complexo de qualidade. Os atributos são:

EFICÁCIA: efeito potencial definido pela capacidade de proporcionar um atendimento exemplar, com o intuito de alcançar a melhoria das condições de saúde 
e bem-estar do indivíduo (Donabedian, 1990); EFETIVIDADE: efeito real obtido no contexto existente (Donabedian, 1990); EFICIÊNCIA: grau máximo de cuidado efetivo obtido ao menor custo possível (Donabedian, 1990); OTIMIZAÇÃO: cuidado efetivo obtido por meio da relação custo e benefício mais favorável, ou seja, é o balanceamento mais vantajoso de custo e benefício no qual o benefício é elevado ao máximo em relação ao seu custo econômico (Donabedian, 1990); ACEITABILIDADE: Sinônimo de adaptação dos cuidados às preferências e expectativas do paciente. Este conceito relaciona-se com a efetividade, custo e benefício e efeitos do tratamento na relação médico-paciente (Donabedian, 1990); LEGITIMIDADE: conformidade com as preferências sociais (Donabedian, 1990); e EQUIDADE: imparcialidade na distribuição do cuidado e de seus efeitos sobre a saúde. É parte daquilo que torna o cuidado aceitável para os indivíduos e legítimo para a sociedade (Donabedian, 1990).

A partir dos pressupostos citados acima, pode-se concluir que a qualidade é um conceito dinâmico, mudando seus referenciais ao longo do tempo. Assim tornase importante conhecer e avaliar a percepção sobre qualidade dos clientes/pacientes e profissionais para melhor direcionar as estratégias e ações, atender as suas expectativas e propiciar uma tomada de decisão mais convicta e compatível com o contexto e objetivos da instituição de saúde.

\subsection{OBTENÇÃO DOS DADOS}

\subsection{1 $O$ contexto da pesquisa}

O estudo foi realizado no pronto-socorro infantil de um hospital de porte extra no município de São Paulo. A opção por este hospital foi motivada por ele possuir protocolo de dor institucional e por ser um hospital certificado pela acreditadora The Joint Comission.

A unidade escolhida possui três certificações, sendo duas internacionais: The Joint Commission e Acreditação Internacional Canadense - Qmentum e uma brasileira, a acreditação com Excelência - ONA Nível III. O pronto-socorro infantil (PSI) atende crianças e adolescentes de até 17 anos incompletos.

O pronto-socorro infantil é dividido por áreas, onde os pacientes são atendidos. Na entrada, quando o paciente chega ao hospital, ele passa pela triagem, 
na qual a enfermeira faz a avaliação inicial e a classificação de risco. Neste hospital é utilizada a classificação Canadense adaptada, segundo a qual a criança pode ser classificada com as cores verde (urgência relativa), amarela (urgência), laranja (emergência), vermelha (emergência), ou azul (prioridade). Essas cores determinam o grau de gravidade do paciente e o tempo máximo de espera. Crianças classificadas com a cor verde podem aguardar 90 minutos; amarela, 30 minutos; laranja, 15 minutos; vermelha devem ser atendidas imediatamente e azul, em até 45 minutos.

Após a triagem, o paciente faz a abertura da ficha para atendimento médico e deve aguardar a chamada, de acordo com a sua classificação. Após o atendimento médico, a criança poderá receber medicações, ou realizar exames de sangue, ou imagem. Quando a medicação prescrita for endovenosa, ou quando a criança necessitar de monitorização continua, ela é encaminhada para a sala de observação. Nesta sala a criança deve ser acompanhada por uma pessoa responsável.

A maioria dos atendimentos nesta unidade ocorre por problemas respiratórios como asma, bronquite, bronqueolite e pneumonia, problemas gastrointestinais, como vômitos e diarreia e também por dor abdominal e cefaleia.

Em média são atendidas por mês 4.778 crianças no pronto-socorro infantil. Entretanto, este volume de atendimento varia ao longo do ano, com aumento nos meses de março, abril e maio, chegando a mais de 6.000 atendimentos por mês durante este período.

\subsection{PARTICIPANTES}

Os participantes deste estudo foram crianças atendidas no pronto-socorro infantil que contemplavam a fase escolar, ou seja, a faixa etária de seis a 12 anos de idade, e seus familiares. Esta faixa etária foi escolhida, pois, sob o ponto de vista do desenvolvimento descrito por Piaget, as crianças escolares encontram-se na fase cognitiva de operações concretas e estão começando a compreender os fenômenos abstratos. É a partir deste estágio (operações concretas) que começam a ver o mundo com mais realismo, deixam de confundir o real com a fantasia (Rappaport et al., 1981).

Os critérios de inclusão dos participantes foram: crianças com queixa de dor, admitidas no pronto-socorro infantil que, posteriormente, tiveram alta médica da sala 
de observação e crianças com conduta médica de internação, porém ainda no pronto-socorro, após receber medicação para dor, que tiveram dor, ou com dor classificada entre os escores de zero até três, segundo a escala numérica, e que fossem capazes de verbalização.

O contato com a criança e seu familiar ocorreu durante $o$ atendimento na sala de observação do pronto-socorro infantil. Enquanto a criança estava recebendo as medicações para dor, a pesquisadora conversou, primeiro com os familiares sobre os objetivos da pesquisa, esclareceu as dúvidas e fez o convite para os pais autorizando a participação na pesquisa, além de solicitar a autorização para a participação da criança na pesquisa.

Durante o tempo de observação, a pesquisadora acompanhou o quadro da criança e sua evolução. Assim que a criança estivesse sem dor, ou com um escore de dor até três, ela era convidada a participar da pesquisa. Após a aceitação por parte da criança e de seu familiar, eram convidados a acompanhar a pesquisadora, a uma sala com portas fechadas para a maior privacidade dos participantes.

Para a participação na pesquisa, os familiares assinaram, antes da entrevista, o Termo de Consentimento Livre e Esclarecido (Apêndice A) e as crianças, o Termo de Assentimento (Apêndice B).

\subsection{ESTRATÉGIAS DE COLETA DOS DADOS}

A seleção das crianças foi realizada pela pesquisadora por meio do prontuário do paciente, o que possibilitou conhecer o histórico do atendimento e o tipo de dor apresentada. Nenhum dos profissionais de saúde do PSI estava ciente do objetivo da pesquisa. Portanto, não foram envolvidos em nenhuma das etapas do processo.

As entrevistas tiveram como foco conhecer a perspectiva da criança e de seu familiar com relação a sua satisfação com o manejo da dor. A entrevista semiestruturada foi utilizada para as crianças e para os familiares (Apêndice $C$ ), sendo direcionadas pela questão norteadora: "Como foi o atendimento no prontosocorro infantil, com relação à dor?"

Em uma entrevista qualitativa, o pesquisador não é neutro e distante. De fato, ele está envolvido emocionalmente, pois há uma relação entre o pesquisador e o pesquisado. A empatia, a sensibilidade, o humor e a sinceridade são ferramentas importantes na pesquisa, uma vez que a entrevista depende de como os participantes estão se sentindo naquele momento (Rubin H, Rubin I, 1995). 
As entrevistas foram realizadas nos períodos da manhã, tarde e noite. A coleta de dados ocorreu durante um período de sete meses, entre 20 de outubro de 2016 e 22 de maio de 2017.

As questões foram respondidas pela criança e pelo familiar que estava presente no momento da entrevista. Esta etapa teve duração de aproximadamente 25 minutos. Durante a entrevista, como as crianças estavam acompanhadas de seus familiares, decidiu-se que a primeira entrevista fosse realizada com a criança, para que não houvesse interferência nas respostas. Todos os participantes aceitaram a proposta.

A maioria das crianças considera divertido desenhar. A partir deste conhecimento, neste trabalho, o desenho foi utilizado como estratégia de aproximação de coleta de dados pois ele facilita a comunicação e a motivação da criança durante a entrevista (Sposito et al. 2013). No entanto, nem todas quiseram desenhar. No caso daquelas que aceitaram desenhar, a pesquisadora pediu um desenho de como havia sido o seu dia no pronto-socorro infantil. Para isso, a pesquisadora ofereceu papel sulfite em branco e uma caixa de giz de cera, instrumentos utilizados na instituição como distração para as crianças. No final da entrevista a criança assentiu que o desenho fosse anexado como material da pesquisa.

As entrevistas foram gravadas e transcritas pela pesquisadora imediatamente após sua realização para assegurar que não houvesse perda de informações. As falas foram corrigidas quanto à gramática, vícios de linguagem e palavras repetidas, sem que fosse alterado o sentido da fala das crianças e dos familiares.

A coleta dos dados foi realizada até que houvesse a repetição do conteúdo das falas dos participantes. Em seguida, realizou-se a conferência de fidedignidade da transcrição para certificar-se da qualidade do material e dar início à análise dos dados.

Os participantes das entrevistas foram identificados com as letras " $C$ " para as crianças, "M" para as mães, "P" para os pais e "V" para avós. As entrevistas foram identificadas com a letra "E", resultando em uma configuração final "CE1" significando "Entrevista da Criança 1 "e "ME1", "Entrevista da Mãe 1", por exemplo.

\subsection{ASPECTOS ÉTICOS}


O projeto de pesquisa fundamenta-se na Resolução 466 de 12 de dezembro de 2012, que regulamenta a pesquisa em seres humanos, conforme determinação do Conselho Nacional de Saúde, do Ministério da Saúde, cujas obrigações do pesquisador são: a garantia do anonimato, a privacidade e a possibilidade de desistência do participante em qualquer etapa do estudo. Esta resolução incorpora referenciais da bioética, tais como autonomia, não maleficência, beneficência, justiça e equidade, visando a assegurar os direitos e deveres referentes aos participantes da pesquisa, ao pesquisador e ao Estado.

Ainda de acordo com a resolução 466/12, o pesquisador deve fornecer, de forma escrita e em linguagem clara, objetiva e de fácil entendimento, o Termo de Consentimento Livre e Esclarecido (TCLE) e/ou o Termo de Assentimento para os participantes, garantindo-Ihes explicações sobre a natureza da pesquisa, seus objetivos, métodos, duração da entrevista, benefícios previstos, potenciais de risco, incômodos que esta possa acarretar-lhes, anonimato, escolha para participar, ou não, da pesquisa e retirada de participação em qualquer fase da mesma.

Diante do exposto acima, o projeto de pesquisa foi encaminhado ao Comitê de Ética em Pesquisa da Escola de Enfermagem da Universidade de São Paulo (EEUSP) e aprovado sob o número 1.508 .647 (Anexo1). O projeto foi aprovado no Comitê de Ética em Pesquisa do Centro Universitário São Camilo, instituição coparticipante, sob o número 1.639.451 (Anexo 2).

Para a participação neste estudo, a pesquisadora fez a leitura do Termo de Consentimento Livre e Esclarecido (Apêndice A) para os pais e do Termo de Assentimento (Apêndice B) para as crianças, além de entregar a cópia impressa para os familiares. Durante a leitura, pontos importantes como a participação voluntária, a desistência em qualquer momento da entrevista e o sigilo foram reforçados.

\subsection{ANÁLISE DOS DADOS}

Os dados foram analisados mediante abordagem da análise temática, caracterizada pela leitura dos dados, com o objetivo de identificar, analisar e descrever seus padrões, denominados temas. É um método que reporta as experiências, significados e realidade dos participantes e permite organizar, descrever e interpretar os dados de forma sintética, porém detalhada para encontrar 
padrões repetidos de significados (Thorne et al., 1997; Sandelowski, 2003a; 2003b; Braun, 2006; Sandelowski, 2012).

No presente estudo foi utilizada a análise temática, uma abordagem que se caracteriza pela realização de leituras detalhadas dos dados a fim de chegar a temas ou conceitos obtidos, a partir da sua interpretação. O objetivo é possibilitar o surgimento de temas que sejam frequentes ou significativos, derivados dos dados brutos (Thomas, 2006; Vaismoradi et al., 2013).

A partir da associação dos textos e da formação das categorias, torna-se viável a observação de valores predominantes nas informações fornecidas pelos entrevistados para dar significado às experiências (Hesse-Biber, 2006).

O desenvolvimento dos temas e códigos pode ser realizado por modo indutivo, caracterizado por uma abordagem mais específica, extraindo os temas dos próprios dados, no caso as entrevistas. $\mathrm{Na}$ análise dos dados do presente estudo optou-se pela utilização dos dois modos de análise, o modo indutivo e o modo dedutivo, sendo, portanto, caracterizado como um modelo híbrido (Thorne et al., 1997; Boyatzis, 1998).

Após as entrevistas, o pesquisador deve se familiarizar com os dados para elaborar os códigos que identificam as características desses dados, informações que serão analisadas posteriormente de forma significativa pelo pesquisador (Braun, 2006). Após a codificação de todos os dados das entrevistas, eles foram agrupados e combinados, conforme assunto e relevância, para formarem os temas potenciais.

O tema representa um conjunto de significados padrão obtido a partir dos dados e capta algo importante com relação à questão de pesquisa. Os dados precisam de evidências para que sejam considerados tema. Assim, considera-se, não necessariamente, algo com maior quantidade de respostas, mas aquilo que é mais significativo e importante para a questão geral (Braun, 2006).

Os temas potenciais são analisados e revisados e alguns excluídos por falta de suporte dos dados, enquanto outros se unem para formar um tema mais amplo, de forma mais significativa e clara. Os temas devem ao final, capturar a ideia dos dados codificados (Braun, 2006).

A partir da análise significativa dos dados, foram gerados dois temas, compostos por subtemas oriundos das respostas das crianças e dos familiares: 
Tema 1: A satisfação percebida pelas crianças e familiares acerca do manejo da dor no pronto-socorro infantil, composto por três subtemas: "Atendimento prioritário", "alívio rápido da dor" e "Acolhimento pela equipe" A satisfação percebida pelas crianças acerca do manejo da dor no pronto-socorro infantil composto por um subtema: "Necessidades básicas atendidas". A satisfação percebida pelos familiares acerca do manejo da dor, composto por um subtema: "Investigação dos sintomas".

Tema 2: A insatisfação percebida pelas crianças e familiares acerca do manejo da dor no pronto-socorro infantil, composto por um subtema: "Demora em aliviar a dor" A insatisfação percebida pelas crianças acerca do manejo da dor no pronto-socorro infantil composto por dois subtemas: "Procedimentos dolorosos" e "Ambiente desconfortável". A insatisfação percebida pelos familiares acerca do manejo da dor composto por um subtema: "Demora pelos resultados dos exames". 
RESULTADOS 


\section{RESULTADOS}

\subsection{PANORAMA DO CENÁRIO DE ESTUDO E CONTEXTUALIZAÇÃO DOS PARTICIPANTES.}

Para o estudo, foram selecionadas 19 crianças entre seis e doze anos de idade, sendo nove meninos (47\%) e dez meninas (53\%) e seus familiares. Com relação à faixa etária, o estudo apresentou uma criança com seis anos de idade, duas com sete anos, duas com oito anos, quatro com nove anos, duas com dez anos, seis com onze anos e duas com doze anos de idade.

Com relação aos familiares, 14 mães, sete pais e um avó estavam presentes acompanhando as crianças, no momento da entrevista. Os familiares se revezavam durante o tempo que estiveram no hospital, pois na sala de observação é permitido apenas um acompanhante. Em alguns casos alguns, os familiares voltaram para casa ou trabalho antes da alta da criança, não podendo estar presente no momento da entrevista.

Quando questionados sobre o início da dor, meninos e meninas variaram nas respostas estabelecendo um intervalo de tempo entre o dia da internação no prontosocorro infantil (PSI) e quatro dias ou mais antes da procura pelo serviço hospitalar. Entretanto, 13 crianças (72\%) começaram a sentir dor no dia da visita ao prontosocorro, ou no dia anterior.

Antes de serem encaminhadas ao PSI, 14 crianças (74\%) tiveram sua dor manejada farmacologicamente em casa, ou na escola.

Com relação à queixa de dor das crianças, observou-se prevalência de dor abdominal ( $42 \%$ das crianças) e cefaleia ( $42 \%$ das crianças) três crianças deram entrada no PSI com queixa das duas - dor abdominal e cefaleia, totalizando $16 \%$ dos participantes.

Ao dar entrada no PSI, a criança passa pelo serviço de triagem do hospital que a classifica de acordo com o risco que seu quadro clínico apresenta. O hospital apresenta o protocolo de classificação Canadense adaptado, sendo a classificação verde destinada às crianças que devem ser atendidas em até duas horas, e a classificação amarela destinada às crianças que precisam de atendimento em até 30 minutos a partir de sua admissão ao PSI.

De acordo com a classificação de risco, $89 \%$ das crianças foram classificadas com risco amarelo e $11 \%$, verde. O tempo para atendimento da primeira consulta 
médica foi de 32,6 minutos para a classificação verde e de 17,3 minutos para a amarela, correspondendo ao tempo previsto no protocolo do hospital.

Após a consulta médica, as crianças foram para a sala de observação onde o gerenciamento da dor e seu manejo farmacológico foram realizados da maneira mais adequada à faixa etária pediátrica.

O tempo de espera para a realização da punção e recebimento das medicações também variou de acordo com a classificação de risco. O tempo para receber as medicações da criança com classificação verde foi em média 43,6 minutos para o procedimento de punção venosa. No caso da classificação amarela, a espera foi de 32,3 minutos, uma vez que a cor amarela tem prioridade no atendimento. Somente após a punção venosa, a criança recebeu as medicações para alívio da dor.

Segundo o protocolo do hospital, o médico tem quatro horas para decidir a conduta a ser adotada para a criança: alta ou internação hospitalar, dependendo da melhora da dor ou do diagnóstico médico. O tempo para a definição da conduta médica é menor para as crianças com classificação verde do que para aquelas com classificação amarela (3,8 horas e 5,8 horas, respectivamente). É importante ressaltar que, no caso da classificação amarela, esse período ultrapassou o tempo do protocolo hospitalar, porque em 6 casos (43\%), as crianças ficaram em observação entre oito e 10 horas e 30 minutos para a definição de conduta médica, e em 3 (50\%) deles optou-se por internação hospitalar.

\subsection{A EXPERIÊNCIA DO ATENDIMENTO NO PRONTO-SOCORRO INFANTIL, SEGUNDO A PERSPECTIVA DA CRIANÇA}

Conforme descrito na metodologia, o desenho dirigido foi utilizado como estratégia de aproximação e coleta de dados para conhecer a experiência da criança durante seu atendimento no pronto-socorro infantil.

Das 19 crianças, apenas nove utilizaram-se do desenho para ilustrar seu atendimento no hospital. 


\section{Criança 02}

Sexo: feminino, 09 anos.

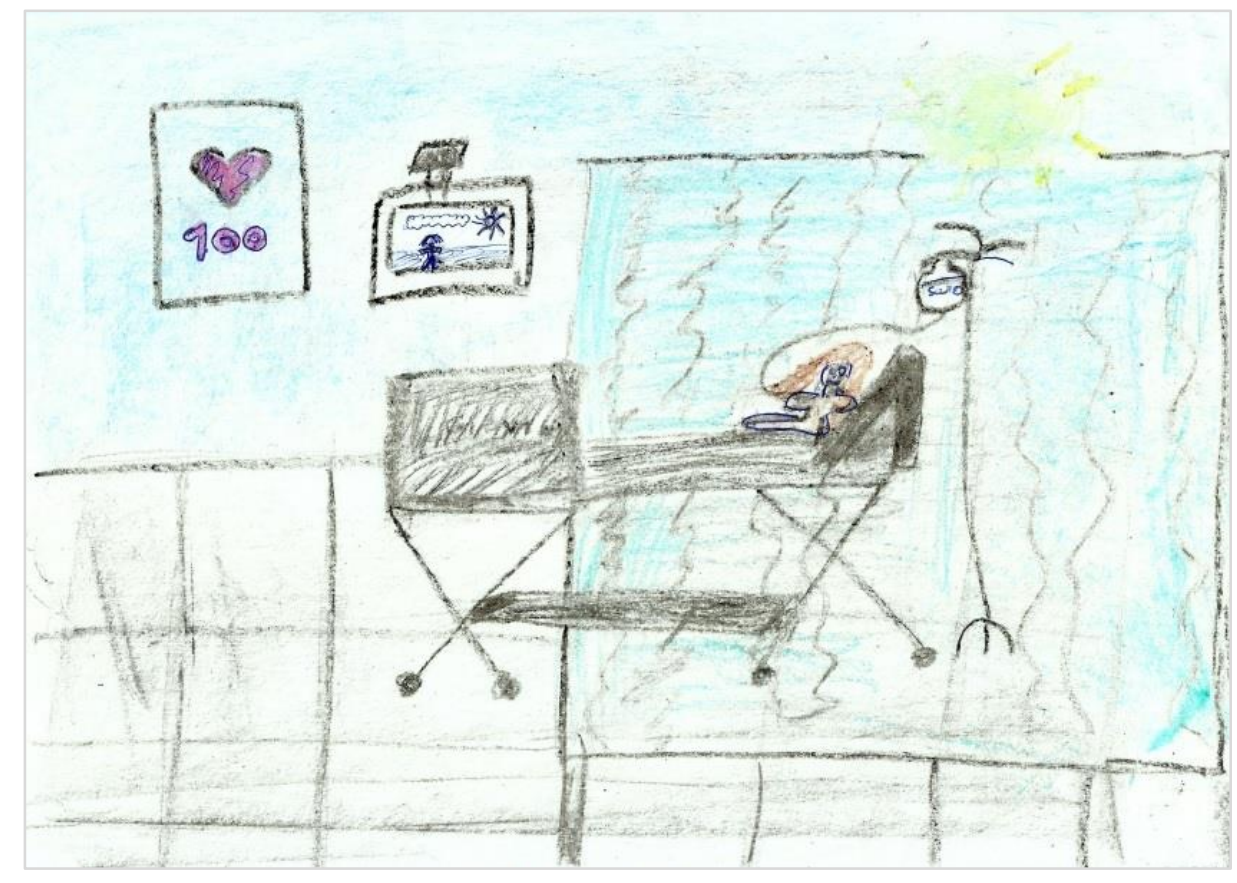

"Eu estou fazendo esse desenho de como que eu estava [...] sentada assistindo TV, tomando soro, tomando dramin ${ }^{\circledast}$. E aqui é como o coração tem que estar."

\section{Criança 03}

Sexo: masculino, 09 anos.

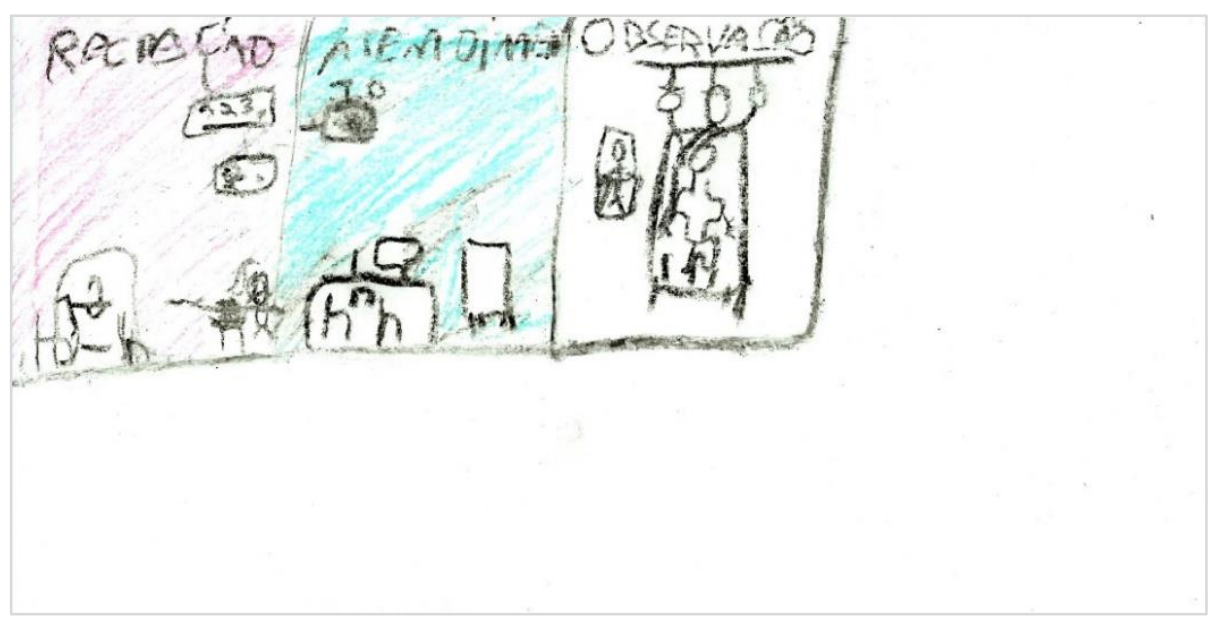


"Aqui as cadeiras, aqui atrás o banheiro, aqui a moça da recepção. Aqui é o número onde a gente foi atendido (consultório médico) e aqui a televisão para assistir os desenhos. Aqui é a observação, a mesa, eu aqui e o soro e aqui é minha mãe.”

\section{Criança 05}

Sexo: feminino, 08 anos.

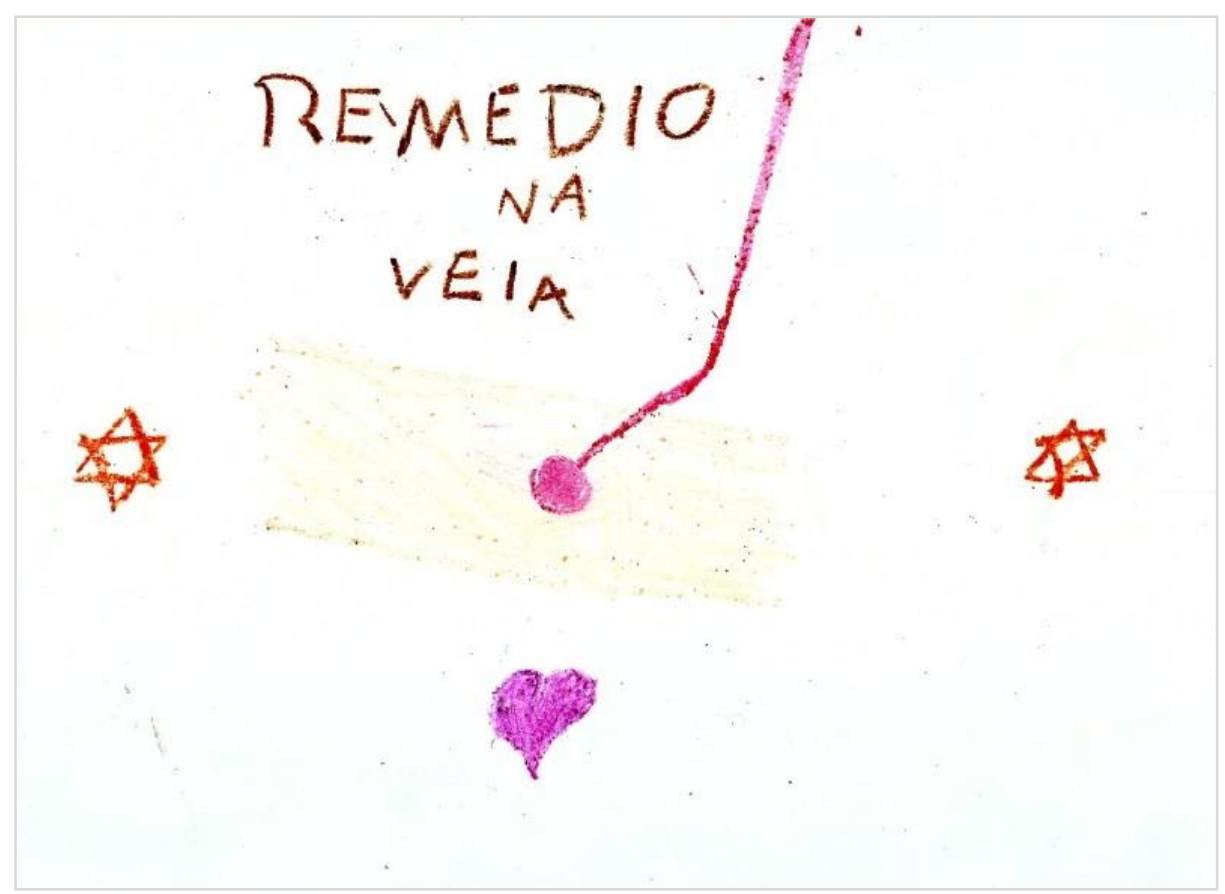

"Fiz a moça colocando o remédio, fiz a agulha e o caninho do remédio."

\section{Criança 06}

Sexo: feminino, 10 anos.

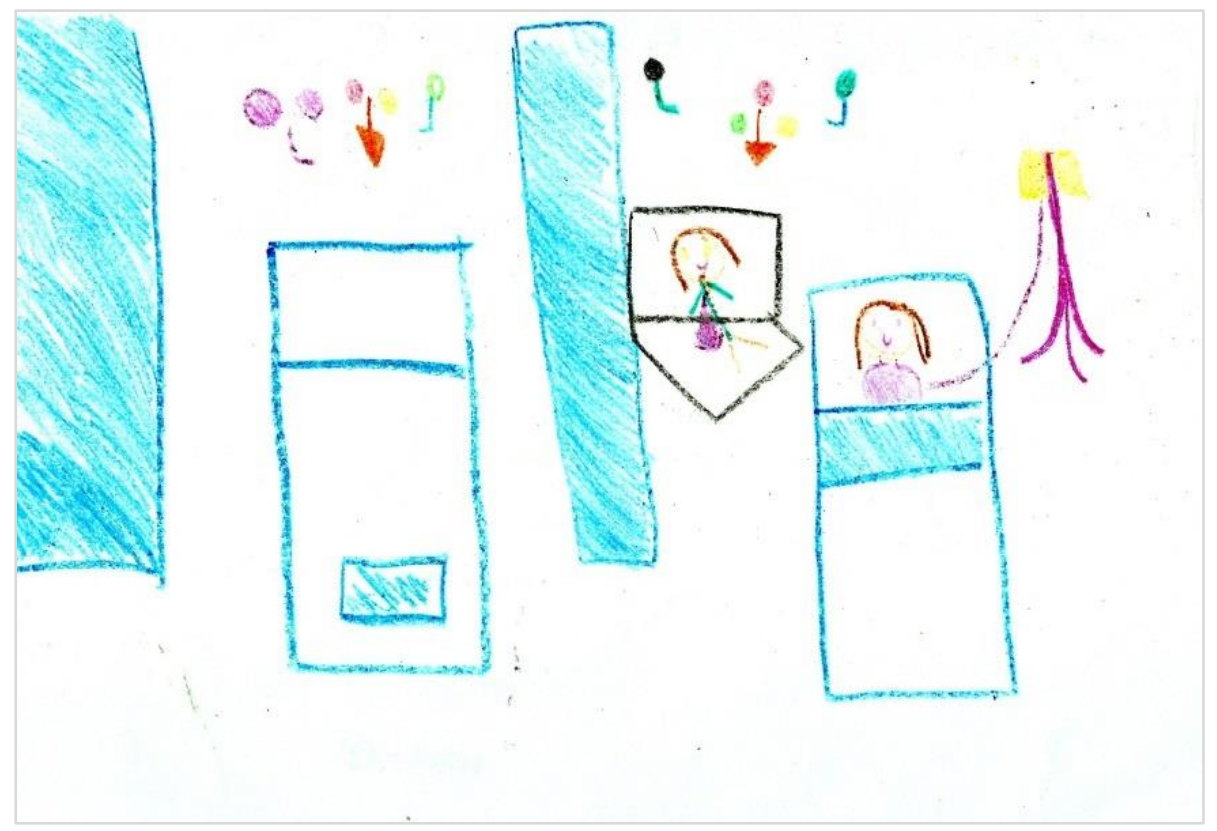


"Eu, a minha mãe, a cortina, a cama, a outra cama, as coisas que estão em cima da cortina, as coisas que estavam em cima da cama e as coisinhas do soro."

\section{Criança 07}

Sexo: feminino, 07 anos.

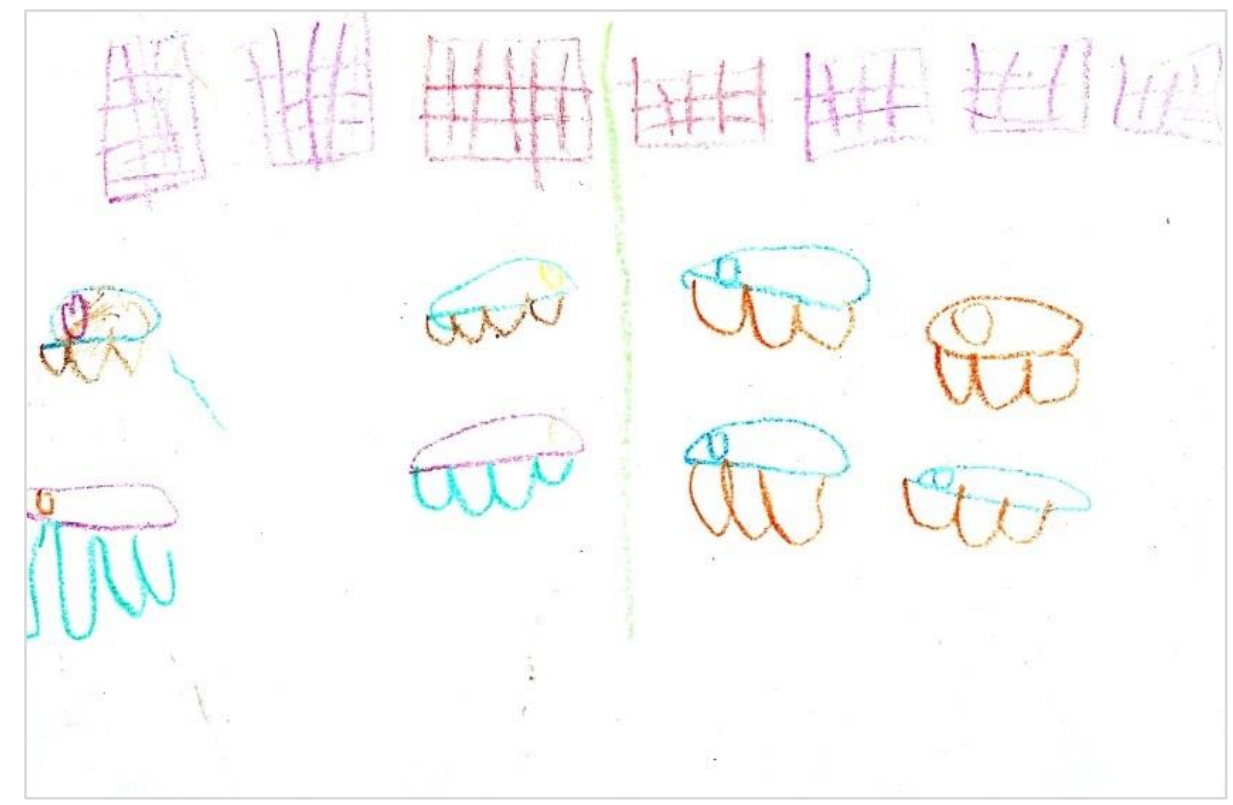

"Desenhei lá o quarto, que eu estava. Aqui são as camas, as janelas e as paredes."

\section{Criança 10}

Sexo: feminino, 11 anos.

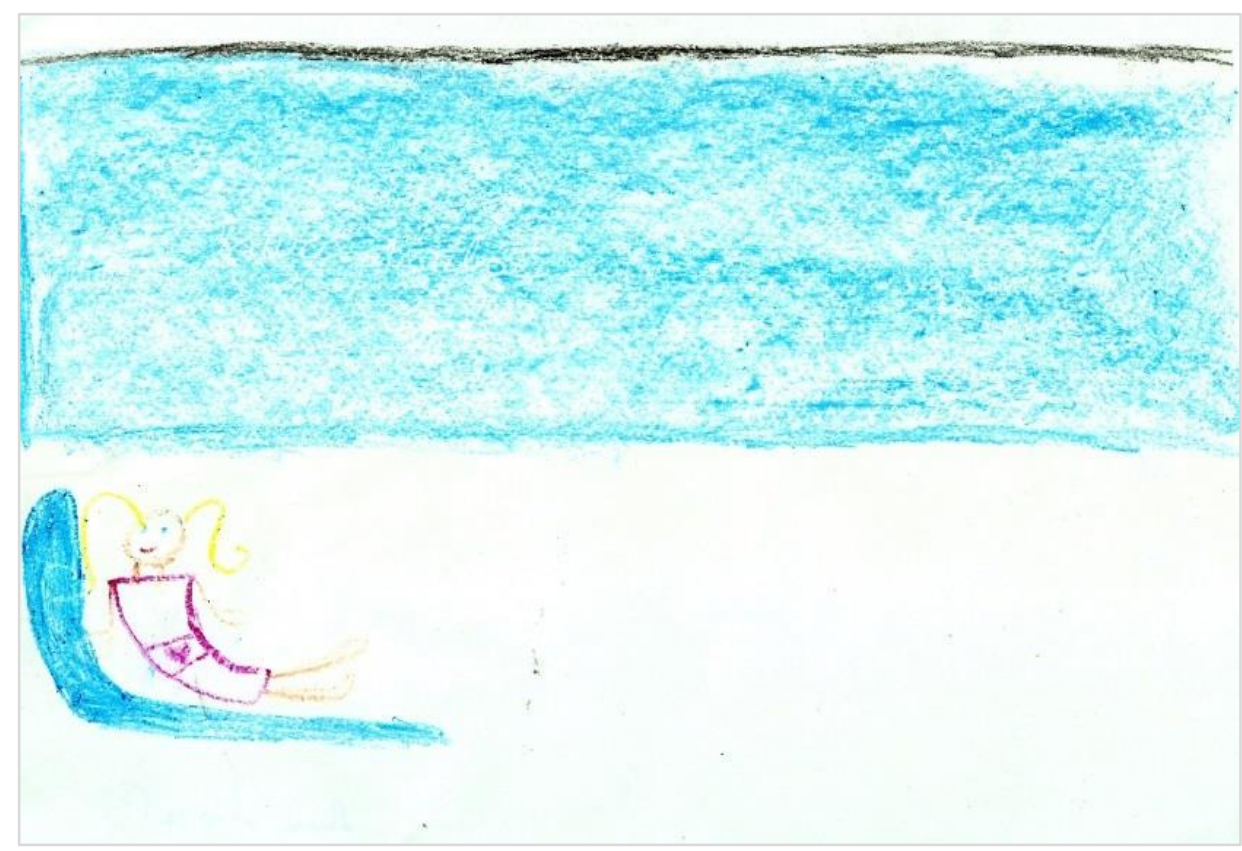


"Eu na cama, a cortina, a cama. Ainda vou desenhar as coisas que estava lá. Que estava tomando, o soro."

\section{Criança 16}

Sexo: masculino, 09 anos.

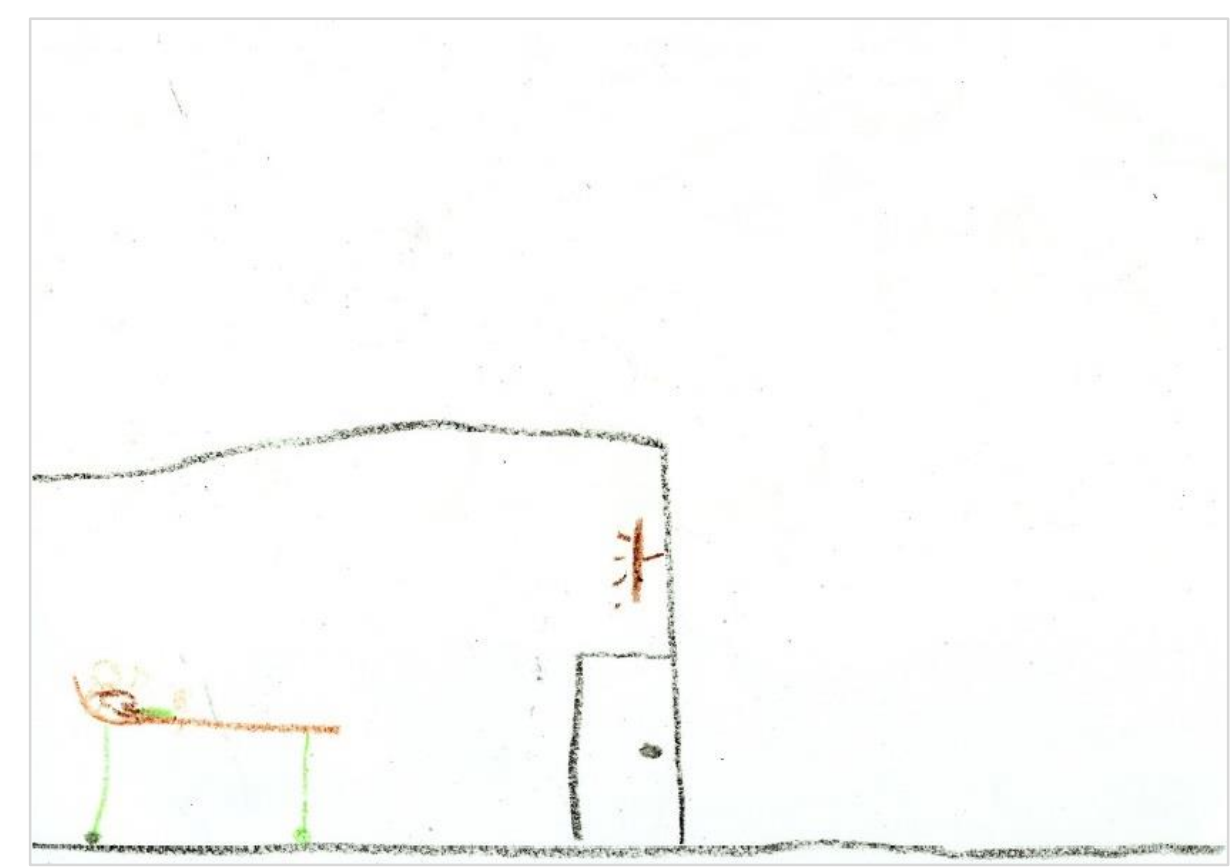

"Eu assistindo tv, nesse quarto (isolamento observação)"

\section{Criança 17}

Sexo: masculino, 09 anos.

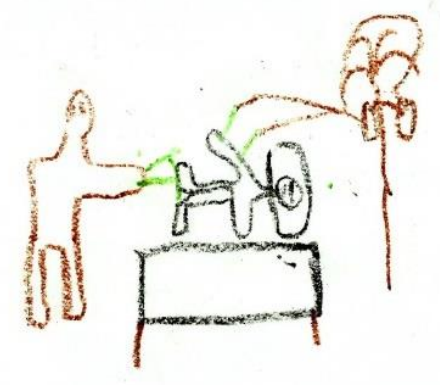

"Eu tomando a vacina. O homem colocando a vacina aqui. [...] Essa daqui é a vacina quando foi colocar e essa daqui é a vacina quando estava indo. [...]É o negocinho onde eles colocavam o soro. E esse aqui era onde saia o soro, o soro passava e entrava por aqui para o meu corpo depois. [...] Os dois foram na veia, eu tomei 2 
soros. Eu devia só tomar 1, mas só que como a primeira vez eu fiquei mexendo, deu errado. Aqui ele está colocando e aqui é a caminha que eu fiquei."

\section{Criança 19}

Sexo: feminino, 07 anos.

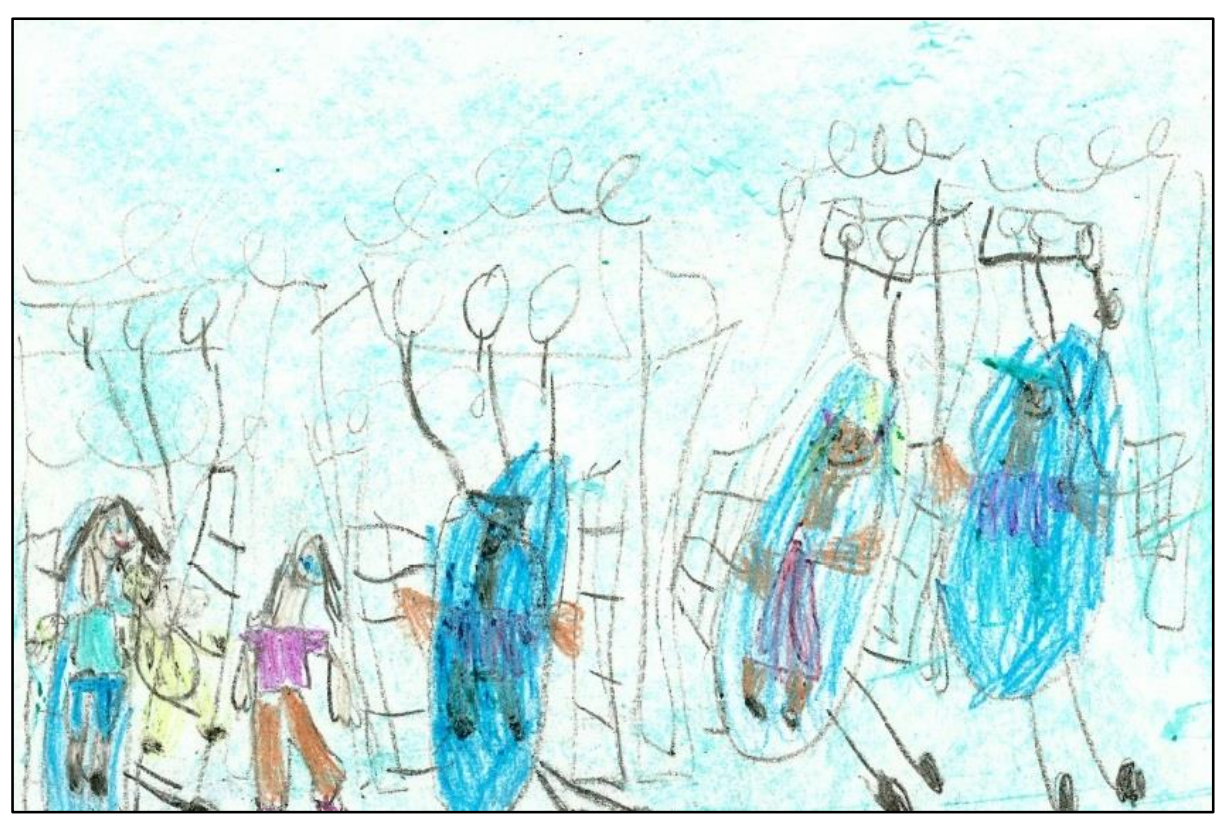

"Eu estava com aminha girafa e com a minha mãe. Eu estava tomando remédio, essa é minha mãe, ela está vendo. [...] os outros só estou inventando mesmo. Porque eu nem sei quem estava lá, só o menino do lado e a menininha que estava na frente."

\subsection{PERCEPÇÃO DA SATISFAÇÃO DA CRIANÇA E DE SEUS FAMILIARES ACERCA DO MANEJO DA DOR NO PRONTO-SOCORRO INFANTIL}

Os resultados sobre a satisfação das crianças e dos familiares acerca do manejo da dor no pronto-socorro infantil foram organizados em subtemas, baseados em suas experiências e foram organizados em dois temas; Tema 1: A satisfação percebida pelas crianças e familiares acerca do manejo da dor no pronto-socorro infantil e Tema 2: A insatisfação percebida pelas crianças e familiares acerca do manejo da dor no pronto-socorro infantil, sendo que cada tema contém subtemas de acordo com os resultados encontrados neste trabalho. 


\subsubsection{Tema 1: A satisfação percebida pelas crianças e familiares acerca do} manejo da dor no pronto-socorro infantil, composto por três subtemas: "Atendimento prioritário", "alívio rápido da dor" e "Acolhimento pela equipe" A satisfação percebida pelas crianças acerca do manejo da dor no prontosocorro infantil composto por um subtema: "Necessidades básicas atendidas". A satisfação percebida pelos familiares acerca do manejo da dor, composto por um subtema: "Investigação dos sintomas".

A satisfação das crianças e dos familiares com relação ao manejo da dor foi percebida durante as entrevistas ao relatarem suas experiências durante 0 atendimento. $O$ ambiente do pronto-socorro é, muitas vezes, considerado estressante e imprevisível. Assim, as experiências e interpretações pessoais variam conforme suas expectativas e importância dada a uma determinada situação, por isso, a experiência das crianças e familiares foi diferente em alguns aspectos e semelhante em outros.

As crianças e familiares concordaram com o atendimento prioritário, o alivio rápido da dor e acolhimento pela equipe.

Solucionar a dor o mais rápido possível, dentro do hospital, significa ser atendido e medicado rapidamente. Dessa forma, a prioridade no atendimento se mostrou fundamental, porque o tempo de espera para a consulta médica diminui.

Conversar diretamente com a criança e sua família sobre sua dor e o tratamento fez com que ambos entendessem o que estava acontecendo durante 0 atendimento. Nesse sentido, o cuidado, carinho e atenção são fundamentais no cuidado.

Para as crianças, o atendimento das necessidades básicas foi essencial, pois quando a criança melhorou a dor, outros aspectos se mostraram importantes como o descanso e a alimentação.

Para os familiares, o momento mais aguardado foi o atendimento médico, pois a partir dele é que a queixa de dor da criança foi investigada.

\subsubsection{Atendimento prioritário}

Quando a criança chega no pronto-socorro sentindo dor ela se sente incomodada com aquele sintoma e quer eliminar da forma mais rápida possível aquela sensação desagradável. 
A queixa de dor carrega incertezas e insegurança nos familiares sobre a condição de saúde da criança, por isso, os acompanhantes ficam apreensivos para descobrir a origem da dor e tratá-la. Os familiares sentem-se estressados até o atendimento médico e somente após a consulta ficam seguros.

Uma das questões mais importantes para a criança e familiar durante 0 atendimento foi o alívio da dor e, para isso, todas as etapas do fluxo de atendimento se mostraram importantes, principalmente a triagem com a classificação de risco, onde $\mathrm{o}$ enfermeiro prioriza $\mathrm{o}$ atendimento.

A partir da classificação de risco, a criança pode ser classificada como urgência relativa, ou seja, não precisando ser atendida imediatamente e podendo esperar até uma hora e meia. Este paciente recebe a cor verde. Por outro lado, a criança pode ser classificada como urgência, ou seja, aquele paciente que necessita de atendimento prioritário devido à gravidade clínica ou sofrimento. Este recebe a pulseira de cor amarela e é atendido em até trinta minutos.

No momento da classificação, os familiares ficam ansiosos para saber a cor da pulseira. Como a maioria conhece o fluxo do pronto-socorro, sabem que a pulseira amarela tem prioridade e que serão atendidos mais rapidamente do que com a pulseira verde.

$\mathrm{O}$ atendimento mais rápido fez com que aquele sentimento do desconhecido e de impotência para ajudar a criança fosse amenizado com a investigação mais precocemente possível de um profissional apto a resolver a situação. A classificação amarela foi citada tanto pelas crianças como pelos familiares e fez com que o atendimento médico ficasse mais rápido e com isso, o alívio da dor também.

"Eu achei legal o atendimento. Foi rápido [...] não demorou. "(Criança 01)

"É hoje foi bom. [...] Porque foi rápido e também o USG foi rápido e com eficiência." (Criança 18)

"Eu achei assim, o que eu mais gostei foi na hora que eu não estava aqui, meu marido falou que foi rápido o atendimento, que no médico passou rápido também, que eu acho que teve a preferência, e isso acho que foi o mais importante, porque quando a gente chega no hospital é o sentimento que todo mundo tem, ser atendido 
rápido, porque você já fica um pouco mais seguro. Porque enquanto você não passa no medico, você fica muito apreensivo " (Mãe 1)

"Mas o problema é quando demora para atender, você fica naquela expectativa, a criança ali passando mal e aquilo ali é meio estressante, mas é, então hoje foi super rápido, mas eu já tive hospitais que eu tive que esperar duas horas para ser atendida, entendeu, ai é estressante, é bem estressante. " (Mãe 03)

"Aqui foi, aqui ajudaram bastante, também viram que eu estava ruim, já priorizaram o atendimento, me trouxeram de cadeira de rodas porque viram que eu não conseguia andar. E já foram me apoiando, foi bem assim bom, me acompanharam bastante mesmo. "(Criança 04)

"[...] a hora que a gente chegou, já viu que era uma coisa um pouco mais preocupante, e já põe a pulseira amarela nela, para ser mais rápido [...] " (Mãe 02)

"Então achei que o atendimento foi bom, foi ótimo até, porque quando eu cheguei falando os sintomas dele, a gente nem esperou, lá mesmo, ela já, já na triagem, ela já triou com a pulseirinha amarela e aqui em cima já chamaram de primeira. " (Mãe 15)

\subsubsection{Alívio rápido da dor}

Neste trabalho foram entrevistadas crianças com queixa de dor que receberam analgesia endovenosa, para isso, elas ficaram na sala de observação. Neste período, são realizados os procedimentos prescritos pelo médico, sejam eles medicações ou exames complementares para a resolução do caso.

O alívio da dor é uma das partes mais importantes do atendimento para as crianças e familiares, porque o principal motivo da procura pelo pronto socorro foi o alívio desta dor, assim, espera-se que a criança tenha sua dor melhorada em decorrência do atendimento.

A velocidade do acesso à criança com dor se mostrou importante neste estudo. Tanto as crianças quando seus familiares gostaram quando receberam a medicação rapidamente, além disso, a melhora ou alívio desta dor também foi apontado como satisfatório. 
"Foi bom, porque quando eu cheguei, eu já subi aqui e já colocaram o soro em mim, os remédios." (Criança 15)

"Ah, acho que foi bom. [...] foi rápido e conseguiu sarar tudo a dor. " (Criança 11)

“Foi rápido, foi bem rápido. [...] foi rápido para tomar remédio. [...] para passar a dor foi um pouco mais demorado, mas foi rápido. "(Criança 11)

"Ah, que passou a dor dela, de ter feito a medicação e a dor dela passar. " (Mãe 2)

"Ah de ter medicado ela rápido, porque as vezes quando a gente vem, as vezes não se medica no pronto socorro, as vezes "ah toma o remédio e compra na farmácia" e a medicação do pronto socorro quando é na veia, acho que é mais rápido, faz efeito mais rápido e a dor passa mais rápido, então acho que isso foi muito bacana, porque ela poderia ter dado uma medicação para tomar em casa, "ah já que não está doendo muito, toma a medicação para tomar em casa" e eu achei bacana de não deixar ela sentir a dor até o final dos exames" (Mãe 6)

\subsubsection{Acolhimento pela equipe}

Quando as crianças chegaram ao pronto-socorro, estavam fragilizadas, com dor, e em um ambiente não familiar. Passaram por vários locais como a triagem, recepção e consultório médico antes de receber algum alívio para sua dor.

O tempo que a criança ficou na sala de observação para receber a medicação, aguardar sua melhora e esperar os resultados dos exames até a sua reavaliação variou de acordo com cada criança. Assim, durante o tempo de permanência nesta sala, a criança espera ser bem atendida, significando para ela que os profissionais de saúde sejam calmos, atenciosos e se comuniquem com uma linguagem que ela consiga entender.

A atenção, paciência e carinho também citados pelos familiares, que apontaram que a comunicação facilitou o vínculo entre o profissional e o acompanhante e a atenção fez com que eles ficassem seguros com o atendimento. Os pais também relataram que a comunicação e a atenção dada diretamente à criança facilitaram a comunicação e seu entendimento. 
"Eu achei que, que eles me atenderam bem, que eles foram muito calmos comigo e, e isso." (Criança 02)

"[...] elas colocaram agulha, e não machucou e elas foram muito atenciosas comigo. Porque tudo que a gente pedia elas levavam, a gente pedia lanchinho, pedia cobertor, a gente pediu, várias coisas e elas traziam tudo." (Criança 06)

"Ah, as médicas todas são atenciosas.[...] Carinhosas assim, educadas." (Criança 9) "[...] a enfermagem foi muito atenciosa, paciente, [...] elas foram muito educadas também, elas fazem com carinho, não faz com pressa sabe, são atenciosas demais. "(Avó 03)

"A atenção, achei que foi muito bom [...] Ah, por parte das enfermeiras, das auxiliares, de tudo. Das médicas também excelente [...] eles explicam, conversam, então foi ótimo. " (Mãe 9)

"Eu achei que os funcionários foram atenciosos, tanto os enfermeiros, quanto a médica. A médica conversou com a gente, as duas médicas [...] foram atenciosas, conversaram com a gente, deram atenção, fizeram perguntas. As enfermeiras foram cordiais também, conversaram com ele, deram atenção. " (Pai 04)

\subsubsection{Necessidades básicas atendidas}

Quando a criança está com dor, toda a atenção é voltada para aquela sensação dolorosa que as impede até mesmo de realizar atividades comuns como andar, comer e, até mesmo, dormir. Com o alívio deste desconforto, as crianças conseguiram retomar as atividades, voltaram a sentir sono e fome, pois a dor que as impedia anteriormente, não as incomodava mais.

O sono foi um dos itens mais citados pelas crianças, que em casa, se sentiam incomodadas com a dor e não conseguiram dormir bem. No hospital, no entanto, após o alívio da dor, conseguiram descansar. Assim, dormir foi citado pelas crianças como algo positivo durante $o$ atendimento para dor.

Durante o tempo de permanência na observação, que foi em média quatro horas, e com a melhora da dor, a fome foi inevitável. Além disso, com a melhora da 
dor, a criança se sentiu mais confortável para se alimentar. Dessa forma, a comida também foi citada pelas crianças como algo positivo durante $o$ atendimento.

"Gostei de dormir. [...] eu consegui dormir bastante aqui. Consegui dormir depois que melhorou a dor." (Criança 06)

"Quando eu dormi. [...] Porque ficou bom. [...] tinha conseguido dormir em casa mais ou menos." (Criança 19)

"Gostei mais da comida." (Criança 03)

"Da comida, porque estava bom. [...] Comi bolacha e tomei um suco." (Criança 12)

"Eu gostei, do lanche.” (Criança 13)

\subsubsection{Investigação dos sintomas}

A investigação dos sintomas da criança foi uma das maiores preocupações dos familiares. Para os familiares, foi imprescindível descobrir o motivo da dor e resolver esta situação desagradável, já que foi um dos motivos, além do alívio da dor, que os levaram ao PSI.

Durante o atendimento médico a investigação teve início. O médico questiona o histórico da queixa de dor para entender a situação, complementa com o exame físico e, se necessário, exame laboratoriais e/ou de imagem. Neste momento, os familiares ficaram mais tranquilos e, junto com o médico, buscaram entender o que estava ocorrendo com a criança. Os familiares são uma parte importante do cuidado, pois conhecem a criança e direcionaram a queixa para o médico.

Até a divulgação dos resultados, os familiares estavam aflitos e inseguros, porque queriam descobrir o motivo do desconforto criança. De fato, eles preferiram que fossem feitos exames, mesmo que o médico não os julgue necessários, naquela situação.

A confiança, durante a investigação dos sintomas, também foi um ponto que chamou atenção dos familiares. A clareza e as explicações dos profissionais de saúde, durante a condução do caso, deixaram a família mais tranquila e orientada 
no processo de investigação da causa da dor na criança, facilitando assim a compreensão e o entendimento dos passos para o desfecho do diagnóstico.

"Então, de que hoje foram mais atenciosos, investigaram mais as coisas, assim." (Mãe 12)

"[...] acho que a doutora que atendeu a primeira foi bem paciente, examinou, viu se não tinha meningite, ela foi bem criteriosa assim, e ela falou, vamos fazer o medicamento, vamos esperar, porque não dá para saber assim, criança é uma caixinha de surpresa, como você vai saber o que tem? " (Mãe 17)

"Eu gosto quando é investigado entendeu? Gosto que faça o que for necessário para fazer. As vezes é melhor você fazer um exame mesmo que não seja necessário, mas por precaução entendeu? " (Mãe 10)

"Da médica ter [...] atendido assim o que eu falei, as queixas, e ter investigado, vamos fazes exames e isso, quem nem eu moro em outro município, as vezes você vai lá e só, a médica não faz nada e você sai, com a dúvida, e depois a dor volta. " (Mãe 02)

"Ela já passou os exames e já deu o outro plano, que se não tivesse diagnostico nenhum já teria outra solução, isso me deixou mais tranquila. " (Mãe 03)

"Passou confiança. A partir do momento que ela, a maneira que ela se dirigiu, deu quase o diagnóstico, mas deixou em aberto para ver os exames, ela falou pode ser uma apendicite, mas vamos descartar, pelo exame pode ser isso, mas vamos ver os exames, então, ela passou confiança na gente. "(Avó 03)

Os resultados sobre a insatisfação das crianças e dos familiares acerca do manejo da dor no pronto-socorro infantil foram organizados em subtemas, baseados em suas experiências que são:

\subsubsection{Tema 2: A insatisfação percebida pelas crianças e familiares acerca do manejo da dor no pronto-socorro infantil, composto por um subtema: "Demora em aliviar a dor" $\mathbf{A}$ insatisfação percebida pelas crianças acerca do manejo da}


dor no pronto-socorro infantil composto por dois subtemas: "Procedimentos dolorosos" e "Ambiente desconfortável". A insatisfação percebida pelos familiares acerca do manejo da dor composto por um subtema: "Demora pelos resultados dos exames".

A insatisfação das crianças e dos familiares com o manejo da dor foi percebida pelos relatos de suas experiências negativas, ou de oportunidades de melhoria durante o atendimento no PSI. Esse descontentamento, durante a assistência, advém do fato de algo não ter ocorrido como esperado ou quando as experiências não foram agradáveis.

A demora para o alívio da dor fez com que a sensação dolorosa permanecesse por mais tempo, deixando a criança irritada e ansiosa com a situação estressante. A dor acarretou uma sensação de impotência aos familiares que ansiavam por um tratamento rápido.

Neste trabalho, as crianças que foram selecionadas estavam na sala de observação, recebendo medicações endovenosas para o alívio da dor. Consequentemente, para que a medicação fosse realizada, foi necessário um procedimento, a punção venosa, que foi considerado pela maioria das crianças como dolorosa.

Além da dor, que levou a criança ao pronto-socorro, a punção venosa também a deixou ansiosa, com medo e nervosa. Independentemente da quantidade de vezes que o procedimento ocorreu, estes sentimentos variaram conforme as experiências anteriores de cada criança.

Permanecer muito tempo no hospital para descobrir o motivo da dor e resolver o problema, fez com que a criança ficasse muito tempo em jejum, e, isto também foi considerado desagradável pelas crianças, gerando um sentimento de desgosto.

Ademais, o ambiente favorável também foi citado pelas crianças como algo que os ajuda na melhora do tratamento para dor. Fatores estressantes, como a luz fez com que aumentasse o tempo de recuperação e o desconforto da criança.

O período que envolve a chegada ao pronto-socorro até o diagnóstico médico foi considerado angustiante pelos familiares. O tempo de espera para a realização dos exames foi visto como prolongado e cansativo. 


\subsubsection{Demora em aliviar a dor}

Quando a criança chega na sala de observação com dor, ela espera que esta dor seja melhorada e, para tal, é necessário que o processo o alívio da dor seja agilizado. A demora para a realização da punção fez com que a medicação também fosse atrasada, e aumentaram o desconforto da criança, porque ela gostaria de receber o mais rápido possível os remédios para ter sua dor melhorada.

Além disso, após receber as medicações, a criança ainda teve que aguardar o efeito da droga e esperar pela melhora da dor. Durante este tempo, a criança continuou tendo uma experiência ruim. Em alguns casos, a melhora pode ocorreu após a primeira medicação, outras somente após várias medicações associadas.

Ver o filho chorar de dor trouxe um sentimento de sofrimento para o familiar e um desejo de que aquele momento fosse o mais breve possível. A demora para o alivio da dor, mesmo após a medicação levou a um descontentamento pelo familiar, que gostaria que suas solicitações fossem atendidas o mais breve possível.

"Não gostei da demora, eu estava com muita dor. [...] quando eu cheguei, demorou muito para chegar o remédio. [...] Porque da outra vez foi bem mais rápido. [...] Porque eu cheguei e tive que esperar um tempão ainda para eles furarem. [...] É que acho que estava bem mais forte dessa vez." (Criança 09)

"Não gostei da dor de cabeça. [...] Achei que demorou para passar a dor." (Criança 13)

"Ver a filha chorando [...] é que a dor estava intensa e sempre [...] porque, vamos supor, o efeito do remédio tem um tempo ali para agir [...] mesmo sendo na veia, então pelo fato de ela estar com aquela dor intensa, a gente quer que passe logo. " (Mãe 10)

"O meu questionamento é com relação a demora na medicação. Achei que demorou [...] Eu acho que quando o familiar, comunica a equipe que está acontecendo alguma coisa com seu filho, acho que deveria ser um pouco mais rápido isso. Igual, quando eu comuniquei eles falavam "vou ver", "vou falar com a médica". "(Pai 04)

"[...] demorou muito para passar a dor dele, mesmo depois de medicado, eu achei que, eu tenho crise de enxaqueca, então assim, você acaba de tomar o remédio e já 
começa a se sentir melhor, aconteceu casos de eu terminar de tomar a medicação, não passar e eu ter que tomar outro, já aconteceu comigo. E, no caso dele hoje, por exemplo, demorou bastante para passar a dor, mesmo depois dele medicado." (Mãe 1)

\subsubsection{Procedimentos dolorosos}

Todas as crianças entrevistadas receberam medicação endovenosa. Para tal precisaram passar pelo procedimento invasivo de punção venosa, que foi considerado doloroso para a maioria das crianças.

As crianças ficaram com medo e nervosas, seja por terem tido experiências anteriores desagradáveis, por não conhecerem o procedimento ou mesmo quando ele teve que ser realizado mais de uma vez, por não ter sido bem-sucedido na primeira tentativa.

Apesar de a maioria das crianças não gostarem da punção pela dor do procedimento, algumas o fariam novamente se fosse com o objetivo de ter sua dor melhorada; ou seja, para elas, foi mais importante resolver a dor, mesmo que para isso fossem sentir a dor da punção. Entretanto, uma das crianças preferiu que a medicação fosse dada sem a agulha.

Além da punção, as crianças também ficaram ansiosas por estarem em uma situação de investigação, sem os resultados e sem saber o que iria acontecer, não sabiam se retornariam para casa, ou se ficariam internadas. Isso ocorreu principalmente com crianças que já tiveram uma experiência prévia de internação.

"Das picadas, eu levei 5. Tive medo da terceira picada. Eu pensava que ia estourar de novo. Gostaria que fosse de uma vez só." (Criança 1)

"Menos de tomar injeção. Aqui, no braço, uma vez, porque dói. Tudo bem, se for para ficar melhor." (Criança 2)

"Furar o braço. Uma vez, porque doeu." (Criança 3)

"De tomar é, injeção. [...] Porque doeu muito. [...] Hoje doeu mais que da outra vez, porque ela ficou tipo, tirando e colocando, tirando e colocando." (Criança 12) 
"Não gosto de ir no médico, [...] não gosto da picada. Porque dói muito. [...] Eu tenho medo quando foi furar o braço. Porque fazia tempo que eu não vinha aqui no hospital, deu medo na hora que foi furar." (Criança 15)

"Na hora que eu tomei injeção. Dói um pouco. [...]Só das costas que eu não tinha tomado antes. Não gostei do das costas. "(Criança 16)

"Foi um pouco doloroso, [...] porque eu não gosto de tomar vacina. [...] aqui (na mão) e aqui (no antebraço). Duas, porque essa daqui deixou minha mão "cheiona" [...]. E esse daqui deu tudo certinho, porque, sabe o que eu fiz? Paralisei essa mão e mexi só as[...] cinco partes do corpo que eu podia mexer." (Criança 17)

"Eu estava nervoso [...] não gostei de ficar internado [...] tomando soro. Eu achei que eu só ia receber alta amanhã [...] achei que ia ficar internado." (Criança 18)

"Não gostei da agulha, porque eu nunca coloquei agulha, e soro e nada eu coloquei, nada. [...] de furar não, não gostei, doeu. Preferiria que não tivesse agulha." (Criança 19)

"Tive medo da vacina porque eu senti um pouquinho de dor." (Criança 06)

\subsubsection{Ambiente desconfortável}

Um aspecto muito importante durante a recuperação da criança é o ambiente. O espaço físico, desde a organização das macas e dos objetos até a atenção dos funcionários e dos outros pacientes que estão no setor, influenciou a experiência dentro do ambiente hospitalar.

Dentro do hospital, existem áreas comuns a todos os pacientes, como é o caso do setor de exames de imagens. No pronto-socorro, algumas vezes os pacientes têm que ir para outros setores para realizar exames, como a radiografia.

Nestes lugares, em alguns momentos, os pacientes graves ficam nos corredores, em macas, esperando pela realização dos exames e a criança pode estar no mesmo ambiente que este paciente. As crianças ficaram assustadas e com medo dos pacientes graves, monitorizados que estavam nos corredores do hospital.

$\mathrm{O}$ ambiente onde as crianças recebem as medicações endovenosas, a sala de observação, pode ser barulhento, por conter um número grande de crianças, 
outras vezes calmo, porém, imprevisível. A luminosidade da sala causou um desconforto nas crianças, podendo ter sido responsável pela demora no alívio da dor.

"Ah, eu acho que foi quando, quando a gente estava fazendo o USG e a gente estava aguardando para fazer e tinha um monte de maca, ai eu fiquei com medo, porque eu não gosto de ver. [...] Pessoas, só que elas estavam meio que, sabe, com coisas meio assustadoras." (Criança 05)

"Teve o problema da luz. É que aquela luz do meio, ela ficava bem na altura da redinha e ai era ruim." (Criança 04)

\subsubsection{Demora pelos resultados dos exames}

Para se chegar ao diagnóstico, exames podem ser necessários, pois facilitam a conclusão assertiva sobre o caso, sendo uma parte importante para o desfecho clínico. Apesar de o hospital dispor de tecnologia suficiente para realizar os exames necessários, algumas vezes o tempo de espera para realizá-los depende de uma série de fatores. O tempo de espera para o resultado dos exames foi considerado longo e cansativo pelos familiares.

Apesar de o tempo previsto para o resultado dos laudos serem comunicados antes dos procedimentos aos familiares, eles foram considerados por eles como demorados. Os familiares expressam descontentamento com o cansaço durante esta espera.

Quando este resultado não é comunicado aos familiares, significa que houve uma falha no atendimento, gerando angústia no familiar por desconhecer aquilo que o profissional julgou essencial para obter o diagnóstico. A falta deste feedback para o familiar sobre os exames fez com que eles ficassem descontentes com 0 atendimento.

"Acho que só essa demora de exame, mas é uma coisa normal, não tem como ser mais [...] o de urina e sangue, mas é, não tem jeito, é o padrão mesmo. " (Mãe 12) 
"Ah, o tempo, a gente perdeu o sábado no hospital, é logico, para descobrir o que ele tinha, mas é demorado os exames de laboratório, demora de $2 h 30$ a $3 h$, então, e essa espera é cansativa, para a gente e para a criança também. " (Mãe 03)

"Demorou um pouco na hora de fazer o exame de imagem" (Pai 15)

"É, a única coisa que eu posso dizer é que tinha uma filinha de pessoas, assim, para fazer o exame de imagem [...] " (Mãe 15)

"Achei que demorou. É, a reclamação é, assim, demorou para fazer os exames, demorou para sair resultado, não me deram feedback dos exames de sangue, então assim, não sei se os exames de sangue dele estavam normais ou não. " (Mãe 13) 
DISCUSSÃO 


\section{DISCUSSÃO}

Os resultados desta pesquisa contribuem e ampliam o conhecimento sobre a satisfação da criança e de seus familiares acerca do manejo da dor em um prontosocorro infantil, mostrando, sob o olhar de quem está sendo cuidado, aspectos importantes para que o atendimento seja considerado satisfatório.

A partir das narrativas, foi possível ouvir os pontos de vista das crianças e dos familiares que vivenciaram o mesmo atendimento. Os resultados deste trabalho revelaram que a importância dada pelas crianças a algumas situações foi diferente daquela da família.

Analisando-se as narrativas das crianças e dos familiares, à luz do Modelo de Donabedian (Donabedian, 1984), composto pelas dimensões: Estrutura, Processo e Resultado, observou-se que os resultados se aproximaram dessa tríade. Neste sentido, é possível perceber que, mesmo que as crianças e seus familiares tenham passado pelo mesmo atendimento, suas percepções possam ser diferentes.

Um estudo conduzido por Ali et al. (2014) propôs que fosse realizado um trabalho mostrando a correlação entre a satisfação da criança e da família. Estes resultados revelam a importância de se estudar não só a percepção dos acompanhantes, mas também ouvir as crianças e conhecer, a partir da fala delas, suas experiências, para assim melhorar o atendimento, de acordo com suas necessidades.

A participação ativa da criança nos seus cuidados deve ser incentivada, tanto pelos profissionais quanto pelos familiares, considerando seus direitos de participação e de voz nos cuidados em saúde (Bubaduéa, et al., 2016).

As crianças e seus familiares concordaram em alguns aspectos relacionados com a satisfação, durante o atendimento: a satisfação com o atendimento rápido e a prioridade no atendimento, com o alívio da dor e com o acolhimento pela equipe. As crianças também ficaram satisfeitas, quando suas necessidades básicas foram supridas durante $\mathrm{o}$ atendimento, e os familiares, destacaram a importância da investigação dos sintomas da criança.

Por outro lado, no que diz respeito à insatisfação, também houve concordância entre as crianças e os familiares, sobre a demora no alívio da dor. Além disso, as crianças ficaram insatisfeitas com a dor nos procedimentos invasivos 
e com o ambiente desconfortável e, os pais, com a demora nos resultados dos exames.

Considerando-se que a criança chega ao pronto-socorro infantil com dor, ser atendido mais rapidamente foi considerado importante tanto para a criança quanto para o familiar. Neste trabalho, a classificação de risco amarela foi apontada como indispensável pelos familiares que sentiram-se satisfeitos pelo fato de suas crianças terem sido priorizadas no atendimento. A prioridade faz com que o fluxo de atendimento seja mais rápido, bem como 0 atendimento médico $e$, consequentemente, o alívio da dor. Este item é relevante especialmente nos dias em que o pronto-socorro está com uma demanda de atendimento maior.

Assim, a segunda dimensão proposta pelo modelo de Donabedian (1984), o Processo, que significa as transações entre pacientes e profissionais em todo 0 oferecimento de cuidados de saúde (Araújo, 2014), corrobora os resultados deste estudo. Vale ressaltar que o processo é a soma de todas as ações que compõem saúde, geralmente, incluindo diagnóstico, tratamento, cuidados preventivos e educação do paciente, mas podendo também incluir as ações tomadas pelos pacientes, ou seus familiares (Araújo, 2014).

No trabalho conduzido por Alston et al (2015), além da espera menor, a prioridade no atendimento, decorrente da classificação de risco mais alta, também foi apontada como importante para os pais. Neste trabalho, mesmo no caso das crianças que não foram priorizadas, seus familiares também destacaram de forma positiva o rápido atendimento.

Diferentemente do presente trabalho, no estudo de Margaret et al. (2002), a satisfação da criança não teve correlação com o tempo de espera. Por outro lado, nos trabalhos de Davis (1995), Margaret et al. (2002) e Byczkowski et al. (2016), os pais relacionaram o tempo de espera mais curto com a maior satisfação no atendimento do pronto-socorro. Brown et al. (1995) reportaram que os pais menos satisfeitos esperaram duas vezes mais para passar em consulta médica do que os pais que estavam satisfeitos com o tempo de espera.

Outro ponto em comum entre as crianças e seus familiares relacionado com a satisfação, neste estudo, foi o alívio da dor. Vários trabalhos mostram um aumento da satisfação quando os filhos têm a dor aliviada (Pagnamenta, 2008; Byczkowski et al., 2016; Liversidge et al., 2016). Com efeito, a dor provoca uma sensação de impotência, insegurança e incerteza nos pais, que ficam ansiosos sobre a condição 
de saúde das crianças. O estudo de Chan et al. (1998) revelou que ao levarem seus filhos ao pronto-socorro, os pais não estão somente procurando a causa da dor, mas também o alívio desta dor. Byczkowski et al. (2016) identificaram e descreveram as dimensões do cuidado centrado para os pais em um pronto-socorro pediátrico, enfatizando que o alívio rápido da dor na criança é extremamente importante para eles.

As crianças que estavam sentindo dor e querendo que esta sensação desagradável desaparecesse, também buscavam o alívio rápido da dor. Weingarten et al. (2014) reportaram que quando perguntadas sobre como o tratamento da dor ganharia nota máxima, algumas crianças afirmaram que a medicação deveria ter sido mais rápida, enquanto outras responderam que gostariam de ter sido medicadas com analgésicos mais potentes.

Solucionar a dor, não apenas com os medicamentos, mas também com suporte emocional faz com que a criança se sinta aliviada. Assim, é fundamental acompanhá-la durante o tempo que ela está em observação, gerenciar sua dor, criar um ambiente confortável que faça com que ela consiga se distrair e oferecer ajuda, quando necessário.

Tanto as crianças quanto os familiares enfatizaram que foi importante melhorar, ou parar de sentir dor, durante o tratamento no hospital. Para as crianças, a resolução da dor no pronto-socorro foi relacionada com a satisfação (Margaret et al., 2002; Weingarten et al., 2014). Diferentemente deste estudo, o trabalho de Margaret et al (2002) mostra que a percepção da resolução da dor da criança não foi relacionada com a satisfação dos pais. No mesmo trabalho, os autores relatam que é importante que os pais se sintam confortáveis para comunicar aos profissionais de saúde a dor dos seus filhos e este diálogo ajuda no gerenciamento e tratamento da dor, diminuindo o tempo que a criança permanece com dor.

Outro aspecto importante mencionado foi o acolhimento pela equipe, considerado relevante neste trabalho, tanto para as crianças quanto para seus familiares. Entender o que está acontecendo, ouvir suas necessidades, medos e anseios e procurar atendê-los da melhor maneira possível, também fazem parte do cuidado. Byczkowski et al. (2013) apontaram que a cortesia, o respeito e a gentileza, por parte dos profissionais, sob a forma de palavras e comportamentos compassivos e atenciosos, foram mencionados pelos pais satisfeitos. 
O acolhimento da equipe faz com que a família também se sinta cuidada, fazendo parte deste cuidado. Isso é fundamental, principalmente no pronto-socorro, um ambiente que, muitas vezes, não proporciona o estabelecimento de vínculo entre as partes envolvidas, pelo fato de ser geralmente agitado e com uma demanda imprevisível.

A comunicação faz parte do acolhimento e é essencial para o diálogo entre os profissionais de saúde e as crianças e seus familiares. Neste estudo, ela foi destacada positivamente tanto pelas crianças, quanto para a família. No entanto, é importante observar que ambos ressaltaram que ela deve ser clara e compreensiva. A comunicação deve ter o poder de acalmar um familiar ansioso por entender o processo de tratamento no pronto-socorro. Entender o que o médico está dizendo, as ações realizadas e os resultados dos exames, faz com que os familiares sintamse seguros durante todo o processo.

Explicar os procedimentos e a rotina do pronto-socorro, não somente para os familiares, mas também para a criança, faz com que ela participe do cuidado e saiba o que está acontecendo. A comunicação direcionada, perguntando sobre o que a criança está sentindo, se está melhorando, se existe uma outra maneira que a faça se sentir melhor é importante na recuperação e no alívio da dor mais rapidamente.

A comunicação adequada à idade e desenvolvimento da criança é muito importante para que ela entenda efetivamente a mensagem transmitida. Explicar 0 procedimento de punção venosa, por exemplo, e fazer com que a criança entenda o que será realizado, a ajuda a acalmar e entender a importância daquele procedimento.

Outros estudos demostram a importância da comunicação para os pais, enumerando alguns aspectos indispensáveis e facilitadores durante a transmissão das informações como: a facilidade de entendimento, comunicação clara, consistente e completa, para que consigam entender a mensagem transmitida (Brown et al., 1995; Davis, 1995; Byczkowski et al., 2013); a interação e comunicação com qualidade, nas quais as informações sejam úteis e necessárias para os familiares (Margaret et al., 2002; Ali et al., 2016) e a comunicação direta com a criança, dando-Ihe a oportunidade de entender e fazer parte do cuidado (Davis, 1995; Byczkowski et al., 2016)

Para as crianças, a atenção e o cuidado da equipe de saúde são essenciais, pois as ajudam no entendimento da situação vivida naquele momento, facilita a 
colaboração, uma vez que elas conseguem entender o que está sendo feito e como está sendo feito, favorecendo o alívio mais rápido da dor. No trabalho de Weingarten et al. (2014) sobre a perspectiva da criança no manejo da dor no pronto-socorro infantil, as crianças indicaram a importância da escuta ativa e do questionamento direcionado a elas.

Em suma, a comunicação é fundamental, quando se trata a dor de uma criança no pronto-socorro. A qualidade da interação e informação adequada com os profissionais de saúde foram correlacionadas com a satisfação geral da criança (Weingarten et al., 2014) e dos pais (Margaret et al., 2002).

A satisfação das necessidades básicas da criança também foi destaque positivo. Alimentação e repouso foram mencionados por elas como importantes, durante $o$ atendimento. Antes do tratamento, as crianças estavam sentindo dor, e por isso, não estavam conseguindo descansar. Após o alívio da dor, no hospital, conseguiram dormir.

Proporcionar cuidado individualizado, levando em consideração a satisfação das necessidades da criança também faz parte do cuidado e deve ser respeitado pelos profissionais de saúde. Entender a situação, perguntar o que a criança está sentindo e fazer o possível para atender suas necessidades, faz com que o atendimento seja melhor e mais confortável para a criança.

Byczkowski et al. (2013) também apontam a atenção com as necessidades básicas como essenciais para a criança e sua família. É importante acompanhar a evolução da dor da criança e oferecer a ela cuidado medicamentoso, comunicação efetiva, alimentação ou um ambiente que favoreça seu descanso.

Os acompanhantes mostraram grande preocupação em conhecer os motivos da dor da criança e seu tratamento. Por conseguinte, neste trabalho, a investigação dos sintomas da criança foi um dos destaques nas entrevistas dos familiares.

Durante o atendimento médico é que a investigação tem início. O profissional questiona o histórico da queixa de dor para entender a situação, complementa com o exame físico e, se necessário, exame laboratoriais e/ou de imagem. Neste momento, os familiares ficam mais tranquilos e, junto com o médico, buscam entender o que está ocorrendo com a criança. Os familiares são uma parte importante do cuidado, pois conhecem a criança e direcionam a queixa para o médico. 
Conhecer as possíveis causas do problema da criança e a conduta a ser adotada, explicadas pelos profissionais com uma linguagem adequada e compreensível, também receberam destaque em outros trabalhos (Spahr et al., 2006; Pagnamenta, 2008; Byczkowski et al., 2016). De fato, no estudo de Brown et al. (1995), a preocupação da equipe com o problema de saúde da criança e em ter o conhecimento sobre a doença foram classificados como satisfatórios para os pais.

Assim, conhecer o diagnóstico da criança foi considerado extremamente importante para os familiares neste trabalho. Descobrir o motivo da dor faz com que eles se sintam mais seguros e confiantes com 0 atendimento. $O$ trabalho de Byczkowski et al. (2016) relata que é importante aliviar a ansiedade e o medo dos pais, com relação ao diagnóstico do filho, pois eles se sentem sobrecarregados com o desconhecimento.

Neste sentido, a segunda dimensão proposta pelo modelo de Donabedian (1984), o Processo, corrobora os resultados deste estudo, pois envolve a dinâmica do cuidado, a inter-relação entre profissionais e pacientes e as ações do cuidado (Araújo, 2014), enquanto a dimensão Resultados, refere-se aos efeitos dos cuidados de saúde (Donabedian, 1984). Engloba todos os cuidados de saúde sobre os pacientes, incluindo alterações no estado de saúde, comportamento, conhecimento, bem como a satisfação do paciente (Araújo, 2014).

Neste trabalho, os pais consideraram positivo o fato de os médicos solicitarem exames laboratoriais e de imagem, durante a investigação. Um familiar referiu, por exemplo, que fossem feitos quantos exames fossem necessários, mesmo aqueles não considerados importantes pelos médicos. A realização de exames na criança, como parte do tratamento, também foi percebida como muito satisfatória para os pais, nos estudos de Davis (1995) e Spahr et al. (2006).

O Tema 2, A insatisfação percebida pelas crianças e familiares, mostrou que a demora no alívio da dor e a falta de atenção foram mencionadas pelos familiares como destaques negativos. A demora para o alívio da dor faz com que a sensação dolorosa permaneça por mais tempo, deixando a criança e seus familiares irritados e ansiosos com a situação estressante.

Neste estudo, as crianças e seus familiares destacaram negativamente o longo tempo de espera para receber a medicação para alívio da dor. Para os familiares, ver a criança reclamar e chorar de dor é penoso, pois querem solucionar este problema de forma imediata. Para as crianças, sentir dor e ficar sofrendo até o 
alívio da dor é muito difícil. Por isso, é indispensável para ambos, receber as medicações necessárias o mais rápido possível. Diferentemente do presente trabalho, a maioria das crianças no estudo de Weingarten et al. (2014) sentiram que não aguardaram muito tempo para receber a medicação.

Segundo Weingarten et al. (2014), quando houve atraso no alivio da dor, as crianças ficaram insatisfeitas com o tratamento. O estudo de Liversidge et al. (2016), sobre as variáveis associadas entre a satisfação dos pais e o manejo da dor da criança, destaca que a satisfação dos pais foi maior quando a criança teve sua dor mitigada em menor tempo.

A demora para atender alguma solicitação, durante o atendimento da criança, aumenta a aflição e o nervosismo dos familiares com a situação não resolvida. Apesar de os profissionais de enfermagem ouvirem as queixas dos familiares, 0 atraso no atendimento gera transtornos para os acompanhantes, que é interpretado por eles como falta de atenção da equipe.

Um estudo de Brown et al. (1995), que teve como objetivo avaliar a satisfação dos pais em um serviço de emergência pediátrica, revelou que muitos pais consideraram que suas necessidades e as das crianças não foram atendidas rápido o suficiente. Vinte anos depois, Alston et al. (2015) mostraram também que o longo tempo de espera pelos profissionais de saúde faz com que os pais sintam que os profissionais não estão atendendo as necessidades das crianças e, consequentemente, se sintam frustrados.

Outro ponto negativo, no presente estudo para as crianças, foi o procedimento invasivo da punção venosa, pois todas tiveram que passar por esta experiência para receber as medicações. De fato, a punção é uma das maiores preocupações para a maioria das crianças; ou seja, o medo do desconhecido, para alguns e o medo do conhecido e assustador, para outros. O procedimento foi considerado doloroso pela maioria delas. Ademais, há uma preocupação das crianças em saber quantas tentativas ainda serão necessárias para que ela receba a medicação para dor, quando o procedimento não é bem-sucedido na primeira tentativa.

Os procedimentos dolorosos são frequentemente temidos e angustiantes para as crianças e suas famílias. Deve-se dar atenção especial à criança, preparando-a para os procedimentos, e para tal, a família e outros membros da equipe 
desempenham papel fundamental nesta preparação, diminuindo sua ansiedade (Howard et al., 2012).

Os profissionais de enfermagem precisam compreender a situação da criança, conversar e explicar, de uma maneira que ela consiga entender, como será realizado o procedimento e a sua importância, bem como evitar expressões faciais negativas. Assim, a criança poderá ficar menos ansiosa e colaborar com o procedimento.

Buscar alternativas, como distrações durante procedimentos, podem ajudar nestes casos. A televisão, música, massagem, entre outros, colaboram para a distração da criança, durante os procedimentos dolorosos. Nesse âmbito, a distração para as crianças foi avaliada pelos pais como satisfatória (Byczkowski et al., 2013; Ali et al., 2016; Byczkowski, et al., 2016).

É importante também que os profissionais não culpem as crianças quando algo sair diferente do planejado, como por exemplo, uma punção malsucedida, ou uma infiltração, que podem ocorrer durante o atendimento. Apesar de a maioria das crianças temerem este procedimento, percebe-se que, a despeito da dor sentida para receber a medicação, a satisfação das crianças está presente, em decorrência do manejo da dor.

A dimensão Estrutura do modelo de Donabedian (1980) delineia o contexto em que os cuidados são prestados, incluindo as características dos recursos, tanto físicos quanto humanos: estrutura física, equipamentos e insumos, quantidade e qualificação dos profissionais e recursos financeiros disponíveis para a manutenção da infraestrutura e da tecnologia para a viabilização dos serviços.

Sob a ótica da dimensão Estrutura do modelo de Donabedian (1980), outro aspecto que contribui para a melhora da criança, além da atenção da equipe, é o ambiente. O espaço físico e sua organização influenciam na experiência das crianças e de seus acompanhantes, dentro do ambiente hospitalar.

Neste trabalho, uma criança ficou assustada quando foi realizar um exame de imagem fora da área do pronto-socorro infantil. Nesta parte do hospital, pacientes adultos ficam em macas, nos corredores, em situações desconhecidas pela criança. De fato, há mais de 20 anos, o trabalho de Davis (1995) mostrou que os pais gostariam que houvesse um local de espera para o raio $\mathrm{X}$ diferente para crianças, longe dos adultos. 
Ademais, o ambiente deve favorecer a recuperação da criança, com leitos confortáveis, temperatura agradável, pouco barulho e pouca luz. Entretanto, quando o ambiente é comum a todos, sem separação individual, muitas vezes, não há possibilidade de contemplar todos os itens mencionados. Não há como controlar o choro de uma criança, ou apagar todas as luzes, quando há mais de um paciente na sala. Tudo isso varia conforme a demanda da sala no momento e pode ser oferecido para alguns e para outros não, dependendo da quantidade e disposição dos pacientes.

Neste estudo, a luminosidade da sala de observação foi citada por uma criança e seu acompanhante como desconfortável para a recuperação da dor. A equipe de saúde precisa ficar atenta a este tipo de solicitação das famílias, valorizando-a e, quando possível, atendendo-a.

Apesar do contentamento com a realização dos exames, o tempo de espera para se obter os resultados foi apontado como um problema para os familiares, durante $o$ atendimento. Mesmo tendo conhecimento sobre o tempo de espera padrão da instituição, este tempo foi avaliado, pelos acompanhantes, como demorado. Quando os exames eram entregues com atraso, a ansiedade dos familiares era ainda maior.

Para melhorar a satisfação, é indispensável a presença de um funcionário da instituição para explicar sobre possíveis atrasos, problemas técnicos, ou sobre a situação atual do pronto-socorro, segundo o trabalho de Locke et al. (2011).

É interessante observar que nenhum artigo sobre satisfação dos pais em pronto-socorro faz referência à demora na entrega dos resultados de exames de sangue e de imagem, mas tão somente ao tempo de espera para sua realização. Neste estudo, a demora para realizar os exames também foi destacada negativamente pelos pais.

Os exames são uma parte importante para a construção do diagnóstico e pode definir a conduta, inclusive cirúrgica, por exemplo. Por esta razão, os familiares ficam ansiosos para conhecer o resultado e saber os próximos passos do tratamento. Não ter conhecimento destes resultados diminui a confiança no tratamento e provoca descontentamento nos familiares. Os trabalhos de Brown et al. (1995) e Davis (1995) também mostram que a falta de informação contribuem para que os pais fiquem menos satisfeitos com o atendimento. 
Discussão 70 
CONSIDERAÇÕES FINAIS 


\section{CONSIDERAÇÕES FINAIS}

Este estudo mostrou, na perspectiva da pesquisa qualitativa, a satisfação da criança e de seus familiares acerca do manejo da dor no pronto-socorro infantil e permitiu ampliar o conhecimento sobre este assunto, pois os participantes tiveram liberdade de contar sobre sua experiência de dor.

Pode-se verificar que, tanto a satisfação quanto a insatisfação das crianças e de seus familiares, têm características semelhantes em algumas situações e diferentes em outras.

Nesta pesquisa, as crianças destacaram como satisfação, pontos importantes durante sua experiência no pronto-socorro infantil, que foram além da queixa de dor propriamente dita, a saber: Atendimento prioritário e alívio rápido da dor; Acolhimento pela equipe e Necessidades básicas atendidas.

Os familiares, por outro lado, assinalaram outros aspectos considerados satisfatórios durante o atendimento: Prioridade no atendimento; Alívio da dor da criança; Acolhimento pela equipe e Investigação dos sintomas.

Este estudo também revelou que as crianças ficaram insatisfeitas com a dor nos procedimentos invasivos e com o ambiente desconfortável, enquanto os pais consideraram a demora nos resultados dos exames um aspecto insatisfatório. Entretanto, tanto as crianças quanto os familiares consideraram insatisfatória a demora no alivio da dor.

Em um ambiente imprevisível, como o pronto-socorro, onde a qualquer momento os profissionais de saúde podem ter que interromper o que estão fazendo para atender a uma emergência, é indispensável que haja diálogo entre o profissional, as famílias e as crianças que estão sendo cuidadas. Explicar de forma clara e compreensiva, ouvir e dar atenção são extremamente importantes, pois a comunicação inadequada e a falta de um feedback podem contribuir para o desapontamento dos familiares.

Os resultados deste trabalho indicaram que o cuidado do profissional de saúde necessita estar centrado na criança e na família, enfatizando os aspectos considerados importantes. Assim, a atenção dada para as crianças, em alguns momentos durante $o$ atendimento, deve ser diferente da atenção dada aos familiares e vice-versa, para que ambos fiquem satisfeitos. 
Algumas limitações foram observadas, durante a análise dos resultados, dentre elas o fato de o estudo ter sido realizado apenas em um hospital e com uma faixa etária especifica. Por conseguinte, mais pesquisas sobre este tema devem ser conduzidas em outros hospitais, principalmente no Brasil, para se conhecer melhor suas realidades e especificidades. Frente a isso, será possível melhorar, de acordo com cada realidade, o manejo da dor do pronto-socorro infantil, que é um local de grande importância devido ao elevado número de crianças que procuram atendimento por queixa de dor.

Entretanto, deve-se destacar que este estudo foi o primeiro realizado no Brasil abordando a temática satisfação da criança e de seus familiares acerca do manejo da dor no departamento de emergência infantil. Os resultados evidenciaram que a satisfação da criança e de seus familiares sobre o manejo da dor foi muito mais do que simplesmente o seu alívio, ou o atendimento prioritário. A satisfação englobou $o$ cuidado médico e de enfermagem, evidenciando que a satisfação não é um indicador de qualidade isolado. De fato, ele é mais do que isso, porque abrange a experiência da criança e dos familiares com todo o serviço da instituição. Este conhecimento contribui sobremaneira para a melhoria da prática clínica, visando a um cuidado de excelência, no âmbito da dor infantil, ao enfatizar a valorização do acolhimento e da comunicação, não só com a criança, mas também com a família. 


\section{REFERENCIAS}




\section{REFERÊNCIAS}

Afilalo M, Tselios C. Pain relief vesus patient satisfaction. Annals of Emergency Medicine. 1996;27(4): 436-8.

Alston KJ, Valrie CR, Walcott C, Warner TD, Fuh B. Experiences of Pediatric Patients With Sickle Cell Disease in Rural Emergency Departments. Journal of Pediatric Hematology Oncology. 2015;37(3): 195-9.

Ali S et al. A Survey of Caregiver Perspectives on Children's Pain Management in the Emergency Department. CJEM. 2016 Mar;18(2):98-105

Alves C. Satisfação do consumidor. Lisboa (Portugal): Escolar; 2003.

American Nursing Associations (ANA). 10 ANA Quality Indicators for Acute Care Settings Healthcare Benchmarks. 1999. p.138-9.

Araujo L, Romero B. Dor: Avaliação do $5^{\circ}$ sinal vital. Uma reflexão teórica. Rev. Dor.2015;16: 291-6.

Araújo RE. Análise exploratória dos indicadores de resultado dos Núcleos de Apoio a Saúde da Família (NASF): a experiência de Belo Horizonte [dissertação]. Belo Horizonte: Escola de Educação Física, Fisioterapia e Terapia Ocupacional, Universidade Federal de Minas Gerais; 2014.

Baker DW. The Joint Comission's Pain Standards: Origins and Evolution. Oakbrook Terrace IL: The Joint Comission. [internet] 2017. [citado 2017 jun 22] Disponível em: https://www.jointcommission.org/assets/1/6/Pain_Std_History_Web_Version_051220 17.pdf

Baren JM. Rising to the challenge of family-centered care in emergency medicine. Academic Emergency Medicine.2001; 8: 1182-5.

Bennet M, Carter B, Dooley F. The Recognition and Assessment of Acute Pain in Children. London, England: Royal College of Nursing. 2009: 1-73.

Boyatzis R. Transforming qualitative information: Thematic analysis and code development. Thousand Oaks; 1998.

Brasil. Ministério da Saúde. Conselho Nacional de Saúde. Resolução n.466, de 12 de dezembro de 2012. Estabelece diretrizes enormas regulamentadoras de pesquisas envolvendo seres humanos. In: Diário Oficial da União. Brasilia;2013.p.59.

Brasil. Ministério da Saúde. Manual Brasileiro de Acreditação Hospitalar. Brasilia-DF; 2002.

Brasil. Lei Federal n.8.069 13 de julho de 1990. Dispõe sobre o Estatuto da Criança e do Adolescente. Diário Oficial da União, Brasília, 1990. 
Braun V, Clarke V. Using thematic analysis in psychology. Qualitative research in psychology. 2006; 3: 77-101.

Brown K, Sheehan E, Sawyer M, Raftos J, Smyth V. Parent satisfaction with services in an emergency department located at a paediatric teaching hospital. J Paediatr Child Health. 1995;31(5):435-9.

Bubadué RM, Cabral IE, Carnevale FA, Asensi FD. Análise normativa sobre a voz da criança na legislação brasileira de proteção à infância. Rev. Gaucha de Enferm. 2016; 37(4).

Burrows F, Berde C. Optimal pain relief in infants and children. BMJ.1993; 307: 8156.

Byczkowski TL, Fitzgerald M, Kennebeck S, Vaughn L, Myers K, Kachelmeyer A, Timm N. A Comprehensive View of Parental Satisfaction With Pediatric Emergency Department Visits. Annals of Emergency Medicine.2013; 62(4): 340-50.

Byczkowski TL, Gillespie GL, Kennebeck SS, Fitzgerald MR, Downing KA, Alessandrini EA. Family-Centered Pediatric Emergency Care: A Framework for Measuring What Parents Want and Value. Acad Pediatr. 2016;16(4):327-35.

Campbell JN. APS 1995 Presidential address. Pain Forum.1996; 5: 85-8.

Carvalho, MMMJ, organizadora. Dor Um estudo multidisciplinar. $2^{\underline{a}}$ ed. Summus editorial; 1999.

Chan L, Russel TJ, Robal N. Parental perception of pain control in their child after discharge from the emergency department: Pediatric Emergency Care.1998.

Committee on Advancing Pain Research, Care, and Education. Relieving pain in America: a blueprint for transforming prevention, care, education, and research [Internet]. Whashington, D.C.: The National Academies Press; 2011 [citado 2017 jun 27]. $\quad$ Disponível em: from:https://www.ncbi.nlm.nih.gov/books/NBK91497/pdf/Bookshelf_NBK91497.pdf

Cordero MA, Mur VN, Padilla LCA, Garcia EY, Garcia AR. Nurse's attitudes to pain in children and their relation to continuing. Nutr. Hosp. Nutr.2012; 27(6): 2066-71.

Costa DM. Busca de atendimento para crianças e adolescentes em serviços de urgência do SUS: uma revisão integrativa [conclusão de curso de graduação]. Porto Alegre: Escola de Enfermagem, Universidade Federal do Rio Grande do Sul; 2015.

Creswell JW. Qualitative inquire and research design: choosing among five approaches. 2 $2^{\mathrm{a}}$ ed. Thousand Oaks:Sage; 2007.

D’innocenzo M, Adami N, Cunha I. O movimento pela qualidade nos serviços de saúde e enfermagem. Rev. Bras, Enferm.2006; 59(1): 84-8. 
Damasceno A, Almeida P, Barroso M. Dor em crianças vítimas de queimadurasestudo epidemiológico. Braz J Nurs.2007;6(2).

Davis JE. Children In Accident And Emergency: Parental Perceptions Of The Quality Of Care. Part 1. Accident And Emergency Nursing.1995;3: 14-8.

Deming W. Qualidade: a revolução da administração. Rio de Janeiro: Saraiva; 1990.

Department of Health. CAMHS Standard, National service framework for children, young people and maternity services [Internet]. London: DH Publications Ordeline; 2004 [citado 2017 ago. 25]. Disponível em: http://webarchive.nationalarchives.gov.uk/20130123204112/http://www.dh.gov.uk/en/ Publicationsandstatistics/Publications/PublicationsPolicyAndGuidance/DH_4089114

Donabedian A. La calidad de la atención médica, definicion y metodos de evaluacion. México: Prensa Medica Mexicana;1984.

Donabedian A. The Definition of Quality and Approaches to its Assessment (Explorations in Quality Assesment and Monitoring). Health Administration Press, Ann Arbor; 1980.

Donabedian A. The seven pilars of quality. Arch.Pathol.Lab. Med. 1990;114(11):1115-8.

Downey LVA, Zun LS. Pain management in the emergency department and its relationship to patient satisfaction. Journal of Emergencies, Trauma, and Shock. 2010; 3 (4): 326-30.

Fein JA, Zempsky WT, Cravero JP, The committee on pediatric emergency medicine and section on anesthesiology and pain medicine. Relief of Pain and Anxiety in Pediatric Patients in Emergency Medical Systems. Pediatrics. 2012; 130(5): 13911405.

Feldman L. O enfermeiro analista de risco institucional. Rev. bras. Enferm. 2004; 57(6): $742-5$

Ferreira AM. Validação do diagnóstico de enfermagem Dor Aguda em crianças hospitalizadas [dissertação]. Porto Alegre: Escola de Enfermagem, Universidade Federal do Rio Grande do Sul; 2009.

Filho A. Reconhecer Flexner: inquérito sobre produção de mitos na educação médica no Brasil contemporâneo. Cad. Saúde Pública. 2010; 26(12): 2234-49.

Finley GA. Supporting Evidence for Childkind Principles; 2010.

Freitas J. Avaliação da qualidade da assistência de enfermagem e da satisfação do paciente de um hospital de ensino da região centro-oeste do Brasil [dissertação]. Goiás: Universidade Federal de Goiás; 2013. 
Gill M, Drendel AL, Weisman SJ. Parent Satisfaction With Acute Pediatric Pain Treatment at Home. Clinical Journal of Pain. 2013; 29(1): 64-9.

Gonçalves B, Holz AW, Lange C, Maagh SB, Pires CG, Brazil CM. O cuidado da criança com dor internada em uma unidade de emergência e urgência pediátrica. Rev Dor. 2013; 14(3): 179-83.

Hesse-Biber SN, Leavy P. The Practice of Qualitative Research. SAGE; 2006. p.404.

Hockenberry M, Wilson D, Winkelstein M. Wong Fundamentos de Enfermagem Pediátrica. São Paulo: Elsevier; 2014.

Howard R, Carter B, Curry J. Good practice in postoperative and procedural pain management: Paediatr Anaesth 22(suppl 1). 2012: 1-79.

Hungler B, Beck C, Polit, D. Fundamentos de Pesquisa em Enfermagem. Métodos, Avaliação e Utilização. Porto Alegre: Artmed; 2004.

Internacional Association for the Study of Pain (IASP). Subcommittee on Taxonomy Pain terms: A current list with definitions and notes on usage [internet]. Washington, DC; 2011.[citado 2017 jul 12]. Disponível em: https://www.iasppain.org/files/Content/ContentFolders/Publications2/ClassificationofChronicPain/Part _III-PainTerms.pdf

Jadav MAR, Lioyd G, McLauchlan C, Hayes C. Routine pain scoring does not improve analgesia provision for children in the emergency department. Emerg. Med. J.2009; 26(10): 695-697.

Kanai KY, Fidelis WMZ. Conhecimento e percepção da equipe de enfermagem em relação à dor na criança internada. Rev Dor. 2010; 11(1): 20-7.

Kelly AM. Patient satisfaction with pain management does not correlate with initial or discharge VAS pain score, verbal pain rating at discharge, or change in VAS score in the Emergency Department. The Journal of Emergency Medicine. 2000; 19(2): 1136.

Leão E, Silva M. Música e dor crônica musculoesquelética: o potencial evocativo de imagens mentais: Rev. Latino-americana de Enfermagem. 2004;12: 235-41.

Linhares M, Doca F. Dor em neonatos e crianças: avaliação e intervenções não farmacológicas. Temas psicol.2010(2); 18: 307-25.

Liversidge XL, Taylor DM, Liu B, Ling SL, Taylor SE. Variables associated with parent satisfaction with their child's pain management. Emergency Medicine Australasia. 2016;28(1):39-43.

Locke R, Stefano M, Koster A, Taylor B, Greenspan J. Optimizing Patient/Caregiver Satisfaction Through Quality of Communication in Pediatric Emergency Department. Pediatric Emergency Care. 2011; 27(11): 1016-21. 
Lowe DA, Monuteaux MC, Ziniel S, Stack AM. Predictors of Parent Satisfaction in Pediatric Laceration Repair. Academic Emergency Medicine. 2012; 19(10): 1166-72.

Manocha S, Taneja N. Assessment of paediatric pain: a critical review: J Basic Clin Physiol Pharmacol. 2016; 27: 323-31.

Margaret N, Clarck T, Warden C. Patient satisfaction in the emergency departmenta survey of pediatric patients and their parents. Acad Emerg Med. 2002; 9(12): 137988.

Mccaffery M, Beebe, A. Pain: Clinical Manual for Nursing Practice. St. Louis, MO: Mosby; 1989.

Mccaul K, Malloti J. Distraction and coping with pain: Psychological Bulletim. 1994; 95: 516-33.

Mcgrath PA. Pain in children. Nature, assessment \& treatment. Nova York: Guilford 1990a.

Mcgrath PA. Pain in children. Nature, assessment \&amp; treatment. Nova York: Guilford 1990b.

Merskey $\mathrm{H}$, Bogduk N. Classification of chronic pain. Descriptions of chronic pain syndromes and definitions of pain terms. Part III: Pain Terms: A Current List with MINAYO, M. O. Pesquisa social: teoria, método e criatividade. . Rio de Janeiro: Vozes, 2003.

Novaes H. O processo de acreditação dos serviços de saúde. RAS.2007; 9(37): 13340.

Novaes HDM. História da acreditação hospitalar na américa latina- o caso Brasil: Revista de administração Hospitalar e Inovação em Saúde; 2015.

Novaes H, Paganini J. Desenvolvimento e fortalecimento dos sistemas locais de saúde na transformação dos sistemas nacionais de saúde: padrões e indicadores de qualidade para hospitais (Brasil). . Washington (DC): Organização Panamericana de Saúde; 1994.

O'Malley PJ, Brown K, Krug SE. Patient - and Family-Centered Care of Children in the Emergency Department. Pediatrics. 2008; 122(2): 511-21.

Organização Mundial da Saúde (OMS). Avaliação dos programas de saúde: normas fundamentais para sua aplicação no processo de gestação para o desenvolvimento nacional na saúde. Genebra; 1981.

Pagnamenta R, Benger, JR. Factors influencing parent satisfaction in a children's emergency department: prospective questionnaire-based study. Emergency Medicine Journal. 2008; 25, (7): 417-9. 
Pereira L, Sousa F. Mensuração e avaliação da dor pós-operatória: uma breve revisão. Rev. Latino-Am. Enfermagem.1998; (3): 77-84.

Phillips D. JCAHO pain management standards are unveiled. Joint Commission on Accreditation of Healthcare Organizations. JAMA. 2000; 284: 428-9.

Pines JM, lyer S, Disbot M, Hollander JE, Shofer FS, Datner EM. The effect of emergency department crowding on patient satisfaction for admitted patients. Academic Emergency Medicine. 2008;15(9): 825-83.

Pope C, Mays N. Pesquisa qualitativa na atenção à saúde. Porto Alegre: ArtMed; 2005.

Queiroz FC. O manejo da dor por profissionais de enfermagem no cuidado de crianças no pós-operatório tardio de cirurgia cardíaca [dissertação]. Ribeirão Preto: Escola de Enfermagem de Ribeirão Preto, Universidade de São Paulo; 2007.

Rappaport C, Fiori W, Davis C. Psicologia do desenvolvimento. CIP-Brasil; 1981.

Risser N. Development of an instrument to measure pediatric satisfaction with nurses and nursing care in primary care settings. Nurs Res.1975; 24(1): 45-51.

Robinson JH, Callister LC, Berry JA, Dearing KA. Patient-Centered Care and Adeherence: Definitions and Applications to Improve Outcomes. Journal of the American Association of Nurse Practitioners. 2008; 20(12): 600-07.

Rodrigues MC, Carâp LJ, El-Warrak LO, Rezende TB. Qualidade e acreditação em saúde. Rio de janeiro: editora FGV. 2011. p.152.

Rossato LM, Magaldi FM. Instrumentos Multidimensionais: Aplicação dos Cartões de Qualidade da Dor: Rev. Latino-Am. Enfermagem. 2006;14(5): 702-07.

Rubin HJ, Rubin IS. Qualitative interviewing: The art of hearing data.Thousand Oaks:Sage; 1995.

Sandelowski M, Barroso J. Writing the proposal for a qualitative research methodology project. Qual. Health Res. 2003a; 13(6): 781-820.

Sandelowski M, Barroso J. Classifying the findings in qualitative studies. Qual. Health Res. 2003b; 13(7): 905-23.

Sandelowski M, Leeman J. Writing usable qualitative health research findings. Qual. Health Res.2012; 22 (10): 1404-13.

Schuster M. Measuring quality of pediatric care: where we've been and where we're going. Pediatrics. 2015; 135(4): 748-51.

Silva L, Tacla M, Rossetto E. Manejo da dor pós operatória na visão dos pais da criança hospitalizada. Esc Anna Nery Rev Enferm.2010; 14(3): 519-26. 
Silva EA. et al. Práticas e condutas que aliviam a dor e o sofrimento em crianças hospitalizadas. Com. Ciências Saúde. 2007;18(2): 157-66.

Sousa FAEF. Dor: o quinto sinal vital. Ribeirão Preto: Rev. Latino-Am. Enfermagem. 2002; 10(3): 446-7.

Souza C, Chianca LM, Diniz AS, Chianca TCM. Principais queixas de pacientes de urgência segundo o protocolo de classificação de risco de Manchester. Rev enferm UFPE.2012; 6 (3): 540-8.

Spahr CD, Flugstad NA, Brousseau DC. The Impact of a Brief Expectation Survey on Parental Satisfaction in the Pediatric Emergency Department. Acad Emerg Med. 2006; 13(12):1280-7.

Sposito AMP, Sparapani VC, Pfeifer LI, Lima RAG, Nascimento LC. Estratégias lúdicas de coleta de dados com crianças com câncer: revisão integrativa. Rev Gaúcha Enferm. 2013;34(3):187-95.

Stewart M, Brown JB, Donner A, McWhinney IR, Oates J, Weston WW, Jordan J. The impact of pacient-centered care on outcomes. The Journal of Family Practice:Home. 2000; 49(9): 796-804.

Stuart PJ, Parker S, Mark, R. Giving a voice to the community: A qualitative study of consumer expectations for the emergency department. Emergency Medicine. 2003;15(4): 369-75.

Swafford L, Allan D. Pain relief in the pediatric patient. Med Clin N Am. 1968; 52: 131-6.

Tacla MTGM, Miyeko H, Lima RAG. Registros sobre dor pós-operatória em crianças: uma análise retrospectiva de hospitais de Londrina, PR, Brasil. São Paulo: Revista Brasileira de Enfermagem. 2008; 61(3): 289-95.

Thomas L, Bond S. Measuring patient's satisfaction with nursing. J Adv Nurs.1996; 26: $747-56$.

Thomas DA. General inductive approach for analyzing qualitative evaluation data. : American Journal of Evaluation. 2006; 27: 237-46.

Thorne S, Kirkham S, Macdonald-Emes J. Focus on Qualitative Methods Interpretive Description: A Noncategorical Qualitative Alternative for Developing Nursing Knowledge. Research in Nursing \& Health. 1997; 20: 169-77.

Thrane SE, Wanless S, Cohen SM, Danford CA. The Assessment and NonPharmacologic Treatment of Procedural Pain From Infancy to School Age Through a Developmental Lens: A Synthesis of Evidence With Recommendations. Journal of Pediatric Nursing. 2016; 31(1): 23-32.

Uspal N, Black, K, Cico S. Pediatric Pain Management in the Emergency Department. Emergency Medicine Practice. 2012; 9: 1-20. 
Vaismoradi $\mathrm{M}$, Turunen $\mathrm{H}$, Bondas $\mathrm{T}$. Content analysis and thematic analysis: Implications for conducting a qualitative descriptive study: Nursing and Health Sciences. 2013; 15: 398-405.

Vale APF et al. Caracterização do perfil de atendimento no serviço de emergência pediátrica de um hospital no interior de Goiás. Revista Faculdade Montes Belos (FMB). 2015; 8(4): 32-202.

Vessey JA, Carlson KL, Mcgill J. Use of distraction with children during an acute pain experience. Nursing Research. 1994; 43(6): 369-72.

Walworth DD. Procedural-support music therapy in the healthcare setting: a costeffectiveness analysis. Journal of Pediatric Nursing. 2005; 20(4): 276-84.

Waseem M, Ravi L, Radeos M, Ganti S. Parental perception of waiting time and its influence on parental satisfaction in an urban pediatric emergency department: are parents accurate in determining waiting time? Southern Medical Journal. 2003; 96(9): 880-3.

Weingarten, L, Kircher J, Drendel AL, Newton AS, Ali S. A survey of children's perspectives on pain management in the Emergency Department. Journal of Emergency Medicine. 2014; 47(3): 268-76.

Wellington N, Rieder M. Attitudes and practices regarding analgesia for newborn circumcision. Pediatrics.1993; 92(4): 541-3.

Wier L, Yu H, Owens PL, Washington R. Overview of Children in the Emergency Department, 2010. Statistical Brief \#157. AHRQ. [internet] 2013. [citado 2017 mar 10] Disponível em: https://www.hcup-us.ahrq.gov/reports/statbriefs/sb157.pdf 


\section{APÊNDICE A - TERMO DE CONSENTIMENTO LIVRE E ESCLARECIDO (TCLE)}

Meu nome é Débora, sou enfermeira, aluna de mestrado da Prof ${ }^{\mathrm{a}}$ Lisabelle $\mathrm{M}$. Rossato e gostaria de lhe convidar a participar de livre e espontânea vontade do estudo "A satisfação da criança e da família com o manejo da dor em Prontosocorro Infantil", que tem como objetivo compreender a satisfação da criança e do acompanhante em relação ao manejo da dor. Este estudo pode não Ihe trazer benefícios diretos e imediatos, mas ajudará a equipe de enfermagem a cuidar melhor de outras crianças e famílias. Vou lhe fazer algumas perguntas para o senhor (a) e outras para seu filho (a), com duração de aproximadamente 20-40 minutos no momento da alta hospitalar. O que o(a) senhor(a) me contar será somente do meu conhecimento e de minha professora, sendo mantido sigilo e respeito a sua privacidade. O relatório final do estudo será publicado, sem que seus nomes sejam mencionados, e o(a) senhor(a) poderá desistir de colaborar com a pesquisa em qualquer momento, sem que você ou seu filho tenham qualquer gasto ou prejuízo à continuidade do tratamento no hospital. $O$ (a) senhor(a) também não será pago ou receberá qualquer benefício. Se em algum momento esta entrevista the trouxer algum desconforto ou constrangimento, poderemos interrompê-la imediatamente e, se for necessário, procuraremos ajuda médica no prontosocorro. Embora nenhum dano físico ou emocional seja esperado durante ou após a entrevista, se algum dano ocorrer, a indenização devida será providenciada pelo pesquisador responsável. Em caso de dúvidas o(a) senhor(a) poderá entrar em contato comigo no endereço: Av. Dr. Enéas de Carvalho Aguiar, 419, CEP 05403000, São Paulo, SP e pelo telefone (11) 3061-7602 em horário comercial e durante 24h pelo email: deboralima@usp.br e/ou com o Comitê de Ética da Escola de Enfermagem da USP: Av. Dr. Enéas de Carvalho Aguiar, 419, CEP 05403-000, São Paulo, SP; e-mail: cepee@usp.br e/ou Fone: 3061-8858 ou ainda com o Comitê de Ética em Pesquisa do Hospital Universitário CEP-HU/USP: Av. Prof. Lineu Pestes, 2565 - Cidade Universitária - CEP: 05508-000 - São Paulo - SP - Telefone: (11) 3091-9457 - Fax: (11) 3091-9479 e-mail: cep@hu.usp.br. Este documento será assinado e rubricado em duas vias, ficando uma via com vocês e a outra comigo. Esta pesquisa atende todas as especificações da Resolução 466, de 12 de dezembro de 2012, que aprova as diretrizes e normas regulamentadoras de pesquisas envolvendo seres humanos.

Assinatura do Familiar

Assinatura do Pesquisador

São Paulo, 


\section{APÊNDICE B - TERMO DE ASSENTIMENTO LIVRE E ESCLARECIDO}

Oi, tudo bem? Meu nome é Débora, eu sou enfermeira e pesquisadora e estou fazendo um trabalho sobre o que você achou do atendimento da sua dor aqui no hospital e gostaria de saber se você poderia me ajudar. Você foi escolhido porque esta/estava com dor e por isso veio no Pronto Socorro, não foi? Este trabalho vai ser assim, vou te fazer algumas perguntinhas sobre a sua dor depois que você estiver liberado do atendimento, que vai demorar aproximadamente 20-40 minutos. Você entendeu? E tudo o que a gente conversar aqui será segredo nosso e seu nome não vai aparecer em nenhum lugar do meu trabalho. Quem estiver com você também poderá ficar com a gente o tempo todo e também vai responder algumas perguntinhas. Mesmo você me ajudando no trabalho, não vai ganhar nada. Este trabalho não vai machucar você, são só algumas perguntas e você só participa se quiser, e se quiser deixar de participar em qualquer momento, você pode.

Quer participar do meu trabalho?

$\mathrm{Eu}$ aceito participar do trabalho sobre a dor nas crianças. Entendi que vou responder algumas perguntas e que posso dizer "sim" e participar, mas que, a qualquer momento, posso dizer "não" e desistir que ninguém vai ficar furioso.

Assinatura da Criança

Assinatura do Familiar

Assinatura do Pesquisador

São Paulo, 


\section{APÊNDICE C - ROTEIRO DE ENTREVISTA}

\section{Roteiro de Entrevista - Crianças e familiares}

Data 1

Plantão

Horário início :

Horário final

\section{Caracterização do entrevistado}

Nome

Data de nascimento

Idade

Queixa principal

Diagnóstico

Classificação de risco

Nome familiar

Parentesco

\section{Pergunta norteadora}

"Como foi o atendimento aqui no Pronto Socorro Infantil em relação a sua dor? "

- Por que vocês vieram para o Pronto Socorro hoje?

- Como foi o atendimento aqui no hospital? O que vocês mais gostaram? O que vocês menos gostaram?

- O que vocês achavam que iria acontecer com vocês quando vieram para o pronto socorro hoje? 


\section{ANEXO 1 - PARECER DO COMITÊ DE ÉTICA EM PESQUISA}

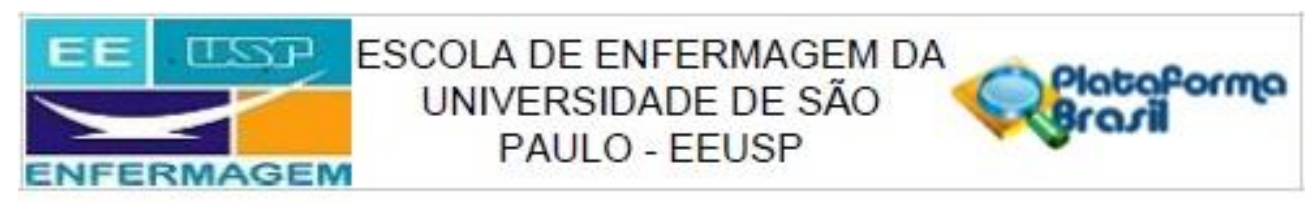

\section{PARECER CONSUBSTANCIADO DO CEP}

\section{DADOS DO PROJETO DE PESQUISA}

Título da Pesquisa: A satisfação da criança e da família com o manejo da dor em Pronto-Socorro Infantil.

Pesquisador: Lisabelle Mariano Rossato

Área Temática:

Versão: 3

CAAE: $53105515 \cdot 1.0000 .5392$

Instituição Proponente: Escola de Enfermagem da Universidade de São Paulo - EEUSP

Patrocinador Principal: Financiamento Próprio

DADOS DO PARECER

Número do Parecer: 1.508.847

\section{Apresentaçäo do Projeto:}

Trata-se de um estudo descritivo exploratório, com abordagem metodológica quali-quantitativa. Os pesquisadores esclarecem que o estudo será realizado noHospital Universitário da Universidade de São Paulo e em um hospital privado da SOCIEDADE BENEFICENTE SAO CAMILO.

Um estudo piloto será realizado com 10 crianças e suas famílias para testar a viabilidade do uso de entrevistas no momento de admissäo e na alta dos Prontos-Socorros Infantis.

A população deste estudo será constituída por crianças atendidas nas unidades de Pronto-socorro infantil de um hospital privado e de um hospital público que contemplem a fase escolar, ou seja, a faixa etária de 6 a 12 anos de idade.

Os critérios de inclusão da população seräo crianças que aceitem participar da entrevista, que estejam ou não em situaçäo de dor e famílias que aceitem participar da entrevista. Os critérios de exclusão são crianças que estejam incapacitadas de participar devido à gravidade do quadro clínico e crianças que forem atendidas direto na sala de emergência.

O contato com a criança e sua familia acontecerá durante o atendimento na unidade, no momento da triagem. A pesquisadora explicará os objetivos da pesquisa, esclarecerá as dúvidas e fará o convite para participação na pesquisa. Para a participar da pesquisa, os responsáveis assinarão, durante a entrevista na triagem, o Termo de Consentimento Livre e Esclarecido e as crianças o

Endereço: Av. Dr Eneas de Carvalho Agular, 419 Bairro: Cerquelra Cesar

CEP: $05.403-000$

UF: SP Municiplo: SAO PAULO

Teletone: (11)3061-8858

E-mall: cepeegusp.tor 


\begin{tabular}{c|c|c|c|c|}
\hline EE & $\begin{array}{c}\text { ESCOLA DE ENFERMAGEM DA } \\
\text { UNIVERSIDADE DE SÃO } \\
\text { PAULO - EEUSP }\end{array}$ \\
ENFERMAGEM & Plotoformo
\end{tabular}

Contrnuaçlo do Parecer: 1508.647

Termo de Assentimento.

Procedimento de coleta dos dados:

A seleçăo das crianças será realizada pela pesquisadora por meio do prontuário na triagem, o que possibilitará conhecer a familia, a criança e o tipo de dor apresentada por ela durante o periodo de observação na unidade. As entrevistas terão como foco conhecer a perspectiva da criança e da família em relação à satisfação do manejo da dor, norteadas por um questionário desenvolvido pela pesquisadora para este estudo, constituido por dados de identificação, escala para avaliação da intensidade da dor e questões semiestruturadas.

A primeira parte da entrevista será realizada no momento da triagem e serão solicitados os dados de identificação da criança e a avaliação da intensidade da dor da criança no momento da triagem e terá duração de aproximadamente 5 minutos. escala Faces Pain Scale-Revised, de acordo com o protocolo da instituiçäo particular. A mesma escala será utilizada para o hospital público.

A segunda parte será realizada no momento da alta hospitalar com a avaliação da intensidade da dor e seu tratamento de acordo com o registro no prontuário. Sobre a satisfação da criança e da familia em relação ao manejo da dor, serão realizadas duas questöes, com duraçäo de aproximadamente de 15 minutos: "Conteme, como foi para você o atendimento aqui no PSI em relaçäo a sua dor?" e "Como você gostaria que tivesse acontecido seu atendimento?" As duas questöes seräo respondidas pela criança e pelo familiar que estiver presente. Critério de Inclusäo:

Objetivo da Pesquisa:

Objetivo Primário:

O objetivo geral deste estudo é avaliar a satisfação da criança e da família em relaçảo ao manejo da dor durante $o$ atendimento em pronto-socorro infantil.

Objetivo Secundário:

- Avaliar a dor das crianças na triagem e na alta hospitalar,

- Correlacionar o tipo do medicamento prescrito com a intensidade da dor na triagem e na alta hospitalar.

\section{Avaliaçäo dos Riscos e Benefícios:}

Riscos:

Se em algum momento esta entrevista lhe trouxer algum desconforto ou constrangimento, poderemos interrompê-la imediatamente e, se for necessário, procuraremos ajuda médica no pronto-socorro.

Endereço: Av, Dr Eneas de Carvaino Agular, 419

Balrro: Cerqueira Cesar

CEP: $\quad 05.403-000$

Telefone: (11)3061-8858

E-mall: cepeegusp.br 


\section{EE. एSIP ESCOLA DE ENFERMAGEM DA ENFERMAGEM UNIVERSIDADE DE SÃO PAULO - EEUSP}

Contrnuaç̧o do Farecer. 1.508 .647

Beneficios:

Este estudo pode não lhe trazer benefícios diretos e imediatos, mas ajudará a equipe de enfermagem a cuidar melhor de outras famílias.

Comentários e Considerações sobre a Pesquisa:

Os pesquisadores esclareceram os pontos ressaltados no parecer anterior, elaboraram os termos de assentimento e de consentimento livre e esclarecido conforme recomendação.

Consideraçöes sobre os Termos de apresentação obrigatória:

Os termos estäo apropriados e atendem à resolução 466 .

Recomendações:

Sem recomendaçōes

Conclusões ou Pendências e Lista de Inadequações:

Aprovado

Consideraçöes Finais a critério do CEP:

- Este CEP informa a necessidade de registro dos resultados parciais e finais na Plataforma Brasil;

- Esta aprovação não substitui a autorização da instituição coparticipante, antes do inicio da coleta de dados.

Este parecer foi elaborado baseado nos documentos abaixo relacionados:

\begin{tabular}{|l|l|c|l|c|}
\hline \multicolumn{1}{|c|}{ Tipo Documento } & \multicolumn{1}{|c|}{ Arquivo } & Postagem & Autor & Situaçäo \\
\hline $\begin{array}{l}\text { Informaçöes Básicas } \\
\text { do Projeto }\end{array}$ & $\begin{array}{l}\text { PB_INFORMAÇÓES_BÁSICAS_DO_P } \\
\text { ROJETO_645866.pdf }\end{array}$ & $\begin{array}{c}31 / 03 / 2016 \\
18: 09: 27\end{array}$ & & Aceito \\
\hline $\begin{array}{l}\text { TCLE / Termos de } \\
\text { Assentimento / } \\
\text { Justificativa de }\end{array}$ & TERMODEASSENTIMENTOABRILapos & $\begin{array}{c}31 / 03 / 2016 \\
18: 07: 55\end{array}$ & $\begin{array}{l}\text { Lisabelle Mariano } \\
\text { Rossato }\end{array}$ & Aceito \\
Ausência & CEP.docx & & & \\
\hline $\begin{array}{l}\text { TCLE / Termos de } \\
\text { Assentimento I } \\
\text { Justificativa de } \\
\text { Ausência }\end{array}$ & TCLEpais_ABRILCEP.docx & $\begin{array}{c}31 / 03 / 2016 \\
18: 07: 23\end{array}$ & $\begin{array}{l}\text { Lisabelle Mariano } \\
\text { Rossato }\end{array}$ & Aceito \\
\hline Outros & & & & \\
\hline $\begin{array}{l}\text { Projeto Detalhado / } \\
\text { Brochura }\end{array}$ & ProjetoDeboraLimaCEPABRIL2016.docx & $\begin{array}{c}31 / 03 / 2016 \\
18: 05: 39\end{array}$ & $\begin{array}{l}\text { Lisabelle Mariano } \\
\text { Rossato }\end{array}$ & Aceito \\
\hline \hline
\end{tabular}

Endereço: Av. Dr Eneas de Carvaho Agular, 419

Bairro: Cerquelra Cesar
UF: SP Muni

CEP: $\quad 05.403-000$

Municiplo: SAO PAULO

Telefone: (11)3061-8858

E-mall: cepeegusp.br 


\section{\begin{tabular}{c|c|c|c|c|} 
EE & $\begin{array}{c}\text { ESCOLA DE ENFERMAGEM DA } \\
\text { UNIVERSIDADE DE SÃO } \\
\text { ENFERMAGEM }\end{array}$ \\
PAULO - EEUSP
\end{tabular}}

Contunuaç̧o do Parecer: 1508.647

\begin{tabular}{|l|l|c|l|c|}
\hline Investigador & ProjetoDeboraLimaCEPABRIL2016.docx & $\begin{array}{c}31 / 03 / 2016 \\
18: 05: 39\end{array}$ & $\begin{array}{l}\text { Lisabelle Mariano } \\
\text { Rossato }\end{array}$ & Aceito \\
\hline Folha de Rosto & $\begin{array}{l}\text { Folhaderostoassinadadiertoraplataforma } \\
\text { Brasil.pdf }\end{array}$ & $\begin{array}{c}06 / 02 / 2016 \\
14: 20: 00\end{array}$ & $\begin{array}{l}\text { Lisabelle Mariano } \\
\text { Rossato }\end{array}$ & Aceito \\
\hline
\end{tabular}

Situaçäo do Parecer:

Aprovado

Necessita Apreciação da CONEP:

Não

SAO PAULO, 19 de Abril de 2016

Assinado por:

Marcelo José dos Santos

(Coordenador) 


\title{
ANEXO 2- PARECER DO COMITÊ DE ÉTICA EM PESQUISA
}

\author{
SAMRO Unvigitiseo CENTRO UNIVERSITÁRIO SÃO \\ CAMILO - UNISC
}

\section{PARECER CONSUBSTANCIADO DO CEP}

\section{Elaborado pela Instituição Coparticipante}

\section{DADOS DO PROJETO DE PESQUISA}

Título da Pesquisa: A satisfação da criança e da família com o manejo da dor em Pronto-Socorro Infantil.

Pesquisador: Lisabelle Mariano Rossato

Área Temática:

Versão: 1

CAAE: 53105515.1 .3001 .0062

Instituição Proponente: Escola de Enfermagem da Universidade de São Paulo - EEUSP

Patrocinador Principal: Financiamento Próprio

\section{DADOS DO PARECER}

Número do Parecer: 1.639 .451

\section{Apresentação do Projeto:}

Pesquisadora descreve que "Embora a dor seja um motivo comum para procurar o Pronto Socorro (PS), evidências consistentes indicam que a dor ainda é subtratada. Resultados de pesquisas mostram que o tratamento inadequado da dor pode ter efeitos prejudiciais; que podem resultar em longo período de internação, a cicatrização mais lenta, o processamento da dor alterada, depressão, ansiedade, e os custos sociais e econômicos consideráveis para a sociedade.Quando a população em questão é a infantil, tudo parece complicar. O primeiro passo para melhorar o tratamento da dor desses pacientes é avaliar com precisão e sistematicamente o cuidado real a ser fornecido. Requer a identificação de lacunas na avaliação e tratamento da dor e melhora dos resultados dos pacientes, medidas relevantes de desempenho baseadas em evidências. Seria conveniente assumir que o alivio da dor e a satisfação da criança e da família estão estreitamente correlacionados. Em outras palavras, para assumir que a dor é bem controlada, os pacientes e seus familiares terão de estar satisfeitos, e vice-versa.

Objetivo da Pesquisa:

Objetivo Geral

- Avaliar a satisfação da criança e da família em relação ao manejo da dor durante o atendimento em prontosocorro infantil.

Endereģo: Rua Raul Pompéia, 144

Bairro: Pompéia CEP: $05.025-010$

UF: SP Município: SAO PAULO

Telefone: (11)3465-2869 Fax: (11)3465-2654 E-mail: coep@saocamilo-sp.br 


\section{CENTRO UNIVERSITÁRIO SÃO Platoformo CAMILO - UNISC}

Contnuaçăo do Parecer. 1.639 .451

Objetivos Especificos

- Avaliar a dor das crianças na triagem e na alta hospitalar, quanto a sua localização e intensidade;

- Correlacionar o tipo do medicamento prescrito com a intensidade da dor na triagem e na alta hospitalar.

\section{Avaliação dos Riscos e Beneficios:}

Não há riscos físicos ou emocionais aos participantes. Benefícios são indiretos aos participantes.

Comentários e Considerações sobre a Pesquisa:

*Instituição Proponente: Escola de Enfermagem da USP.

*Projeto de pesquisa vinculado: Mestrado.

*Instituição Coparticipante: $O$ estudo será realizado no Pronto-socorro Infantil de um Hospital particular e em um Hospital Universitário na cidade de São Paulo.

*Tipo de pesquisa: Trata-se de um estudo descritivo exploratório, com abordagem metodológica qualiquantitativa.

*Caracterização do participante do estudo: A população deste estudo será constituída por 150 crianças atendidas nas unidades dos Prontos-socorros infantis do hospital privado e do hospital público que contemplem a fase escolar, ou seja, a faixa etária de 6 a 12 anos de idade.

*Recrutamento e Abordagem dos participantes: O contato com a criança e sua família acontecerá durante o atendimento na unidade, no momento da triagem.

*Procedimento junto ao participante:

A primeira parte da entrevista será realizada no momento da triagem e serão solicitados os dados de identificação da criança $e$ a avaliação da intensidade da dor da criança no momento da triagem e terá duração de aproximadamente 5 minutos. escala Faces Pain Scale-Revised (Hicks, Von Baeyer, Spafford; Van Korlaar; Goodenough, 2001), de acordo com o protocolo da instituição particular. A mesma escala será utilizada para o hospital público.

A segunda parte será realizada no momento da alta hospitalar com a avaliação da intensidade da dor e seu tratamento de acordo com o registro no prontuário. Sobre a satisfação da criança e da família em relação ao manejo da dor, serão realizadas duas questões, com duração de aproximadamente de 15 minutos: "Conteme, como foi para você o atendimento aqui no PSI em relação a sua dor?" e "Como você gostaria que tivesse acontecido seu atendimento ?" As duas questões serão respondidas pela criança e pelo familiar que estiver presente.

*Análise dos dados: As variáveis contínuas serão analisadas com estatística descritiva e as categóricas, por meio de frequència absoluta e relativa.

*Obtenção do TCLE e a descrição do TCLE: a abordagem será realizada na triagem no Pronto

Enderę̧o: Rua Raul Pompéia, 144

Bairro: Pompéia CEP: $05.025-010$

UF: SP Municipio: SAOPAULO

Telefone: (11)3465-2669 Fax: (11)3465-2654 E-mail: coep@saocamilo-sp.br 
Contnuaçäo do Parecer. 1.639.451

Socorro Infantil. O texto do TCLE está claro e compreensivel. O Termo de Assentimento está com uma linguagem acessivel, entretanto, há informações que não cabem ser ditas a criança como por exemplo direito a indenização. Assim, foi solicitado revisão do termo de assentimento por e-mail. A pesquisadora fez a revisão do termo e enviou por e-mail (versão 3), sendo anexado por esse CEP. Infere-se que o pesquisador irá obter o termo de assentimento lendo-o para a criança.

*Prazo para a Coleta de dados estimada para 30/06/16 a 30/09/16.

*Orçamento: valor total de R\$ 200,00 , será subsidiado pelo próprio pesquisadores.

Consideraçôes sobre os Termos de apresentação obrigatória:

Foram apresentados os seguintes documentos:

- Folha de Rosto de Pesquisa Envolvendo Seres Humanos assinada pelo pesquisador e instituição proponente,

- Apresentou a carta de autorização do hospital Privado. Sendo anexado por esse CEP.

Conclusões ou Pendências e Lista de Inadequações:

Após contato por e-mail a pesquisadora envio a carta de autorização da instituição coparticipante (privada) e o termo de assentimento com conteúdo e linguagem adequada a criança (versão 3). Assim, o protocolo foi aprovado.

Considerações Finais a critério do CEP:

Apresentar o relatório de acompanhamento da pesquisa após 6 meses.

Informações no site: www.saocamilo-sp.br $\rightarrow$ institucional $\rightarrow$ coep $\rightarrow$ relatório de pesquisa.

Enviar o relatório por meio da Plataforma Brasil, Anexar o relatório no ícone "Enviar Notificação".

Este parecer foi elaborado baseado nos documentos abaixo relacionados:

\begin{tabular}{|l|l|c|l|c|}
\hline \multicolumn{1}{|c|}{ Tipo Documento } & \multicolumn{1}{|c|}{ Arquivo } & Postagem & Autor & Situação \\
\hline Informações Básicas & PB_INFORMAÇÖES_BASICAS_DO_P & $31 / 03 / 2016$ & & Aceito \\
do Projeto & ROJETO 645866.pdf & $18: 09: 27$ & \\
\hline TCLE / Termos de & TERMODEASSENTIMENTOABRILapos & $\begin{array}{c}31 / 03 / 2016 \\
18: 07: 55\end{array}$ & $\begin{array}{l}\text { Lisabelle Mariano } \\
\text { Rossato }\end{array}$ & Aceito \\
Assentimento I & CEP.docx & & & \\
Justificativa de & & $31 / 03 / 2016$ & Lisabelle Mariano & Aceito \\
Ausência & & $18: 07: 23$ & Rossato & \\
\hline TCLE / Termos de & TCLEpaisABRILCEP.docx & & & \\
Assentimento / & & & & \\
Justificativa de & & & & \\
\hline
\end{tabular}

Endereço: Rua Raul Pompéia, 144

Bairro: Pompéia CEP: 05.025-010

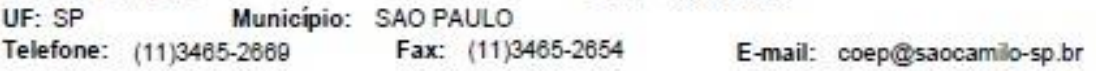




\section{ats}

\section{CENTRO UNIVERSITÁRIO SÃO CAMILO - UNISC}

Contnuaçăo do Parecer. 1.639.451

\begin{tabular}{|c|c|c|c|c|}
\hline Ausência & TCLEpaisABRILCEP.docx & $\begin{array}{c}31 / 03 / 2016 \\
18: 07: 23\end{array}$ & $\begin{array}{l}\text { Lisabelle Mariano } \\
\text { Rossato }\end{array}$ & Aceito \\
\hline Outros & $\begin{array}{l}\text { Cartadeesclarecimentoaoparecererista.d } \\
\text { ocx }\end{array}$ & $\begin{array}{c}31 / 03 / 2016 \\
18: 06: 56\end{array}$ & $\begin{array}{l}\text { Lisabelle Mariano } \\
\text { Rossato }\end{array}$ & Aceito \\
\hline $\begin{array}{l}\text { Projeto Detalhado / } \\
\text { Brochura } \\
\text { Investigador }\end{array}$ & ProjetoDeboraLimaCEPABRIL2016.docx & $\begin{array}{c}31 / 03 / 2016 \\
18: 05: 39\end{array}$ & $\begin{array}{l}\text { Lisabelle Mariano } \\
\text { Rossato }\end{array}$ & Aceito \\
\hline $\begin{array}{l}\text { Informações Básicas } \\
\text { do Projeto }\end{array}$ & $\begin{array}{l}\text { PB_INFORMAÇÖES_BÁSICAS_DO_P } \\
\text { ROJETO_645866.pdf }\end{array}$ & $\begin{array}{c}07 / 03 / 2016 \\
21: 12: 41\end{array}$ & & Aceito \\
\hline $\begin{array}{l}\text { TCLE / Termos de } \\
\text { Assentimento / } \\
\text { Justificativa de } \\
\text { Ausência }\end{array}$ & $\begin{array}{l}\text { TERMODEASSENTIMENTOaposCEP.d } \\
\text { oc } x\end{array}$ & $\begin{array}{l}07 / 03 / 2016 \\
21: 01: 02\end{array}$ & $\begin{array}{l}\text { Lisabelle Mariano } \\
\text { Rossato }\end{array}$ & Aceito \\
\hline $\begin{array}{l}\text { TCLE / Termos de } \\
\text { Assentimento / } \\
\text { Justificativa de } \\
\text { Ausência }\end{array}$ & TCLEpaisaposCEP.docX & $\begin{array}{c}07 / 03 / 2016 \\
21: 00: 42\end{array}$ & $\begin{array}{l}\text { Lisabelle Mariano } \\
\text { Rossato }\end{array}$ & Aceito \\
\hline $\begin{array}{l}\text { Projeto Detalhado / } \\
\text { Brochura } \\
\text { Investigador }\end{array}$ & ProjetoDeboraLimaAPOSCEP.docx & $\begin{array}{c}07 / 03 / 2016 \\
20: 57: 48\end{array}$ & $\begin{array}{l}\text { Lisabelle Mariano } \\
\text { Rossato }\end{array}$ & Aceito \\
\hline $\begin{array}{l}\text { Informaçőes Básicas } \\
\text { do Projeto }\end{array}$ & $\begin{array}{l}\text { PB_INFORMAÇŐES_BÁSICAS_DO_P } \\
\text { ROJETO_645866.pdf }\end{array}$ & $\begin{array}{c}06 / 02 / 2016 \\
14: 25: 20\end{array}$ & & Aceito \\
\hline $\begin{array}{l}\text { Projeto Detalhado / } \\
\text { Brochura } \\
\text { Investigador }\end{array}$ & ProjetoDeboraLimacorrigido.docx & $\begin{array}{c}06 / 02 / 2016 \\
14: 24: 21\end{array}$ & $\begin{array}{l}\text { Lisabelle Mariano } \\
\text { Rossato }\end{array}$ & Aceito \\
\hline $\begin{array}{l}\text { TCLE / Termos de } \\
\text { Assentimento / } \\
\text { Justificativa de } \\
\text { Ausência } \\
\end{array}$ & $\begin{array}{l}\text { TERMODEASSENTIMENTOcorriqido.do } \\
\mathrm{cx}\end{array}$ & $\begin{array}{c}06 / 02 / 2016 \\
14: 23: 51\end{array}$ & $\begin{array}{l}\text { Lisabelle Mariano } \\
\text { Rossato }\end{array}$ & Aceito \\
\hline $\begin{array}{l}\text { TCLE / Termos de } \\
\text { Assentimento / } \\
\text { Justificativa de } \\
\text { Ausência }\end{array}$ & TCLEcorrigido.docx & $\begin{array}{c}06 / 02 / 2016 \\
14: 23: 22\end{array}$ & $\begin{array}{l}\text { Lisabelle Mariano } \\
\text { Rossato }\end{array}$ & Aceito \\
\hline Folha de Rosto & $\begin{array}{l}\text { Folhaderostoassinadadiertoraplataforma } \\
\text { Brasil.pdf }\end{array}$ & $\begin{array}{c}06 / 02 / 2016 \\
14: 20: 00 \\
\end{array}$ & $\begin{array}{l}\text { Lisabelle Mariano } \\
\text { Rossato }\end{array}$ & Aceito \\
\hline \begin{tabular}{l|} 
Informações Básicas \\
do Projeto
\end{tabular} & $\begin{array}{l}\text { PB_INFORMAÇŐES_BÁSICAS_DO_P } \\
\text { ROJETO_645866.pdf }\end{array}$ & $\begin{array}{c}16 / 12 / 2015 \\
12: 45: 43\end{array}$ & & Aceito \\
\hline
\end{tabular}

Situação do Parecer:

Aprovado

Necessita Apreciação da CONEP:

Não

Endereço: Rua Raul Pompéia, 144
Bairro: Pompéia
Municipio: SAO PAULO
CEP: $05.025-010$
UF: SP
(11)3465-2669
Fax: (11)3465-2654
E-mail: coep@saocamilo-sp.br 


\section{\&ै SÃOCAMILO CENTRO UNIVERSITÁRIO SÃO Q Platoforma}

Contnuaçăo do Parecer: 1.639 .451

SAO PAULO, 18 de Julho de 2016

Assinado por:

Adriana Aparecida de Faria Lima

(Coordenador)

Afilalo, M. and C. Tselios. (1996), 'Pain Relief Vesus Patient Satisfaction', (Ed.)^(Eds.), Annals of Emergency Medicine.

Alston, K. J., C. R. Valrie, C. Walcott, T. D. Warner and B. Fuh. (2015), 'Experiences of Pediatric Patients with Sickle Cell Disease in Rural Emergency Departments', Journal of Pediatric

Hematology Oncology Vol. 37, No. 3, pp. 195-199.

Alves, C. (2003), 'Satisfação Do Consumidor. ', (Ed.)^(Eds.), Escolar.

ANA, A. N. A. (1999), '10 Ana Quality Indicators for Acute Care Settings ', (Ed.)^(Eds.), Healthcare Benchmarks.

Araujo, L. and B. Romero. (2015), 'Dor: Avaliação Do 5o Sinal Vital. Uma Reflexão Teórica.',

$($ Ed.)^(Eds.), Rev. Dor.

Baren, J. M. (2001), 'Rising to the Challenge of Family-Centered Care in Emergency Medicine.',

(Ed.)^(Eds.), Academic Emergency Medicine.

Brasil, M. d. S. (2002), 'Manual Brasileiro De Acreditação Hospitalar', (Ed.)^(Eds.).

Brasil. (13 de julho de 1990. ), 'Estatuto Da Criança E Do Adolescente', (Ed.)^(Eds.), Diário Oficial da União.

Burrows, F. and C. Berde. (1993), 'Optimal Pain Relief in Infants and Children. ', (Ed.)^(Eds.), BMJ

Byczkowski, T. L., M. Fitzgerald, S. Kennebeck, L. Vaughn, K. Myers, A. Kachelmeyer and N. Timm.

(2013), 'A Comprehensive View of Parental Satisfaction with Pediatric Emergency

Department Visits', Annals of Emergency Medicine Vol. 62, No. 4, pp. 340-350.

Campbell, J. N. (1996), 'Aps 1995 Presidential Address. ', (Ed.)^(Eds.), Pain Forum.

Costa, D. M. (2015), 'Busca De Atendimento Para Crianças E Adolescentes Em Serviços De Urgência

Do Sus: Uma Revisão Integrativa', Universidade Federal do Rio Grande do Sul.

Damasceno, A., P. Almeida and M. Barroso. (2007), 'Dor Em Crianças Vítimas De QueimadurasEstudo Epidemiológico.', (Ed.)^(Eds.), Braz J Nurs. .

Deming, W. (1990), 'Qualidade: A Revolução Da Administração. ', (Ed.)^(Eds.), Saraiva.

Donabedian, A. (1980), The Definition of Quality and Approaches to Its Assessment (Explorations in

Quality Assesment and Monitoring), Health Administration Press, Ann Arbor.

_- - . (1984), 'La Calidad De La Atención Médica, Definicion Y Metodos De Evaluacion.', (Ed.)^(Eds.), Prensa Medica Mexicana.

- - . (1990), 'The Seven Pilars of Quality. ', (Ed.)^(Eds.), Arch.Pathol.Lab. Med.

Downey, L. V. A. and L. S. Zun. (2010), 'Pain Management in the Emergency Department and Its

Relationship to Patient Satisfaction', (Ed.)^(Eds.), Journal of Emergencies, Trauma, and Shock.

D'Innocenzo, M., N. Adami and I. Cunha. (2006), 'O Movimento Pela Qualidade Nos Serviços De Saúde E Enfermagem. ', (Ed.)^(Eds.), Rev. Bras, Enferm. 
FC., Q. (2007. ), 'O Manejo Da Dor Por Profissionais De Enfermagem No Cuidado De Crianças No Pós-Operatório Tardio De Cirurgia Cardíaca ', dissertação, Escola de Enfermagem de Ribeirão Preto, Universidade de São Paulo.

Fein, J. A., W. T. Zempsky , J. P. Cravero , C. o. P. E. Medicine. and S. o. A. a. P. Medicine. (2012), 'Relief of Pain and Anxiety in Pediatric Patients in Emergency Medical Systems', (Ed.)^(Eds.), PEDIATRICS.

Feldman, L. (2004), 'O Enfermeiro Analista De Risco Institucional. ', (Ed.)^(Eds.), Rev. bras. Enferm. . Filho, A. (2010), 'Reconhecer Flexner: Inquérito Sobre Produção De Mitos Na Educação Médica No Brasil Contemporâneo.', (Ed.)^(Eds.), Cad. Saúde Pública. .

Freitas, J. (2013), 'Avaliação Da Qualidade Da Assistência De Enfermagem E Da Satisfação Do Paciente De Um Hospital De Ensino Da Região Centro-Oeste Do Brasil ', Universidade Federal de Goiás. .

Gill, M., A. L. Drendel and S. J. Weisman. (2013), 'Parent Satisfaction with Acute Pediatric Pain Treatment at Home', Clinical Journal of Pain Vol. 29, No. 1, pp. 64-69.

- - . (2013), 'Parent Satisfaction with Acute Pediatric Pain Treatment at Home', (Ed.)^(Eds.), The Clinical Journal of Pain.

Gonçalves, B., A. Holz, C. Lange, S. Maagh, P. CG. and C. Brazil. (2013), 'O Cuidado Da Criança Com Dor Internada Em Uma Unidade De Emergência E Urgência Pediátrica', (Ed.)^(Eds.), Rev Dor.

Health., D. o. (2004), 'National Service Framework for Children, Young People and Maternity Services: Core Standards. ', (Ed.)^(Eds.), HMSO.

Hockenberry, M., D. Wilson and M. Winkelstein. (2014), 'Wong Fundamentos De Enfermagem Pediátrica. ', (Ed.)^(Eds.), Elsevier

Kanai, K. Y. and W. M. Z. Fidelis. (2010), 'Conhecimento E Percepção Da Equipe De Enfermagem Em Relação À Dor

Na Criança Internada', (Ed.)^(Eds.), Rev Dor.

Kelly, A. M. (2000), 'Patient Satisfaction with Pain Management Does Not Correlate with Initial or Discharge Vas Pain Score, Verbal Pain Rating at Discharge, or Change in Vas Score in the

Emergency Department', (Ed.)^(Eds.), The Journal of Emergency Medicine.

Linhares, M. and F. Doca. (2010), 'Dor Em Neonatos E Crianças: Avaliação E Intervenções Não Farmacológicas. ', (Ed.)^(Eds.), Temas psicol

Locke, R., M. Stefano, A. Koster, B. Taylor and J. Greenspan. (2011), 'Optimizing Patient/Caregiver Satisfaction through Quality of Communication in Pediatric Emergency Department',

(Ed.)^(Eds.), Pediatric Emergency Care.

Lowe, D. A., M. C. Monuteaux, S. Ziniel and A. M. Stack. (2012), 'Predictors of Parent Satisfaction in Pediatric Laceration Repair', (Ed.)^(Eds.), Academic Emergency Medicine.

Margaret, N., T. Clarck and C. Warden. (2002), 'Patient Satisfaction in the Emergency Department-a Survey of Pediatric Patients and Their Parents. ', (Ed.)^(Eds.), Acad Emerg Med.

Merskey, H. and N. Bogduk. (1994), 'Classification of Chronic Pain. Descriptions of Chronic Pain Syndromes and Definitions of Pain

Terms. Part lii: Pain Terms: A Current List with

Definitions and Notes on Usage.', (Ed.)^(Eds.), IASP Press.

Novaes, H. (2007), 'O Processo De Acreditação Dos Serviços De Saúde. ', (Ed.)^(Eds.), RAS.

Novaes, H. and J. Paganini. (1994 ), 'Desenvolvimento E Fortalecimento Dos Sistemas Locais De Saúde Na Transformação Dos Sistemas Nacionais De Saúde: Padrões E Indicadores De Qualidade Para Hospitais (Brasil). ', (Ed.)^(Eds.), Organização Panamericana de Saúde. Novaes, H. d. M. (2015), 'História Da Acreditação Hospitalar Na América Latina- O Caso Brasil', (Ed.)^(Eds.), Revista de administração Hospitalar e Inovação em Saúde.

O'Malley, P. J., K. Brown, S. E. Krug and C. o. P. E. Medicine. (2008), 'Patient - and Family-Centered Care of Children in the Emergency Department', (Ed.)^(Eds.), Pediatrics. 
OMS, O. M. d. S. (1981), 'Avaliação Dos Programas De Saúde: Normas Fundamentais Para Sua Aplicação No Processo De Gestação Para O Desenvolvimento Nacional Na Saúde. ', (Ed.)^(Eds.).

Pagnamenta, R. and J. R. Benger. (2008), 'Factors Influencing Parent Satisfaction in a Children's Emergency Department: Prospective Questionnaire-Based Study', Emergency Medicine Journal Vol. 25, No. 7, pp. 417-419.

Pereira, L. and F. Sousa. (1998), 'Mensuração E Avaliação Da Dor Pós-Operatória: Uma Breve Revisão. ', (Ed.)^(Eds.), Rev. Latino-Am. Enfermagem

Pines, J. M., S. Iyer, M. Disbot, J. E. Hollander, F. S. Shofer and E. M. Datner. (2008), 'The Effect of Emergency Department Crowding on Patient Satisfaction for Admitted Patients', (Ed.)^(Eds.), Academic Emergency Medicine.

Risser, N. (1975), 'Development of an Instrument to Measure Pediatric Satisfaction with Nurses and Nursing Care in Primary Care Settings. ', (Ed.)^(Eds.), Nurs Res..

Robinson, J., H., L. Callister, J. A. Berry and K. Dearing, A. (2008), 'Patient-Centered Care and Adeherence: Definitions and Applications to Improve Outcomes', (Ed.)^(Eds.), Journal of the American Association of Nurse Practitioners.

Rodrigues, M. C., L. EL-Warrak, LO. Rezende, TB. (2011), 'Qualidade E Acreditação Em Saúde.', (Ed.)^(Eds.), editora FGV.

Schuster, M. (2015), 'Measuring Quality of Pediatric Care: Where We've Been and Where We're Going. ', (Ed.)^(Eds.), Pediatrics.

Silva, B. A., A. M. Oliveira, E. G. Rossetto and A. V. Zani. (2014), 'Caracterização Da Demanda E Procura De Um Pronto Atendimento Infantil: Opinião De Pais E Responsáveis ', (Ed.)^(Eds.), Semina: Ciências Biológicas e da Saúde.

Silva, L., M. Tacla and E. Rossetto. (2010), 'Manejo Da Dor Pós Operatória Na Visão Dos Pais Da Criança Hospitalizada. ', (Ed.)^(Eds.), Esc Anna Nery Rev Enferm

Souza, C., L. Chianca, A. Diniz and T. Machado. (2012), 'Principais Queixas De Pacientes De Urgência Segundo O Protocolo De Classificação De Risco De Manchester. ', (Ed.)^(Eds.), Rev enferm UFPE.

Stewart, M., J. B. Brown, A. Donner, I. R. McWhinney, J. Oates, W. W. Weston and J. Jordan. (2000), 'The Impact of Pacient-Centered Care on Outcomes', (Ed.)^(Eds.), The Journal of Family Practice:Home.

Stuart, P. J., S. Parker and R. Mark. (2003), 'Giving a Voice to the Community: A Qualitative Study of Consumer Expectations for the Emergency Department', (Ed.)^(Eds.), Emergency Medicine. Swafford, L. and D. Allan. (1968), 'Pain Relief in the Pediatric Patient. ', (Ed.)^(Eds.), Med Clin N Am Thomas, L. and S. Bond. (1996), 'Measuring Patient's Satisfaction with Nursing.', (Ed.)^(Eds.), J Adv Nurs.

Uspal, N., K. Black and S. Cico. (2012), 'Pediatric Pain Management in the Emergency Department. ', $(\text { Ed. })^{\wedge}($ Eds.), Emergency Medicine Practice.

Vale, A. P. F., V. R. Silva, B. d. O. M. Mendonça, E. J. B. Barros, R. d. M. Mota, V. C. d. C. O. Oliveira and D. S. N. Nogueira. (2015), 'Caracterização Do Perfil De Atendimento No Serviço De Emergência Pediátrica De Um Hospital No Interior De Goiás.', (Ed.)^(Eds.), Revista Faculdade Montes Belos (FMB).

Waseem, M., L. Ravi, M. Radeos and S. Ganti. (2003), 'Parental Perception of Waiting Time and Its Influence on Parental Satisfaction in an Urban Pediatric Emergency Department: Are Parents Accurate in Determining Waiting Time?', (Ed.)^(Eds.), Southern Medical Journal.

Weingarten, L., J. Kircher, A. L. Drendel, A. S. Newton and S. Ali. (2014), 'A Survey of Children's Perspectives on Pain Management in the Emergency Department.', Journal of Emergency Medicine Vol. 47, No. 3, pp. 268-276.

Wellington, N. and M. Rieder. (1993), 'Attitudes and Practices Regarding Analgesia for Newborn Circumcision.', (Ed.)^(Eds.), Pediatrics

Wier, L., H. Yu, P. Owens and R. Washington. (2013), 'Overview of Children in the Emergency Department, 2010.', (Ed.)^(Eds.), HCUP Statistical Brief \#157. 